THE METABOLISM

\title{
OF ALGAE
}

\section{G. E. FOGG}

\section{METHUEN'S MONOGRAPHS ON BIOLOGICAL SUBJECTS}




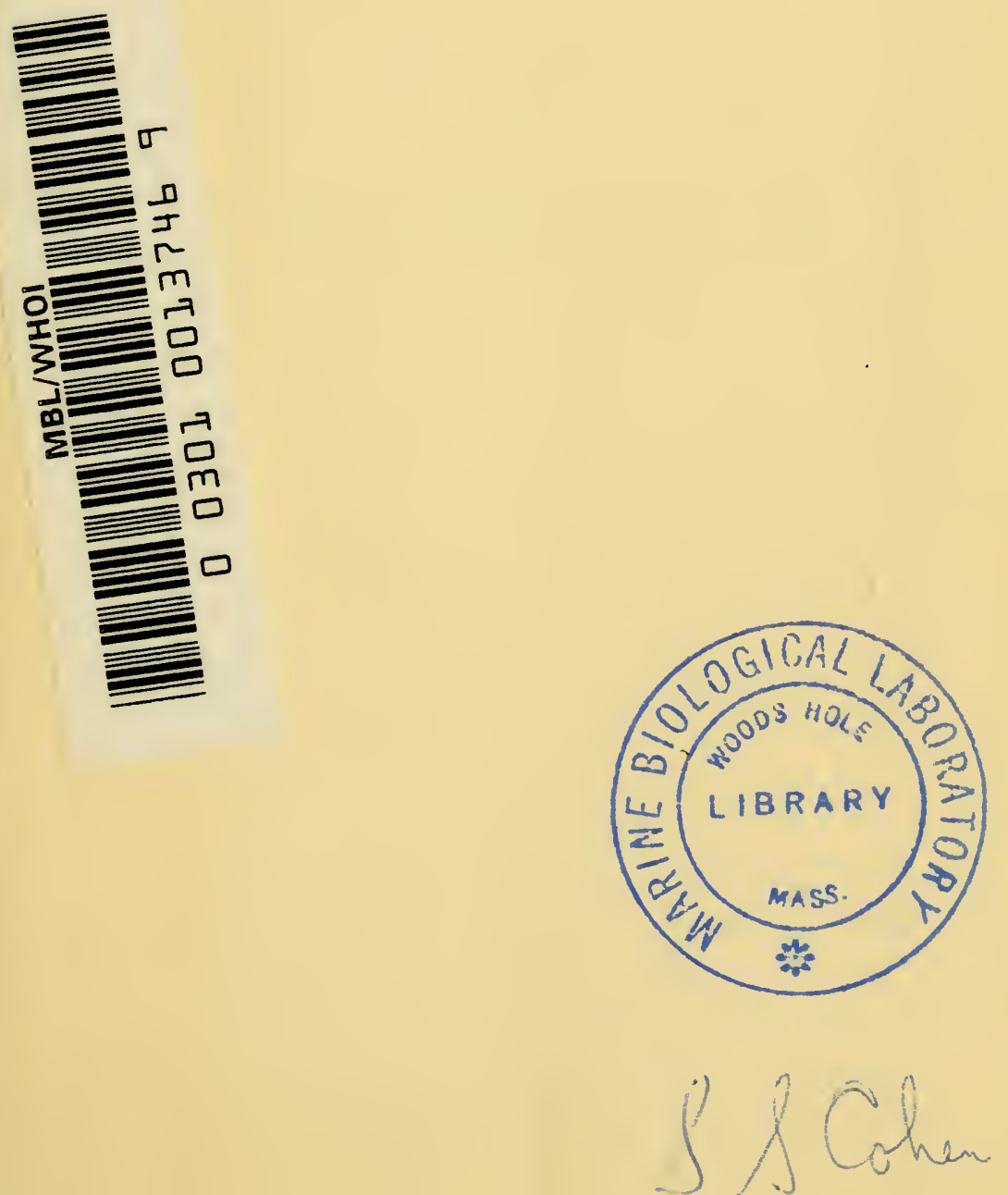



\section{Methuen's Monographs on Biological Subjects}

General Editor: Michael Abercrombie

\section{THE METABOLISM OF ALGAE}





\title{
THE METABOLISM OF
}

\section{ALGAE}

\author{
by \\ G. E. FOGG \\ B.Sc.(Lond.), Ph.D.(Cantab.) \\ READER IN BOTANY, \\ UNIVERSITY COLLEGE, LONDON
}

WITH 20 DIAGRAMS

LONDON: METHUEN \& CO. LTD. NEW YORK: JOHN WILEY \& SONS, INC. 
First published in 1953

I. I

CATAlogue No. 4122/U (METHUEN)

PRINTED IN GREAT BRITAIN 


\section{To}

the memory of

MY FATHER 



\section{PREFACE}

THE algae are, on the whole, unobtrusive organisms, and although their beauty of form and variety of life history have not failed to attract the attention of the morphologist, the student of metabolism has generally preferred to work with material more readily available or showing more obvious chemical activity. However, there is a growing recognition that algal metabolism has its own distinctive features and that its study has both academic and economic value. In this book I have attempted to bring together information scattered through a variety of scientific publications into a general account of the subject which will be of interest to students of botany, microbiology and biochemistry.

My thanks are due in particular to Professors F. E. Fritsch, F.R.S., and W. H. Pearsall, F.R.S. There is much in this book derived from their teaching for which acknowledgement cannot be made by citation of published works and without their encouragement and help I could not have persisted in this field of study. I am also grateful to my colleague P. J. Syrett for his helpful criticism of the manuscript; such errors as still occur must be attributed to lack of thoroughness on my part, not his. Finally I must record my thanks to those persons, named in the list of references, who have allowed me to quote their unpublished results.

G. E. F.

UNIVERSITY COLLEGE, LONDON August 1952 



\section{CONTENTS}

CHAP.

PREFACE

PAGE

Vii

I INTRODUCTION I

II THE PHOTOTROPHIC ASSIMILATION OF CARBON I7

III THE CHEMOTROPHIC ASSIMILATION OF CARBON 48

IV AUTOTROPHIC ASSIMILATION WITH SPECIAL REFERENCE TO NITROGEN METABOLISM

V HETEROTROPHIC ASSIMILATION

84

VI THE PRODUCTS OF METABOLISM

VII GROWTH AND METABOLISM

I06

VIII SUMMARY AND CONCLUSIONS

REFERENCES

I 34

INDEX 
'I should rather incline to believe, that that wonderful power of nature, of changing one substance into another, and of promoting perpetually that transmutation of substances, which we may observe every where, is carried on in this green vegetable matter in a more ample and conspicuous way.'

JOHN INGENHOUSZ, $1779^{152}$ 


\section{INTRODUCTION}

THE term 'alga' is a difficult one to define. In the broad sense in which it is used by modern authorities ${ }^{106,259}$ it includes a number of types of organism (see Table $\mathrm{I}$ ) which differ profoundly one from another in cell organization and which have little in common except that their characteristic mode of nutrition is photosynthetic and that they cannot be included in any other division of the plant kingdom. This grouping together of phylogenetically remote classes of organisms, while artificial from some points of view, is nevertheless convenient, particularly if the transformations of matter and energy which comprise their metabolism are to be considered. Regarded in this way, these organisms form a more homogeneous group with sufficiently marked characteristics to justify special consideration.

On the one hand algae are distinguished from the morphologically more complex higher plants by the variety and flexibility of chemical activity characteristic of the more primitive forms of life. On the other hand they differ from organisms such as bacteria, fungi and protozoa, in having a chemical economy based upon photosynthesis, in which the accumulation rather than the breakdown of organic matter predominates. In bulk of material involved this algal type of metabolism perhaps exceeds any other. The total yield of photosynthesis in the oceans, in which algae are the only photosynthetic organisms, has been estimated to be from $\mathrm{I} \cdot 6$ to $15.5 \times 10^{10}$ tons of carbon fixed per year, and is evidently at least as much as that of land plants. ${ }^{247,}{ }^{209}$ In soil and in freshwater algal metabolism is generally on a lesser scale but is nevertheless of considerable importance,

It is not altogether surprising, then, that the metabolic activities of algae should have attracted attention while the description and classification of species was yet in a chaotic 
state. In books published in 1779 both Priestley ${ }^{237}$ and Ingenhousz ${ }^{152}$ described experiments on the gas exchanges accompanying the photosynthesis of the simple algae which grew by chance in their apparatus. Priestley was sufficiently interested in this 'green matter', which he doubted to have 'ever been properly noticed by botanists', to make further experiments with it, observing, among other things, that its growth was promoted by certain organic materials. Priestley also determined the composition of the gas enclosed in the bladders of marine algae. Ingenhousz made fewer experiments with algae but realized more of their possible rôle in the economy of nature, as is evident from the sentence which is quoted at the beginning of this book.

As in physiology generally, further progress in the study of the metabolism of algae had to await the development of the physical sciences and during the greater part of the nineteenth century algae were studied almost exclusively from morphological and taxonomic points of view. Thus Sachs $^{256}$ in his text-book of plant physiology, published in I $\$ \$ 2$, used algae as examples wherever possible but was able to say very little about their metabolism beyond making the generalization that it essentially resembles that of higher plants. Experimental investigation of algae increased towards the close of the century but then followed three principal lines which remained to a large extent independent for a considerable period.

Examination of the chemical constituents of algae was until recently confined to the larger seaweeds and to such smaller forms as very occasionally occur in a reasonably pure state in sufficient quantity for analysis. Two classes of substance have received most attention. Following the description of alginic acid by Stanford in $1883,{ }^{266}$ many studies of the carbohydrates and related compounds present in algae have been made. Other workers have been more interested in the pigments which form such a striking feature of these organisms. The work of Willstätter and Stoll published in $1913^{301}$ is of particular importance in forming the basis of our present-day knowledge of algal pigments. Only recently has interest in the nitrogenous and 
lipide constituents of algae developed. Particularly noteworthy series of papers on algal chemistry have been produced by Haas, Colin, Heilbron and Percival and their respective collaborators (see references).

A second type of investigation has been concerned with the growth of algae in culture. Microscopic algae were not neglected by the microbiologists following Pasteur but progress in their investigation was slow in comparison with that in other branches of microbiology, probably because of the greater technical difficulties in culture and manipulation. Many studies were made with cultures which were not absolutely pure and work of this type, for example that of Molisch published in 1896,195 showed the mineral requirements of simple algae to be much the same as those of higher plants. Further reliable work on nutrition could only be carried out with pure cultures. Beijerinck in 1890 first described the isolation, in what was probably pure culture, of Chlorella vulgaris and similar unicellular green algae by means of the methods developed by Koch for bacteria. ${ }^{26}$ Subsequently other techniques appropriate to particular kinds of algae were worked out but these need not be particularized since the history of algal culture techniques has been summarized by Pringsheim, ${ }^{241}$ himself a distinguished worker in this field. By 1920 many species had been isolated in a bacteria-free state and investigations under controlled conditions were undertaken. At first qualitative studies of nutritional requirements (see ref. 132 , for example) predominated. Precise quantitative methods for the investigation of the growth of simple algae were introduced by Bristol Roach in $1926^{250}$ in a study of the effects of carbon compounds on soil algae. Such work has established the main features of the growth in culture and the major nutritional requirements of those algae which are most easily grown under laboratory conditions. More direct studies on the metabolism of algae in culture were begun by Pearsall and Loose, who in $1937^{225}$ showed that the main trends of the chemical changes occurring during the growth of a Chlorella population are similar to those occurring during the development of a leaf of a higher plant. 
In a third kind of investigation algal material has been used in short-term biochemical experiments. Many algae have qualities which particularly suit them for precise physico-chemical investigation and have occasionally been used as material by biochemists interested in particular aspects of metabolism. Engelmann used algae extensively in his elegant work, published in $188_{3},{ }^{80}$ on the light factor in photosynthesis. Later, in 1919, Warburg ${ }^{290}$ described the use of Chlorella as a system in which photosynthesis may be studied under the least complicated conditions and since then this and similar species have played an increasingly important part in the elucidation of the mechanism of this process. The investigations of oxidative assimilation by the colourless alga Prototheca, reported by Barker in $1935^{-6,22,23}$ provide an example of work with algae which is of fundamental importance in another field of biochemistry.

The distinction between these various lines of research, clear-cut for many years, is now disappearing as it becomes more generally recognized that the metabolism of the algae is a distinct field of study in itself and that to be properly understood its various aspects must be related one to another. The comparatively late development of this attitude is shown by the fact that no comprehensive reviews of algal physiology or biochemistry appeared until those of Myers and Blinks in $1955^{100,}{ }^{20}$ Part of the present increase in interest in the subject is a reflexion of the general development in microbiological chemistry that has occurred in recent years; part is due to the economic necessity of obtaining information about organisms which appear to have considerable potentialities as sources of materials and power. Seaweeds have always been utilized by man to some extent and are now finding increasing use as raw materials for the production of a variety of substances valuable in industry. ${ }^{208}$ 'The capacity for synthesis of microscopic algae has not as yet been put to any direct economic use although it appears likely that eventually their value in this respect may be greater than that of the seaweeds. The harvesting of naturally occurring planktonic algae does not appear to be an 
economic possibility and attention has so far been concentrated on the large-scale culture of forms such as Chlorella. The use of mass cultures of diatoms for the production of fat was first suggested by Harder and von Witsch ${ }^{133}$ during the Second World War and the suggestion that Chlorella might be used for the same purpose was made independently in 1947 by Spoehr and Milner. ${ }^{263}$ Since high photosynthetic efficiencies can be more easily achieved and maintained with unicellular algae than with conventional crop plants the idea of using these organisms for the large-scale production of industrially useful organic matter is an attractive one and has been the subject of much speculation, discussion and experiment. ${ }^{192,} 262,223,204,48$

In the present state of our knowledge of algal metabolism the facts must to a great extent be interpreted in terms of concepts established by the biochemical investigation of other types of organisms. There can be little doubt that the general pattern of metabolism in algae is the same as that in other forms of life. Thus, it must be expected that in algae life involves continual synthesis and breakdown by enzyme-catalysed reactions of the substances of high potential chemical energy, such as proteins and nucleic acids, which make up the fabric of their protoplasm. It is less certain that the chemical mechanisms involved in these processes in algae are the same as those which have been found in other organisms. For example, although the remarkable similarity of reaction sequences found to take place in such diverse organisms as yeast and vertebrates suggests that the mechanisms by which carbohydrates are broken down in respiration are fundamentally the same in all organisms, there is not otherwise much justification for assuming that the respiratory processes of algae are similar to those of other organisms. The facts known concerning algal respiration are worth considering at some length in this connexion since this will give the best idea of the extent of the correspondence between the chemical mechanisms of algae and of other organisms and will also provide a useful basis for the discussion in subsequent chapters of processes which intermesh with respiration. 
Apart from determinations of the rate of the process in various species (for references see 40 ) general studies of algal respiration appear to have been made only by Genevois ${ }^{115}$ and by Watanabe. ${ }^{294,} 295,296$

The respiration of a hexose sugar, which substance may for convenience be considered to be the immediate substrate for the process, takes place by a sequence of reactions which may in the first place be separated into two stages, one of breakdown or glycolysis, and one of oxidation of the products of glycolysis. The mechanism of glycolysis is known in considerable detail from studies on muscle and yeast ${ }^{267}, 41,19$ and involves the phosphorylation of hexose followed by splitting of the molecule into $\mathrm{C}_{3}$ compounds which after a series of transformations give rise to pyruvic acid, generally regarded as the end product of the process (Fig. I). Under anaerobic conditions, pyruvic acid is not removed by the oxidative mechanism and fermentation occurs, the intermediates of glycolysis then giving rise by mutual oxidation-reduction to end products the nature of which varies according to the organism and the conditions to which it is exposed. The mechanism of glycolysis in algae does not appear to have been investigated in detail, but there is indirect evidence that it follows essentially the same course as that just outlined. Thus, substances such as pyruvic acid, phosphoglyceric acid and triose and hexose phosphates, which are known to be intermediates in yeast and muscle glycolysis, have been shown to be present in the green algae, Chlorella and Scenedesmus. ${ }^{52}$ Pyruvic acid has been found to be a suitable substrate for respiration in Chlorella, ${ }^{83}$ Prototheca $^{14}$ and Ulva ${ }^{295}$ among the Chlorophyceae, in Myelophycus, a brown alga, ${ }^{295}$ and in Gelidium, a red alga, ${ }^{295}$ but not, however, in a blue-green alga, Cylindrospermum, even under conditions apparently favourable for the penetration of this acid into the cells. ${ }^{298}$ Under anaerobic conditions various species of Chlorophyceae have been found capable of fermentations of a mixed acid type $e^{115}$ and glucose is fermented by Prototheca to give lactic acid as the only product as in muscle. ${ }^{22}$

In the aerobic respiration of vertebrate tissues pyruvic 


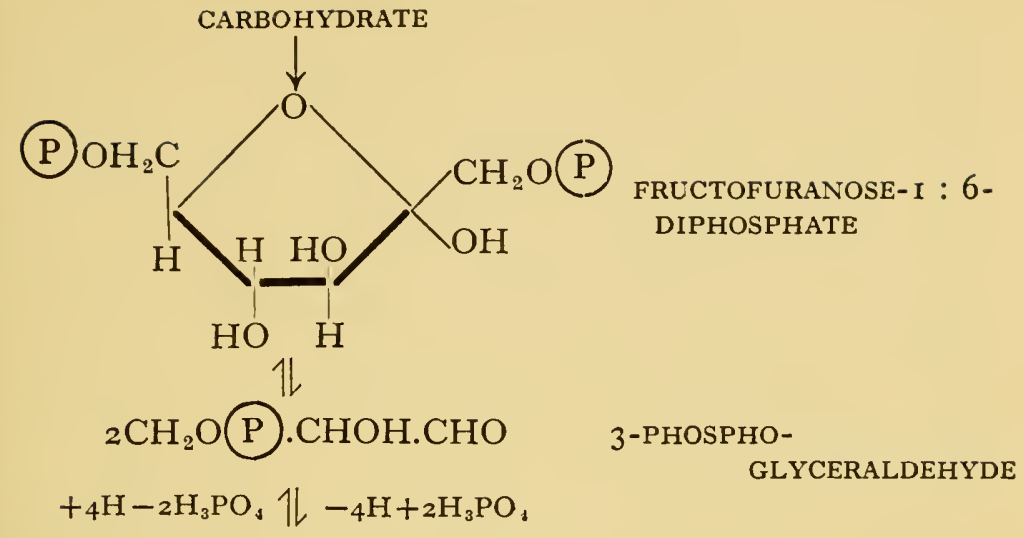

$2 \mathrm{ADP}+{ }_{2} \mathrm{CH}_{2} \mathrm{O}$ P. CHOH.COOP I : 3-PHOSPHOGLYCERIC $\mathbb{1}$

ACID

$2 \mathrm{ATP}+2 \mathrm{CH}_{2} \mathrm{O}$ P. $\mathrm{CHOH} . \mathrm{COOH}$ 1

${ }_{2} \mathrm{CH}_{2} \mathrm{OH}$.CHO@. $\mathrm{COOH}$ $+2 \mathrm{H}_{2} \mathrm{O}$ I $-2 \mathrm{H}_{2} \mathrm{O}$

$2 \mathrm{ADP}+{ }_{2} \mathrm{CH}_{2}: \mathrm{CO} \underset{1}{\mathrm{P}} \cdot \mathrm{COOH}$

$2 \mathrm{ATP}+2 \mathrm{CH}_{3} \cdot \mathrm{CO} \cdot \mathrm{COOH}$

3-PHOSPHOGLYCERIC ACID

2-PHOSPHOGLYCERIC ACID

PHOSPHO-ENOLPYRUVIC

ACID

PYRUVIC ACID

FIG. I. Scheme summarizing the reactions of glycolysis. For simplicity certain reactions have been omitted. (P) denotes the phosphate group, ADP, adenosine diphosphate, and ATP, adenosine triphosphate (for further information see ref. I9).

acid is completely oxidized to give carbon dioxide and water by means of the system, represented in Fig. 2, known as the Krebs or tricarboxylic acid cycle. ${ }^{19}$ This, or some similar system involving di-carboxylic acids, is generally assumed to occur in all aerobic organisms. Certain of the acids concerned have been shown to take part in the metabolism of Chlorella and Scenedesmus ${ }^{52}$ and also to serve as substrates for respiration in Chlorella, ${ }^{83}$ Ulva, Myelophycus and Gelidium. ${ }^{295}$ Cell-free extracts of Chlorella have been found to contain dehydrogenases for these acids, which are 
Pyruvic

Acetic

Citric

Aconitic

$\mathrm{COOH}$

$\stackrel{\mathrm{CO}}{\mathrm{I}}$

$\mathrm{COOH}$

$\mathrm{COOH}$

$\mathrm{CH}_{2}$

CO

COOH Oxaloacetic

$\mathrm{CH} . \mathrm{COOH}$

$\mathrm{C}(\mathrm{OH})$

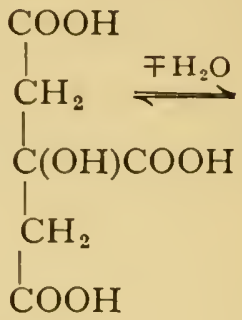

$\mathrm{COOH}$

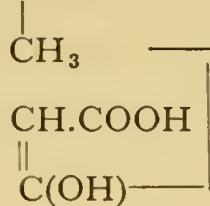

$\mathrm{COOH}$

$\sqrt{ } \mp 2 \mathrm{H}$

$\mathrm{COOH}$

$\mathrm{CH}_{2}$

$\mathrm{CHOH} \quad$ Malic

Iso-citric

$$
\| \pm \mathrm{H}_{2} \mathrm{O}
$$

$\left.\right|_{\mathrm{COOH}} ^{\mathrm{CH}}$

$\left.\right|_{\mathrm{COOH}} ^{\mathrm{CH}}$

$\mathrm{CH}$

C. $\mathrm{COOH}$

$\mathrm{COOH}$

$\mathrm{CHOH}$

CH.COOH

$\mathrm{CH}_{2}$

$\mathrm{COOH}$

$\mathrm{COOH}$

$$
\sqrt{ } \pm \mathrm{H}_{2} \mathrm{O}
$$

$\mathrm{COOH}$

$\stackrel{\mathrm{CH}}{\stackrel{\mathrm{F}_{2} \mathrm{H}}{\longleftarrow}}$

$\mathrm{COOH}$

$\stackrel{\mathrm{CH}}{\mathrm{COOH}}$

Fumaric

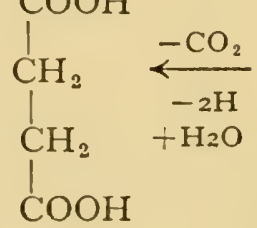

Succinic

$$
\|_{\gamma} \mp_{2 \mathrm{H}}
$$

$\mathrm{COOH}$

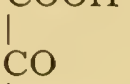

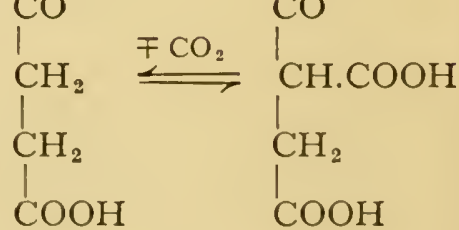

$\alpha$-Ketoglutaric Oxalosuccinic

FIG. 2. Scheme summarizing the reactions of the tricarboxylic acid cycle (for further information see ref. I9). 
known to be concerned in the cycle. ${ }^{84}$ The respiration of Chlorella, ${ }^{193}$ of Myelophycus and of Gelidium ${ }^{295}$ is reduced in the presence of malonate, which is a specific inhibitor for succinic dehydrogenase, an essential for the tricarboxylic acid cycle represented in Fig. 2. However, malonate has been found not to inhibit the respiration of $U l v a^{295}$ or Cylindrospermum. ${ }^{298}$ This evidence points to the existence of some alternative mechanism, as yet unidentified, for the oxidation of succinic acid in these algae, but it should be noted that, as has happened in experiments with Chlorella, 84,193 the medium used for Ulva may not have been sufficiently acid to secure adequate penetration of malonic acid into the cells (see p. 55). There is also some evidence that, in addition to the tricarboxylic acid system, Chlorella contains a pyruvic dehydrogenase by means of which the direct oxidation of this substance can take place. ${ }^{84}$ It may be concluded that while there is evidence that reactions concerned in the tricarboxylic acid cycle occur in algae there is as yet no conclusive proof of the participation of this system in normal algal respiration.

Pyruvic acid enters the tricarboxylic acid cycle after oxidative decarboxylation to yield acetic acid which then condenses with oxaloacetic acid to give citric acid (see Fig. 2 and ref. 19). The presence of thiamine (vitamin $B_{1}$ ), in the form of its pyrophosphate, co-carboxylase, is essential if this reaction is to take place. Thus, the rate of oxidation of pyruvic acid by thiamine-deficient Prototheca is greatly enhanced by the addition of thiamine. ${ }^{14}$ The presence of thiamine may also be necessary for other decarboxylations involved in the tricarboxylic acid cycle. Thiamine has been demonstrated in all of the numerous algae in which it has been sought; including species of Chlorophyceae, Phaeophyceae, Rhodophyceae, ${ }^{116}$ Bacillariophyceae ${ }^{305}$ and Myxophyceae, 149,282 and those forms which are unable to synthesize it or one of its constituent parts for themselves must be supplied with the appropriate substance if they are to grow (see Chapter V). There is thus no reason to doubt that thiamine plays an essential part in the metabolism of all algae and this suggests a similarity of their 
respiratory mechanisms to those of other forms of life.

The oxidations which occur in the course of the tricarboxylic acid cycle are accomplished by means of dehydrogenases, the hydrogen being eventually transferred to free oxygen. This terminal process often occurs through cytochromes, hydrogen carriers which appear to be of universal occurrence in aerobic organisms. ${ }^{19}$ The demonstration of cytochromes in algae is rendered difficult by the presence of photosynthetic pigments but it has been accomplished for a red alga, Porphyra, ${ }^{40}$ for Vaucheria, ${ }^{143}$ which is generally classified with the Chlorophyceae but which in metabolism more resembles a member of the Xanthophyceae, for the flagellate, Euglena, ${ }^{143}$ and for the brown seaweed, Fucus. ${ }^{143}$ It must be noted, however, that in these last three algae the cytochrome that has been found seems to be part of the photosynthetic rather than the respiratory mechanism. ${ }^{143}$ The respiration of Chlorella supplied with sugar is affected by carbon monoxide in a manner characteristic of oxidations involving cytochrome. ${ }^{75}$ The presence of cytochrome oxidase in Polytomella caeca, a colourless member of the Chlorophyceae, has been reported. ${ }^{153}$ These are indications that the cytochrome system is of general occurrence in algae but there is evidence that in many species alternative oxidation mechanisms exist. Thus concentrations of cyanide sufficient to inhibit the oxidation of substrates supplied exogenously (i.e. in the external medium) are without effect on, or may even stimulate, endogenous respiration (i.e. using substrates stored within the cell) in various species of Chlorophyceae. ${ }^{75}, 115,291,109,274,218$ Cyanide is an inhibitor for enzymes containing heavy metals and thus prevents the operation of the cytochrome system. The cyanide-stable respiration of these forms may possibly be carried on by enzymes of the flavo-protein type, which are cyanide-insensitive and, although probably chiefly concerned with intermediate hydrogen transfers, are, in some cases, capable of transferring hydrogen to molecular oxygen. ${ }^{19}$ Riboflavin, a component of the prosthetic group of the flavo-proteins, has been demonstrated in all the algae 
in which it has been sought, i.e. representatives of the Chlorophyceae, Euglenineae, Phaeophyceae and Rhodophyceae. ${ }^{1,} 85,141,296$ Peroxidase and polyphenol oxidases have been shown to be present in various algae ${ }^{40}$ but the part which these enzymes play in respiration has not yet been established.

The transfer, storage and utilization of the free energy released in respiration appears usually to be effected through phosphorylated compounds. The best known example of the formation of such compounds is one occurring in the course of glycolysis in yeast, that in which the energy released by the oxidation of the aldehyde group of 3 -phosphoglyceraldehyde is used for the introduction of a new phosphate group in the $\mathrm{I}$ - position with a relatively small over-all change in free energy (see Fig. I). From the I : 3-phosphoglyceric acid which is produced, the phosphate radical is transferred to adenosine diphosphate giving adenosine triphosphate in which form it may be used for the phosphorylation of other substances thus raising their potential chemical energy content to the level necessary for their participation in synthetic reactions. ${ }^{19,}{ }^{41}$ Certain of the substances involved in the phosphorylation cycle of yeast, e.g. hexose phosphates and phosphoglyceric acid, are known to be present in Scenedesmus, Chlorella ${ }^{29}, 52$ and Euglena. ${ }^{1}$ Adenosine triphosphate itself is perhaps absent from Chlorella but phosphorylated compounds which may have a similar rôle are evidently present in this alga ${ }^{79}$ together with an enzyme capable of hydrolysing adenosine triphosphate. ${ }^{84}$ Adenosine di- and triphosphates have been identified in Euglena. ${ }^{1}$ The relative proportions of the different phosphorus containing fractions in Chlorella alter following illumination of the cells in a manner which suggests that phosphorylated compounds are acting as energy carriers. ${ }^{304}$ Evidence that the manner in which the energy of phosphate bonds is utilized in synthesis is similar in algae and in other organisms is available in the case of starch or glycogen formation, in which the energy necessary for the polymerization of glucose is provided from the phosphate bond of glucose-I-phosphate. ${ }^{19}, 41$ Phosphorylases 
catalysing this reaction, similar to those found in the tissues of higher animals and plants, have been reported as present in Polytomella caeca ${ }^{186,25}$ and in the blue-green alga Oscillatoria princeps. ${ }^{102}$

The available evidence thus suggests that the mechanism of respiration in algae is of the same general pattern as that in other organisms, but that certain of the enzyme systems involved may, at least in some species, be different from those found in yeast or vertebrates. It will, however, be noticed that much of the evidence which has been quoted relates to species of Chlorophyceae and that information about the mechanism of respiration in algae belonging to other classes is meagre. This illustrates a point which deserves particular emphasis. Our present knowledge of algal metabolism is based upon the examination of very few types out of the great variety which exists, about half of the investigations referred to in this book having, in fact, been carried out with species of Chlorococcales. Species belonging to other classes have received a little attention but it cannot yet be said that a representative sample of the various types has been examined with any degree of thoroughness. Considerable differences in metabolism have been found to exist between closely related species of algae ${ }^{109}$ and such results make it clear that generalizations based upon observations on one form only should be treated with reserve. Table I shows the distribution among the several classes of those genera of algae mentioned in this book.

As a framework for the consideration of the variety of types of metabolism which exists among the algae a classification appears best which recognizes that the manner in which an organism obtains the energy necessary for the maintenance of its life and the organism's powers of synthesis are independent. Organisms have for a long time been classified broadly into autotrophs, those capable of growth on inorganic nutrients only (e.g. photosynthetic organisms), and heterotrophs, those needing organic substances for growth. The inadequacy of this classification was made apparent by the discovery that certain species, 


\section{TABLE I}

CLASSIFICATION OF THE ALGAE SHOWIŇG THE GENERAL FEATURES OF THE CLASSES AND THE TAXONOMIC POSITIONS OF THE GENERA MENTIONED IN THE TEXT

Genera marked with an asterisk include colourless species. For further information on classification and morphology see 106, 107, 259.

\section{CHLOROPHYTA}

Class

Chlorophyceae (green algae; flagellate, coccoid and filamentous forms; more abundant in fresh than in saltwater and tending to be terrestrial)
Order

Volvocales

Chlorococcales

Ulotrichales

Cladophorales

Chaetophorales

Oedogoniales

Conjugales

Siphonales

Charales

\section{CHRYSOPHYTA}

Xanthophyceae

('yellow-green'

algae; flagellate, coccoid and filamentous forms; most abundant in freshwater)

Bacillariophyceae

(diatoms; unicellular "forms; widely distributed in freshwater, marine and terrestrial habitats)
Heterochloridales Heterococcales Heterotrichales Heterosiphonales

Pennales

Centrales

\section{Genera}

Chlamydomonas, Chlorogonium, Coccomyxa, Haematococcus, Polytoma, ${ }^{*}$ Polytomella*, Tetrachloris

Ankistrodesmus, Chlorella, Prototheca*, Scenedesmus, Trebouxia Enteromorpha, Hormidium, Monostroma, Stichococcus, Ulva Cladophora

Oedogonium

Zygnema

Valonia, Vaucheria (?) Nitella
Monodus

Tribonema

Asterionella, Navicula, Nitzschia*, Pinnularia Ditylium 
Chrysophyceae . (mainly flagellates, water marine)
Synura, Ochromonas

Chrysomonadales

Chrysosphaerales

Chrysotrichales

\section{PYRROPHYTA}

Cryptophyceae . (mainly flagellates; freshwater and marine)

Dinophyceae (mainly flagellates; most abundant in the sea)

\section{Cryptomonadales}

Cryptococcales

(A) Desmokontae Prorocentrum

(B) Dinokontae: Dinoflagellata

Dinococcales Dinotrichales

EUGLENOPHYTA

Euglenineae . (flagellates; most abundant in freshwater)

\section{PHAEOPHYTA}

Phaeophyceae . Ectocarpales (brown seaweeds; filamentous and more elaborate forms; all but a few marine)

Tilopteridales

Cutleriales

Sporochnales

Desmarestiales Laminariales

Sphacelariales Dictyotales Fucales

Astasia, ${ }^{*}$ Euglena

Gymnodinium, Peridinium

Chilomonas*, Cryptomonas

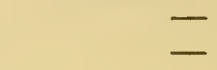

\section{ena}

lena


Gigartinales

Rhodymeniales Ceramiales

\section{CYANOPHYTA}

Myxophyceae . Chroococcales (blue-green algae; unicellular and filamentous forms lacking a nucleus as found in other algae; freshwater, marine and terrestrial)
Chondrus, Gigartina, Iridaea

Rhodymenia

Bostrychia
Chamaesiphonales Pleurocapsales Nostocales

Stigonematales
Chroococcus, Gloeocapsa Microcystis, Synechococcus, Synechocystis

Anabaena, Anabaeniopsis, Aphanizomenon, Aulosira, Beggiatoa*, Calothrix, Cylindrospermum, Gloeotrichia, Nostoc, Oscillatoria, Phormidium, Tolypothrix Mastigocladus

such as Euglena pisciformis, possess chlorophyll and are photosynthetic and yet require organic growth factors. ${ }^{71} \mathrm{It}$ is thus necessary to distinguish between the use of organic substances as a source of energy and their use as growth factors by organisms unable to synthesize particular metabolites for themselves. The following is the relevant part of a classification which recognizes this distinction. ${ }^{57}, 181$

\section{Nomenclature based upon energy sources.}

A Phototrophy: energy chiefly provided by photochemical reaction.

(I) Photolithotrophy: growth dependent upon exogenous inorganic hydrogen donors (e.g. most green plants, in which water acts as the hydrogen donor).

(2) Photo-organotrophy: growth dependent upon exogenous organic hydrogen donors (e.g. photosynthetic bacteria belonging to the Athiorhodaceae, in which organic substances such as fatty acids act as hydrogen donors in photosynthesis $^{247}$ ). 
B Chemotrophy: energy provided entirely by dark chemical reactions.

(I) Chemolithotrophy: growth dependent upon oxidation of exogenous inorganic substances (e.g. the 'chemosynthetic' bacterium Nitrosomonas, which oxidizes ammonia to nitrite ${ }^{247}, 267$ ).

(2) Chemo-organotrophy: growth dependent upon oxidation or fermentation of exogenous organic substances (e.g. non-photosynthetic bacteria, fungi and animals).

II. Nomenclature based upon ability to synthesize essential metabolites.

A Autotrophy: all essential metabolites are synthesized (e.g. most green plants).

(I) Autotrophy sensu stricto: ability to reduce oxidized inorganic nutrients such as nitrate.

(2) Mesotrophy: inability to reduce one or more oxidized inorganic nutrients (=need for one or more reduced inorganic nutrients such as ammonia).

B Heterotrophy: not all essential metabolites are synthesized ( = need for exogenous supply of one or more essential metabolites, i.e. growth factors or vitamins; animals and many fungi and bacteria are of this type).

Composite names may be used for the concise, if uncouth, characterization of a nutritional type with respect to the chief energy source as well as to the capacity for synthesis of essential cell constituents, e.g. Chlorella vulgaris is photolithoautotrophic, whereas Prototheca zopfii is chemo-organoheterotrophic. To avoid confusion it should be particularly noted that the terms autotrophic and heterotrophic as used in this book are as re-defined in this classification. 


\section{THE PHOTOTROPHIC ASSIMILATION}

\section{OF CARBON}

SINCE the energy transformations occurring in the metabolism of living organisms are chiefly brought about by chemical changes in carbon compounds, the assimilation of this element and the absorption of energy cannot be considered apart. Photosynthesis, the characteristic method of carbon assimilation of the algae, occupies a central place in the metabolism of these organisms and an account of the process is an indispensable foundation for the consideration of their other chemical activities.

The process of photosynthesis may be represented by the following over-all equation:

$$
\mathrm{CO}_{2}+2 \mathrm{H}_{2} \mathrm{O} \rightarrow\left(\mathrm{CH}_{2} \mathrm{O}\right)+\mathrm{H}_{2} \mathrm{O}+\mathrm{O}_{2}
$$

i.e. as an oxidation-reduction in which water acts as the hydrogen donor and carbon dioxide as the hydrogen acceptor. The oxygen evolved in photosynthesis has been shown to come exclusively from the water used and therefore two water molecules are needed as hydrogen donors for each one of carbon dioxide. The first stable product of the reduction of carbon dioxide may for present purposes be supposed to be a carbohydrate and is accordingly represented as $\left(\mathrm{CH}_{2} \mathrm{O}\right)$ in equation (I). The photosynthetic quotient $\left(Q_{P}=\Delta \mathrm{O}_{2} /-\Delta \mathrm{CO}_{2}\right)$ is then unity. Photosynthesis is endergonic and proceeds with an accumulation of at least I $2 \mathrm{k}$-cal. per mole of carbon dioxide reduced. This energy is obtained as light of wavelengths between about 400 and $700 \mathrm{~m} \mu$, absorbed by the photosynthetic pigments. Chlorophyll acts as the photochemical sensitizer and photosynthesis has never been found to occur in its absence. The minimum number of light quanta required for the reduction of one molecule of carbon dioxide to the reduction level of the 
carbon in carbohydrates is still the subject of debate but the weight of evidence is at present in favour of this number being at least eight.

Kinetic studies have shown that photosynthesis is not a simple process but that it consists of both a photochemical reaction and others able to proceed in the dark. Comparative biochemistry suggests that the generation of reducing power and the assimilation of carbon dioxide are separate processes and experimental evidence seems to show conclusively that in isolated chloroplasts the first of these processes can occur independently of the other. Reducing power is generated by a process including at least one 'dark reaction' as well as the photochemical reaction and results in the splitting of water to yield an oxidized portion, which is ultimately disposed of by elimination of elementary oxygen, and hydrogen, which is transferred to some as yet unidentified intermediary acceptor. Hydrogen from this intermediary substance is then used for the reduction of the assimilated carbon dioxide.

This concept of photosynthesis is based on results obtained with both algae and higher plants. There can be little doubt that in all important respects the mechanism of photosynthesis is the same in algae as in other plants. Good evidence for this is that the principal photosynthetic pigment in all classes of algae and in the higher plants is the same, i.e. chlorophyll $a 0^{272}$ The first stable product of the photosynthetic fixation of carbon dioxide has also been found to be the same in higher plants as in the algae Chlorella and Scenedesmus. ${ }^{29}$ It may be noted that although the principal pigments of the photosynthetic bacteria are chlorophylls they are different from those to be found in the algae so that there is here the possibility of a difference, although it seems unlikely that it can be a very profound one, in the photochemical mechanisms of the two types.

In the following sections of this chapter an account will be given of such features of photosynthesis as are especially characteristic of the algae or of which consideration is necessary for the understanding of other chemical activities of these organisms. Detailed treat- 

ment of photosynthesis is to be found in a number of recent publications. ${ }^{247}, 248,100,30,99,113,261$

THE ALGAL PIGMENTS AND THE UTILIZATION OF LIGHT IN PHOTOSYNTHESIS

Three principal types of pigment are to be found in algae. These are the chlorophylls, the carotenoids and the phycobilins. The chlorophylls are characterized by possessing a cyclic tetrapyrrolic nucleus containing magnesium. They are soluble in fat solvents giving fluorescent solutions having pronounced absorption bands in the blue or bluegreen and in the red or infra-red (Fig. 3). Carotenoid pigments are likewise soluble in fat solvents but have a yellow or orange colour resulting from absorption in the blue and the green (Fig. 3). Carotenoids generally contain about

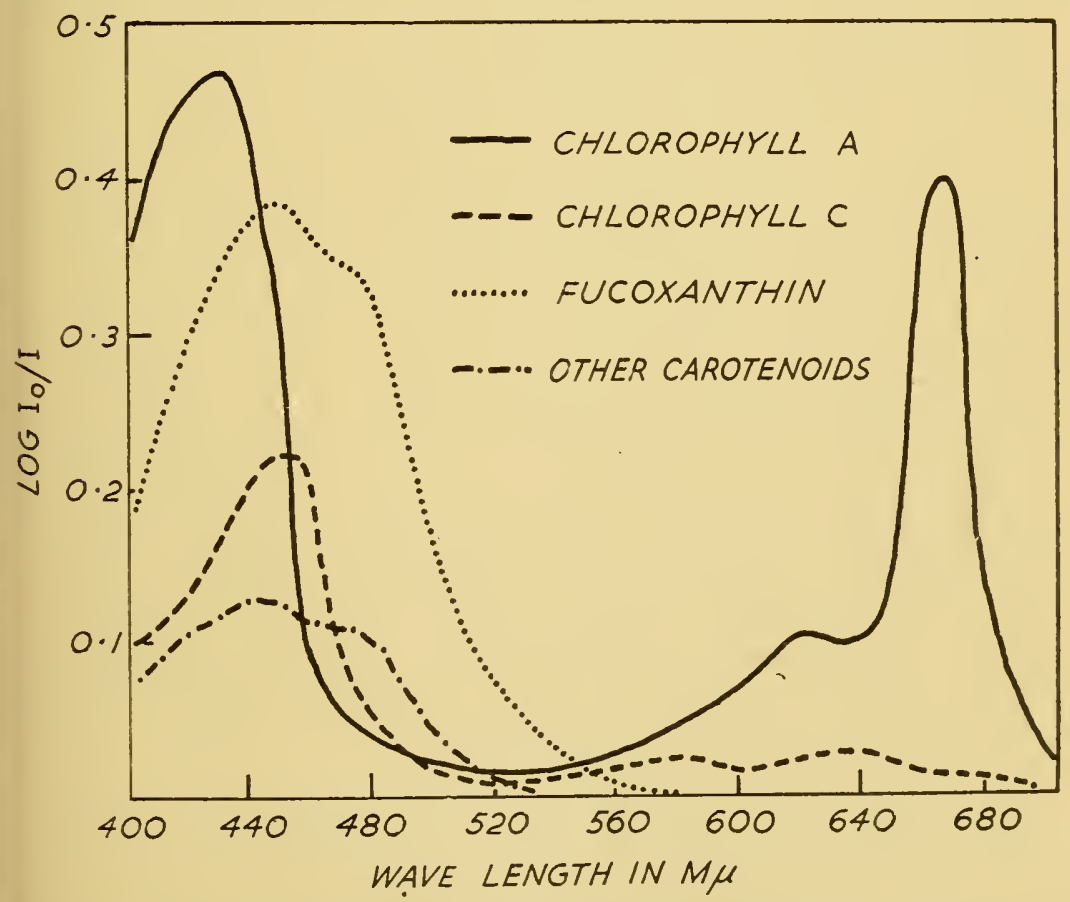

FIG. 3. Absorption spectra of methanol solutions of pigments extracted quantitatively from cells of Navicula minima (after ref. 280). 
40 carbon atoms, most of which are united into a long polyene chain, i.e. one having alternating double and single bonds. Carotenoid pigments are of two sorts, the carotenes, which are hydrocarbons, and the xanthophylls, which are oxygen derivatives of carotenes. The phycobilins are characterized by having a metal-free linear tetrapyrrolic chromophoric group linked to a protein of the globulin type. Unlike the other photosynthetic pigments they are soluble in water and insoluble in fat solvents. The differences between the two types of phycobilin, the phycocyanins and phycoerythrins, are not clearly marked, but the former are generally blue whereas the latter are generally red (for an absorption spectrum of a phycobilin see Fig. 7). Phycobilins are strongly fluorescent. More detailed accounts of the chemistry and properties of these three classes of pigments are to be found elsewhere. ${ }^{62}, 247,248,271,272$

The principal pigments occurring in the different classes of algae are shown in Table 2. Chlorophyll $a$ is the most abundant chlorophyll in all types of algae, as it is in higher plants. Chlorophyll $b$, which is also to be found in higher plants, occurs in the Chlorophyceae and Euglenineae but is absent from the other classes, in which, however, chlorophylls $c, d$ or $e$, may be present. $\beta$-carotene is the most abundant carotene in all classes, but $\alpha$-carotene, characteristic of Chlorophyceae and higher plants, is absent from some classes and is replaced in the Bacillariophyceae by $\varepsilon$-carotene. The xanthophylls are numerous and each algal class possesses its characteristic sorts. Those of the Chlorophyceae are similar to those to be found in higher plants. It is to be noted that the Siphonales differ somewhat from other orders of the Chlorophyceae in their carotenoids. In the Siphonales $\alpha$ - and not $\beta$-carotene is more abundant and

- indicates the principal pigment of its group, o a pigment comprising less than half the total pigments of its group, $\bigcirc$ a pigment comprising only a small fraction of the total pigments of its group, - absent, - incompletely examined, and ? uncertain. The Cryptophyceae, which show diverse coloration and regarding the pigments of which nothing is known, are omitted from this table. 
TABLE 2

THE PRINCIPAL PIGMENTS OF THE DIFFERENT CLASSES OF ALGAE (data from ref. 272)

Chlorophylls

Chlorophyll $a$

Chlorophyll $b$

Chlorophyll $c$

Chlorophyll $d$

Chlorophyll $e$

Carotenes

$\alpha$-carotene

$\beta$-carotene

$\epsilon$-carotene

Xanthophylls

Lutein

Zeaxanthin

Violaxanthin

Flavoxanthin

Neoxanthin

Siphonein

Siphonoxanthin

Fucoxanthin

Neofucoxanthin

Diatoxanthin

Diadinoxanthin

Dinoxanthin

Neodinoxanthin

Peridinin

Myxoxanthin

Myxoxanthophyll

Un-named

Phycobilins

$r$-phycoerythrin

$r$-phycocyanin

$c$-phycoerythrin

$c$-phycocyanin

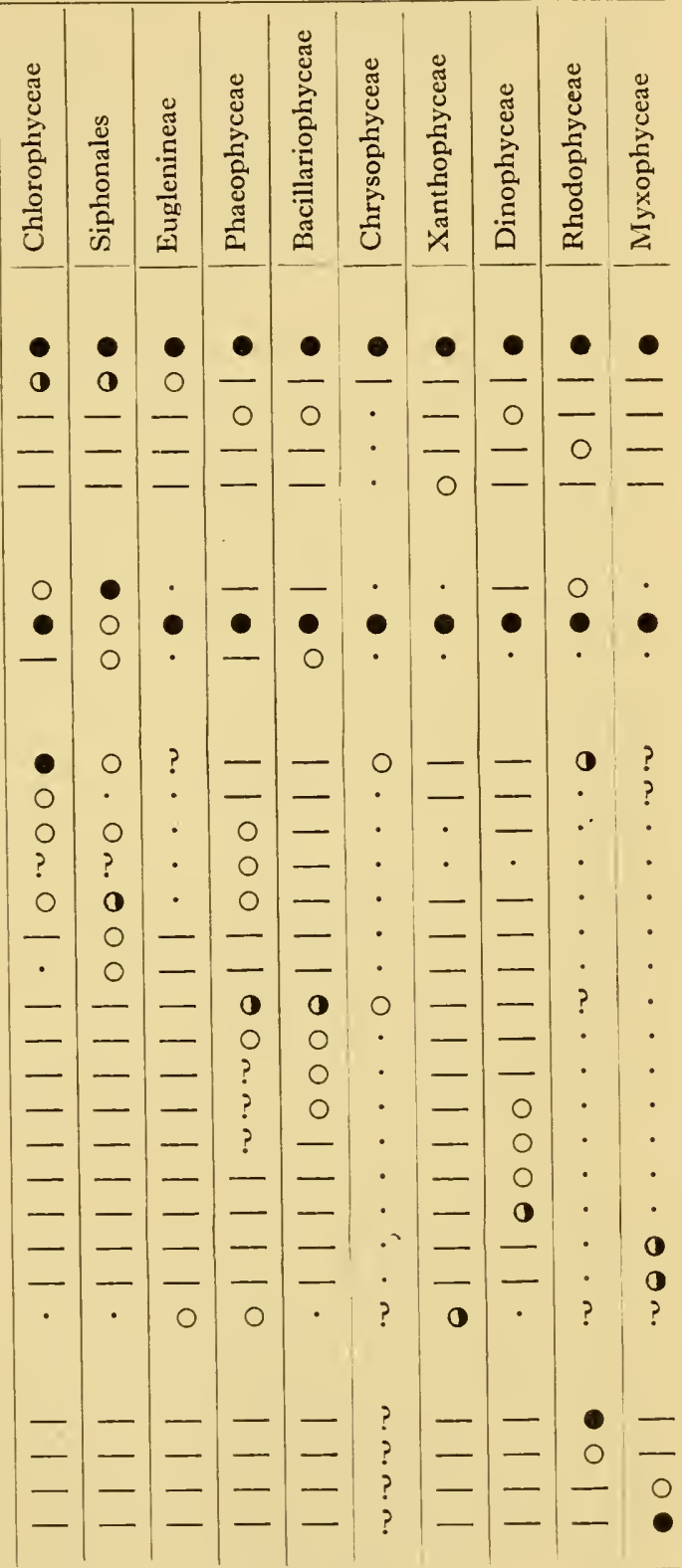


although, with the possible exception of zeaxanthin, the xanthophylls typical of other Chlorophyceae are present, two xanthophylls peculiar to this order are more abundant. Only the Rhodophyceae and Myxophyceae possess phycobilins, phycoerythrin being more characteristic of the former and phycocyanin of the latter. The pigments produced by these two classes although similar are not identical, and they are usually termed $r$ - or $c$-forms according to whether they occur in the Rhodophyceae or Myxophyceae respectively.

The variation to be found in the chromatophore pigments of the algae stands in marked contrast to the conservatism in this respect shown by higher plants.

Evidence of the part played in photosynthesis by these various pigments has been obtained principally by comparison of the absorption spectra of algae with their 'action spectra' for photosynthesis. ${ }^{248}$ To a rough approximation the spectral absorption curve of an alga, when effects due to the scattering of light inevitable in a poly-phase system are reduced to a minimum, is the sum of those of its individual pigments. The action spectrum curve of photosynthesis is obtained by determining the photosynthetic efficiency of light, usually measured in terms of oxygen production, at different wavelengths. These determinations must be made at low light intensity since with light saturation light of all wavelengths that can be utilized will produce the same effect. A further point is that it is necessary to make the comparisons for equal numbers of quanta not for equal energy contents, since the photochemical effect of a light quantum remains the same although the energy per quantum varies with wavelength. If all the energy absorbed by the pigments is available for photosynthesis then the curves for the absorption and action spectra should be super-imposable and since the different pigments have absorption maxima at different wavelengths, it is sometimes possible, by comparing the two curves, to determine whether or not light absorbed by a particular pigment is being utilized in photosynthesis or not (see Figs. 6 and 7).

Such comparison, however, is not straightforward be- 
cause it is only possible to determine the absorption spectra of individual pigments after extraction from the plant whereas it is known that the absorption properties as thus determined may differ appreciably from those which a pigment possesses in the living plant. For example, the main absorption band in the red of chlorophyll has a peak at about $660 \mathrm{~m} \mu$ in solvents such as alcohol and acetone whereas in living plants this peak is seen to be shifted by about ${ }_{5} \mathrm{~m} \mu$ towards longer wavelengths. The striking change in colour, from brown to green, which brown algae and diatoms undergo upon killing is due to a displacement of the absorption band in the green of fucoxanthin towards the position in the shorter wavelengths characteristic of the extracted pigment. ${ }^{293}$ Such displacements of absorption bands in vivo are generally ascribed to chemical combination of the pigments with each other and with lipide and protein. Allowance can be made for such alterations in absorption properties in interpreting action spectra but where the absorption bands of pigments in vivo overlap, and it is consequently impossible to determine the positions of peaks accurately, correction must be arbitrary and there is a corresponding uncertainty in the conclusions derived. A further assumption that must be made in the interpretation of action spectra is that the pigments are uniformly distributed within the chromatophores. If there is unequal distribution then one pigment may screen another and estimation of the partition of light absorption among the different pigments cannot be made correctly from knowledge of absorption properties and relative concentrations only.

Much of the early work on the rôle of algal pigments in photosynthesis was made using colour filters which were only capable of isolating broad regions of the spectrum. Such work sometimes led to conclusions which have been confirmed by more critical studies but it is unnecessary to discuss it in detail here (for references see 248 , 107). In the more modern investigations action curves for photosynthesis have been determined using narrow spectral bands isolated by means of monochromators. 
The rôle of carotenoids has been established most convincingly in the case of diatoms. ${ }^{72,293,280}$ In an investigation with Navicula minima, for example, the quantum yield of photosynthesis has been measured at different wavelengths (Fig. 4) and compared with the corresponding

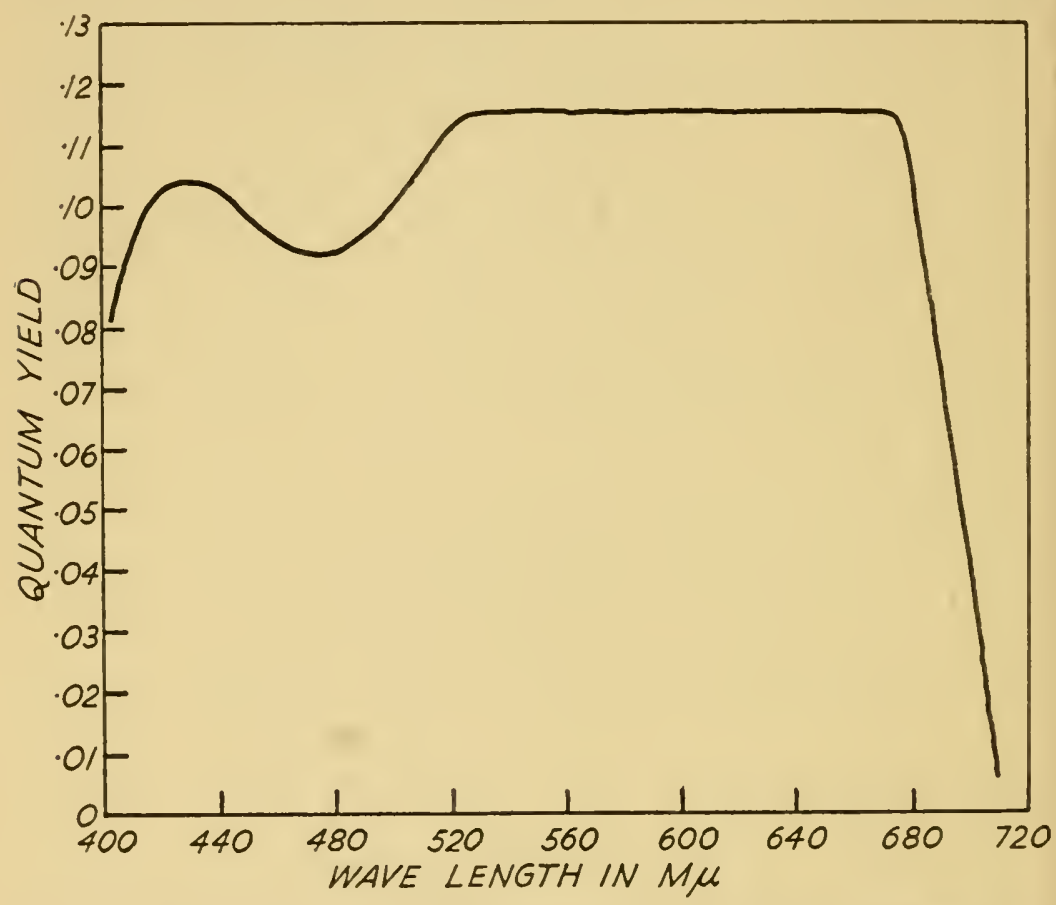

FIG. 4. Quantum yield of photosynthesis by Navicula minima as a function of wavelength (after ref. 280).

estimates of the distribution of light among chlorophylls, fucoxanthin and other carotenoids (Fig. 5). The corrections for band shifts necessary for the estimation of the absorption of the different pigments in vivo were determined using cells extracted with dilute methanol which removed chlorophyll $c$ and fucoxanthin without extracting the other pigments. The quantum yield of photosynthesis was found to be nearly constant from 520 to $680 \mathrm{~m} \mu$, dropping rapidly at wavelengths greater than $680 \mathrm{~m} \mu$ and showing a slight dip in the blue between 430 and $520 \mathrm{~m} \mu$. Comparisons 
THE PHOTOTROPHIC ASSIMILATION OF CARBON 25

between this efficiency curve and those for the distribution of absorption among the pigments in vivo indicate that light absorbed by fucoxanthin is utilized in photosynthesis with about the same efficiency as that absorbed by chlorophyll. Thus at $55^{\circ} \mathrm{m} \mu$, where some 80 per cent of the light absorption is by fucoxanthin, there is no decline in quan-

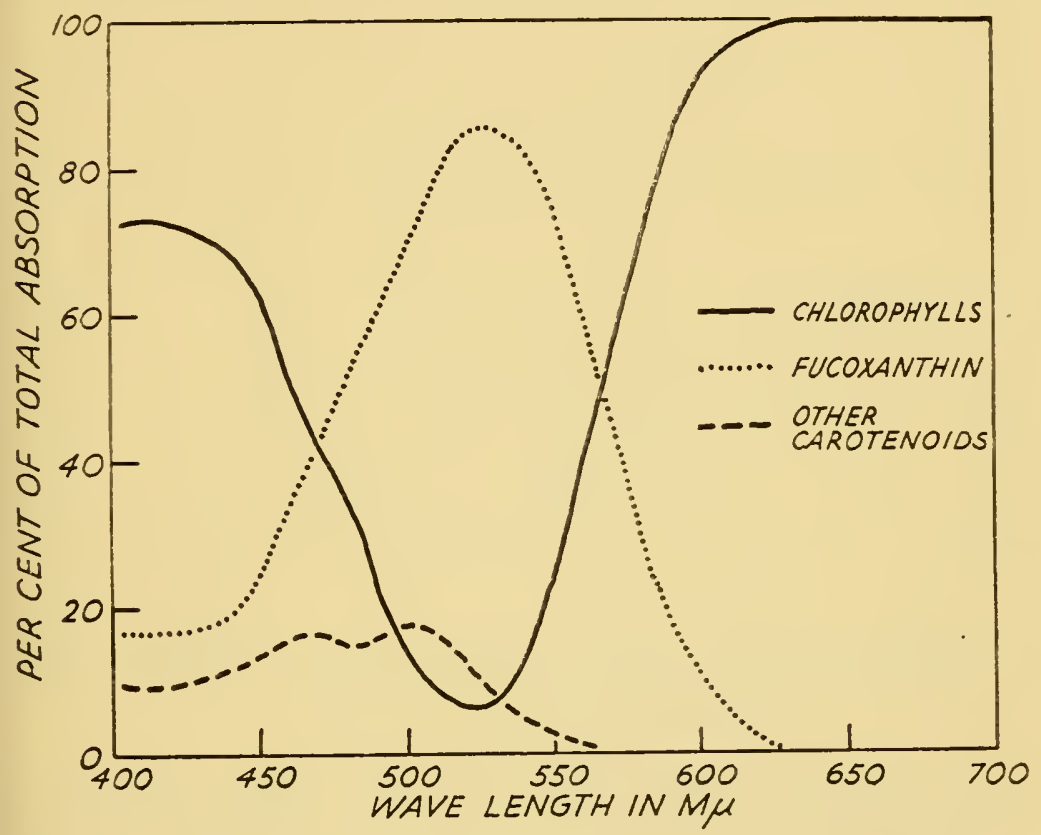

FIG. 5. Curves showing the estimated distribution of light absorption among the different groups of pigments in live cells of Navicula minima (after ref. 280).

tum yield as compared with that at $65^{\circ}$ m $\mu$ where 100 per cent of the light is absorbed by chlorophylls. Light absorbed by other carotenoids, however, does not appear to be available for photosynthesis. ${ }^{280}$

Fucoxanthin appears to be effective in the same way in Phaeophyceae, comparison of the action and absorption spectra for Coilodesme (Fig. 6) showing a high photosynthetic activity in the region 500 to $560 \mathrm{~m} \mu$ where absorption is chiefly by this pigment. ${ }^{139}$ In green algae such as 
Chlorella, ${ }^{78}$ Ulva and Monostroma ${ }^{139}$ light absorbed by carotenoids appears to be partly, but not entirely, utilized in photosynthesis. In Chroococcus, however, light absorbed by carotenoids seems to be for the most part unavailable for photosynthesis. ${ }^{77}$ Carotenoids sometimes occur elsewhere in the protoplast than in the chromatophore and are

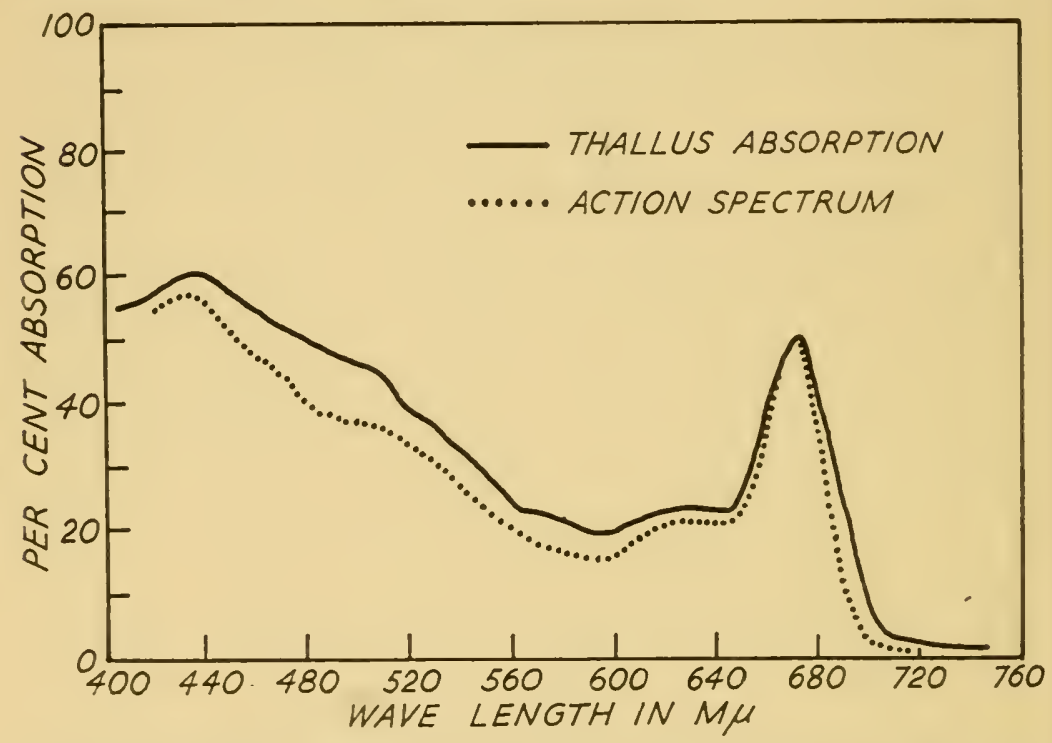

FIG. 6. Absorption and action spectra of Coilodesme californica. The action curve for photosynthesis, corrected to relative rates for equal numbers of incident quanta, has been made to coincide with the absorption curve at $675 \mathrm{~m} \mu$. The relatively minor divergence between the two curves in the region 500 to $560 \mathrm{~m} \mu$ suggests that light absorbed by fucoxanthin is effective in photosynthesis (after ref. r39).

presumably then inactive in photosynthesis and it may be that within the chromatophore spatial arrangements exclude some carotenoid molecules from participation in active light absorption. Another possibility is that certain types of carotenoid are able to absorb light for use in photosynthesis but that others are quite inactive in this way.

Because their main absorption bands are widely separated from those of the chlorophylls, the phycobilins provide 
particularly clear examples of accessory pigments participating in photosynthesis. In Chroococcus the quantum yield at $600 \mathrm{~m} \mu$ is about the same as at 660 to $680 \mathrm{~m} \mu$, where nearly all the light absorption is due to chlorophyll $a$, in spite of the absorption by phycocyanin at this wavelength being about six times that of chlorophyll $a .{ }^{77}$ Thus the

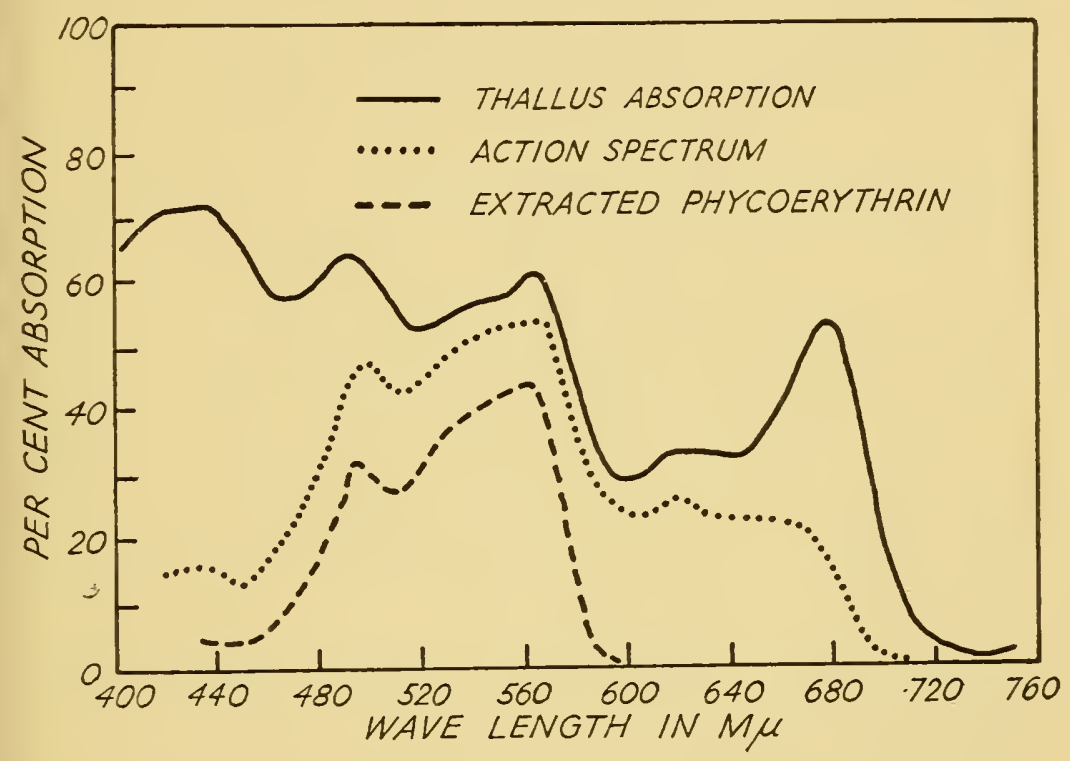

FIG. 7. Absorption and action spectra of Porphyra nereocystis. The action spectrum for photosynthesis corresponds more closely to the absorption spectrum of the water extract of the alga, which contains phycoerythrin as the principal phycobilin pigment, than to the absorption curves of chlorophylls and carotenoids (after ref. 139).

photosynthetic efficiency of phycocyanin in Chroococcus must equal that of chlorophyll. The phycobilins in Rhodophyceae are effective in the same way and in certain species, e.g. Porphyra nereocystis, there is the curious situation that light absorbed by these pigments is utilized more efficiently than that absorbed by the chlorophylls themselves. ${ }^{139}$ This is shown in Fig. 7, in which the photosynthetic efficiency at wavelengths at which all the absorption is by chlorophylls 
is seen to be much less than that at wavelengths where the absorption is almost entirely due to phycobilins.

Light absorbed by chlorophyll $b$ in Chlorella ${ }^{78}$ and by chlorophyll $c$ in Navicula $a^{280}$ appears to be equally available for photosynthesis with that absorbed by chlorophyll $a$.

Further information about the part played by accessory pigments in photosynthesis comes from studies of fluorescence. Fluorescence occurs when radiant energy absorbed by a substance is re-emitted almost instantaneously as light. This light is necessarily of a longer wavelength than that which excites the fluorescence and is of a characteristic wavelength for a given pigment. The yield of fluorescence, i.e. the ratio of the energy emitted to that absorbed, gives information regarding the fate of the excitation energy. In living Nitzschia closterium the yield of chlorophyll fluorescence is the same whether it is excited by red light $(600 \mathrm{~m} \mu)$, absorbed exclusively by chlorophyll, or by blue-green light $(470 \mathrm{~m} \mu)$, three-quarters of which is probably absorbed by carotenoids. ${ }^{73}$ Similar studies with Gigartina, Iridaea, ${ }^{211}$ Porphyridium, ${ }^{74,103}$ Porphyra and Oscillatoria ${ }^{74}$ have established that light absorbed by phycobilins can also excite fluorescence of chlorophyll $a$. This evidence of a transference of energy from accessory pigments to chlorophyll suggests that light absorbed by the former pigments is not utilized directly in the photochemical reaction. It appears, in fact, that all light energy used in photosynthesis must pass through chlorophyll $a .{ }^{74,103}$ Thus in Chlorella only chlorophyll $a$ fluoresces and its fluorescence is excited by light absorbed by chlorophyll $b{ }^{74}$ Since chlorophyll $a$ is the principal photosynthetic pigment in all the algal classes this provides evidence that the photochemical reaction is of the same nature in all algae. However, it has been found that light absorbed by phycobilins is sometimes more effective in exciting the fluorescence of chlorophyll $a$ than is light absorbed by this chlorophyll itself and that light absorbed by chlorophyll $a$ excites the fluorescence of another pigment which is perhaps chlorophyll $d .{ }^{74}$ These findings, which fit in with the observation mentioned above that light absorbed by phycobilins is more effective in 
photosynthesis than that absorbed by chlorophyll, can be explained if it is assumed that chlorophyll $a$ exists in two states of combination, one active in photosynthesis, to which energy transference from phycobilins is possible, and another, inactive in photosynthesis, from which energy transference to the unidentified fluorescent pigment occurs. ${ }^{248}$

After it was first postulated by Engelmann, ${ }^{80,81}$ the existence of chromatic adaptation among algae was for a long time the subject of controversy (see $107,247,248$ for references). This problem, of whether or not the characteristic pigmentation of particular forms is of biological advantage to them, is now largely resolved by the findings that have been outlined in the preceding paragraphs. Chromatic adaptation is most clearly exemplified by the algae of the littoral region of the sea, in which, as a general rule, red algae occupy the lowest zone and green algae the highest, whilst brown algae are to be found in the intermediate position. Whereas yellow light predominates in the sunlight reaching the earth's surface, blue-green light is transmitted to the greatest extent by clear seawater. The pigmentation of the littoral algae is thus complementary to the quality of light characteristic of the positions which they occupy and will consequently secure maximum light absorption. Since it has been shown that the energy absorbed by the principal accessory pigments is utilized in photosynthesis it is clear that the pigmentation of the different algae is such as to enable each to make the maximum use of the light energy available in its characteristic habitat. Chromatic adaptation of this sort is genetically determined, but there is evidence that, in some species at least, ontogenetic adaptation can also occur. ${ }^{107,247}$ However, the zonation of algae to be expected from this simple view of chromatic adaptation may be blurred by several circumstances. Thus changes in the proportions of individual photosynthetic pigments may occur in response to variation in intensity as well as in quality of light or more effective absorption of particular wavelengths may be obtained by increase in total concentration of pigments or by increase in thallus thickness rather than by changes in the 
relative amounts of the individual pigments. It is also evident that a species in which a particular type of pigmentation is determined genetically may become adapted to an environment in which its pigmentation, although not a disadvantage, is no longer an advantage.

\section{THE HYDROGEN DONOR}

The energy made available through absorption by the pigments is used to effect reductions by means of hydrogen derived from some specific substance. In normal photosynthesis by higher plants and by the majority of algae this hydrogen donor is water. In certain algae, however, other substances can be utilized at least as the ultimate source of hydrogen. This ability to make use of a wider variety of hydrogen donors in photosynthesis is a respect in which the algae resemble the bacteria and which appears to be a type of biochemical variation characteristic of the more primitive classes of organisms.

The process of 'photoreduction' by means of elementary hydrogen, which can occur in various species of algae after a period of adaptation under anerobic conditions, was discovered by Gaffron in 1939. 110,247 Adapted algae become able to carry out various reactions which they were not able to effect before. In the dark they are able to absorb hydrogen from an atmosphere containing a high proportion of this gas, providing that hydrogen acceptors such as oxygen are available, or to liberate it into an atmosphere of pure nitrogen by fermentation of a substrate such as glucose. Oxygen and hydrogen can thus be absorbed simultaneously by adapted algae and the reduction of carbon dioxide may be coupled with this. In the light, exchanges involving hydrogen are accelerated and photosynthesis from carbon dioxide and hydrogen can occur. The value of the quotient $\Delta \mathrm{H}_{2} / \Delta \mathrm{CO}_{2}$ is in accordance with the over-all equation:

$$
\mathrm{CO}_{2}+2 \mathrm{H}_{2} \rightarrow\left(\mathrm{CH}_{2} \mathrm{O}\right)+\mathrm{H}_{2} \mathrm{O}
$$

i.e. the process is similar to the photosynthesis with hydrogen as hydrogen donor which occurs in the purple bac- 
THE PHOTOTROPHIC ASSIMILATION OF CARBON $3^{\text {I }}$

teria. ${ }^{247}$ The quantum yield of this process is of the same order as that for normal photosynthesis. ${ }^{249}$

Hydrogenases, enzymes capable of introducing hydrogen into cellular metabolism, are well known in bacteria ${ }^{267}$ and it appears that in certain algae there are similar enzymes, which, however, only become active after reduction. This reduction occurs during adaptation under anaerobic conditions and is reversed when de-adaptation takes place in the presence of oxygen or in the presence of carbon dioxide if the intensity of illumination exceeds a certain limit. It seems likely that in photosynthesis by adapted algae the photochemical reaction involves the decomposition of water as in normal photosynthesis ${ }^{247}$ and that the hydrogen donors provided by the hydrogenase reaction are used for the reduction of the oxidized products of this reaction, which would otherwise be disposed of by processes leading eventually to the liberation of oxygen. If the light intensity is high then these oxidation products accumulate at a rate faster than that at which they can be reduced by the hydrogenase system and this leads to the oxidation and inactivation of the hydrogenase. ${ }^{247}$ Certain substances such as hydroxylamine and $o$-phenanthroline stabilize adapted algae against de-adaptation in the light, evidently by inhibiting the oxidation of the hydrogenase by these intermediates of photosynthesis, but at the same time reduce the quantum efficiency of the process by a half. ${ }^{111,112}$

Not all algae can be adapted to hydrogen in this way. The process has been studied principally in Scenedesmus sp. and has been found to occur also in a number of other algae, but many species have been found not to possess the property (Table 3 ). A long period is required for adaptation by the marine algae but Chlamydomonas moewusii either does not require adaptation or has an adaptation period shorter than ro minutes. ${ }^{105}$ It is to be noted that the distribution of the capacity does not appear to depend on phylogenetic relationships. The capacity is present in members of at least four algal classes but does not necessarily occur in all members of a taxonomic group, e.g. it is absent from Chlorella whereas it occurs in Scenedesmus. 
TABLE 3

ALGAE WHICH HAVE BEEN TESTED FOR ABILITY TO CARRY OUT PHOTOREDUCTION ${ }^{105}$

Class

Species successfully adapted

Chlorophyceae

- Scenedesmus obliquus

Ankistrodesmus sp.

Chlamydomonas moeutusii

Ulva lactuca

Bacillariophyceae

Phaeophyceae

Rhodophyceae

Myxophyceae

\section{然}

Porphyra umbilicalis
Pophyridium cruentum
Synechococcus elongatus

Synechococcus elong
Synechocystis sp.
Species not showing photoreduction

Chlorella pyrenoidosa

Nitzschia spp.
-
Oscillatoria sp.

Nostoc muscorum

Cylindrospermum sp.

This type of photosynthesis probably does not occur to any great extent in algae under natural conditions. After carrying out the reaction for several days certain algae have been found to have shown no multiplication or increase in chlorophyll concentration comparable to that caused by a similar period of normal photosynthesis. ${ }^{247}$ It is, however, generally found that green algae do not grow under anaerobic conditions. There is some evidence that the products of photosynthesis using elementary hydrogen are similar to those of normal photosynthesis ${ }^{45}, 113$ and there is no reason to suppose that they are inherently unsuitable as substrates for growth. Porphyridium, a red alga, has been found to increase in dry weight and pigmentation while carrying on photosynthesis using elementary hydrogen under anaerobic conditions. ${ }^{105}$

A blue-green alga, Oscillatoria, and a diatom, Pinnularia, have been reported as able to use hydrogen sulphide, which is actually an inhibitor of photosynthesis in higher plants, as hydrogen donor. 205,247 The evolution of oxygen is here replaced by the deposition of sulphur within the cells and the process is thus apparently similar to that in the green sulphur bacteria, represented in equation 3 :

$$
\mathrm{CO}_{2}+2 \mathrm{H}_{2} \mathrm{~S} \rightarrow\left(\mathrm{CH}_{2} \mathrm{O}\right)+\mathrm{H}_{2} \mathrm{O}+2 \mathrm{~S} \text {. }
$$

Hydrogen-adapted Synechococcus and Scenedesmus have also been found to be able to utilize hydrogen sulphide as a 
hydrogen donor in photosynthesis, although if elementary hydrogen is present this is used preferentially. ${ }^{104}$ This use of hydrogen sulphide by algae has not yet been investigated in detail, but there are indications that it may be a widespread phenomenon, especially among Euglenineae and other flagellates. ${ }^{150}$

Photosynthetic processes utilizing water, elementary hydrogen or hydrogen sulphide, are included under the heading of photolithotrophy in the classification of nutritional types given in the first chapter. An example of photo-organotrophy, in which an organic substance acts as hydrogen donor, is provided by hydrogen-adapted Scenedesmus which will utilize substances such as glucose in preference to hydrogen for this purpose. ${ }^{247}$ No case of obligate photo-organotrophy in an alga appears to have been recorded so far.

\section{THE ABSORPTION OF CARBON DIOXIDE}

The majority of algae live in an aquatic environment in which carbon dioxide is present in various forms in equilibrium with each other:

$$
\mathrm{CO}_{2}+\mathrm{H}_{2} \mathrm{O} \rightleftharpoons \mathrm{H}_{2} \mathrm{CO}_{3} \rightleftharpoons \mathrm{HCO}_{3}{ }^{-}+\mathrm{H}^{+} \rightleftharpoons \mathrm{CO}_{3}{ }^{--}+2 \mathrm{H}^{+}
$$

The concentrations of these several forms depend on a number of factors including hydrogen ion concentration, the amount of base in excess of the equivalent of the strong acid radicals present, the partial pressure of carbon dioxide in the atmosphere and the temperature. ${ }^{247}, 136$ In considering the activities of algae, whether in culture or in freshwater or seawater, it is often important to know which of these forms is acting as the immediate source of carbon dioxide. It is necessary to bear in mind, of course, that the form in which carbon dioxide enters the cèll is not necessarily the same as that which forms the immediate substrate for photosynthesis.

It is generally held that unionized molecules penetrate cell membranes more rapidly than ions and in agreement with this there is evidence that undissociated carbon dioxide is utilized by certain algae whereas bicarbonate and carbonate ions are not. Thus in Chlorella the rate of photosynthesis 
has been found to be dependent on the concentration of the undissociated form even though both ionic forms are present in considerable excess ${ }^{290}$ and direct measurements have shown that only undissociated carbon dioxide can penetrate into the vacuole of Valonia coenocytes. ${ }^{212}$ However, the results with Chlorella cannot be considered altogether reliable since the buffer solutions used not only varied in hydrogen ion concentration but were very alkaline for physiological media, those for the lower concentrations of undissociated carbon dioxide having $\mathrm{pH}$ values of over I0. ${ }^{213}$ In Valonia the permeability of the vacuole membrane towards carbon dioxide was studied whereas for photosynthesis it is the permeability of the plasma membrane, which is almost certainly different, which is of more importance.

It is frequently observed that algae can carry on rapid photosynthesis in alkaline bicarbonate solutions in which the concentration of undissociated carbon dioxide is extremely low. This may be explained if it is assumed that the bicarbonate acts indirectly by maintaining the supply of undissociated carbon dioxide, the rate of diffusion of which would otherwise be limiting, in the vicinity of the cells, but the effect might equally well be due to the absorption of the bicarbonate ions themselves. Active absorption of anions is a property common to all growing plant cells and there seems to be no reason for supposing that bicarbonate ions are exceptional in not being absorbed by this mechanism.

Unequivocal evidence of such direct utilization of bicarbonate ions is difficult to obtain since the ratio $\left[\mathrm{CO}_{2}\right] /\left[\mathrm{HCO}_{3}{ }^{-}\right]$in solutions cannot be altered without changing hydrogen ion concentration too. However, over three or four $\mathrm{pH}$ units around neutrality photosynthesis appears not to be directly affected by hydrogen ion concentration. ${ }^{76}, 213,52$ Within this range it should be possible to obtain information regarding the absorption of these two forms of carbon dioxide by study of the performance of algae in solutions in which the ratio of their concentrations is varied. In this way evidence has been obtained which 
indicates that Scenedesmus quadricauda is able to utilize both undissociated carbon dioxide and bicarbonate ions, the latter being more readily utilized, only io to $20 \mu$ moles per litre being required for maximum growth whereas the corresponding value for undissociated carbon dioxide is $80 \mu$ moles per litre. ${ }^{213}$ Similar experiments with Chlorella pyrenoidosa, on the other hand, show that this species is not able to utilize bicarbonate and it thus appears that there may be two types of algae with respect to carbon dioxide absorption. ${ }^{214,216}$ Both the Scenedesmus and the Chlorella have been found to possess carbonic anhydrase so that the difference between them cannot be ascribed to differences in ability to convert carbon dioxide into bicarbonate. ${ }^{215}$ Experimental evidence confirms the expectation that bicarbonate absorption is an active process of anion absorption rather than one of simple diffusion and shows that under certain circumstances it does not begin until the alga has been activated by exposure to light for some time. ${ }^{217}$ The mechanism of this induction effect is not known.

Carbonate ions evidently cannot serve directly as a source of carbon dioxide and may have an inhibitory effect upon growth. ${ }^{213}$

By absorption of carbon dioxide algae may increase the alkalinity of the medium surrounding them to the point where calcium and magnesium carbonates are precipitated. Many species, particularly those belonging to the Siphonales, Rhodophyceae and Myxophyceae, are characterized by the production of calcareous deposits which are often incorporated in cell membranes, as for example in Corallina. ${ }^{106,107}$ Such calcification is generally supposed to be brought about by photosynthesis, but the fact that calcareous and non-calcareous species may grow side by side, apparently in similar states of photosynthetic activity, suggests that the mechanism may not be so simple. ${ }^{40}$

In general the total concentration of all forms of carbon dioxide in seawater is sufficient not to limit the photosynthesis of unicellular plants under conditions likely to be met with in the open sea. This is shown by experiments 
with Nitzschia closterium, for example. ${ }^{136}$ The concentrations of all forms of carbon dioxide available in freshwater vary much more than those in seawater, but generally they are such as not to be limiting for photosynthesis by phytoplankton except in the surface layers of waters poor in dissolved minerals under conditions of bright sunlight and calm. With bulkier algae, e.g. Gelidium, in which the rate of diffusion through the tissues up to the site of fixation is limiting, the saturating concentration of carbon dioxide may be considerably higher than that normally to be found in seawater. ${ }^{284}$

\section{THE FIXATION OF CARBON DIOXIDE}

The transformations undergone by intermediates in the metabolic processes of plants are frequently extremely rapid and until recently the nature of those involved in the photosynthetic fixation of carbon dioxide remained a matter for speculation, the available analytical techniques being inadequate for the separation and detection of the minute amounts of the substances concerned. Our present knowledge of the intermediates in photosynthesis is based largely upon results obtained by the school of Calvin and Benson and confirmed and extended by Gaffron and Fager, using isotopic tracer techniques in conjunction with paper partition chromatography and ion-exchange methods. In these investigations the unicellular algae Scenedesmus and Chlorella have been the principal materials for study.

If Scenedesmus or Chlorella is supplied with radioactive carbon dioxide in the dark it is found that malic, succinic, fumaric, citric, glutamic and aspartic acids and alanine, become labelled with radioactive carbon and together account for 95 per cent of the total radioactivity of the algal products. These compounds appear to be labelled by reversible carboxylation reactions such as are well known in other organisms and which occur independently of the capacity for photosynthesis. Under anaerobic conditions radioactive carbon fixed in this manner remains in the water-soluble fraction, only when aerobic respiration takes place is it transferred to polysaccharide, fat or protein. If 

the alga is supplied with radioactive carbon dioxide for a short period in the light then killed and extracted immediately, it is found that not only is the rate of fixation from ten to a hundred times greater than that in the dark, but that different compounds become labelled, phosphoglyceric

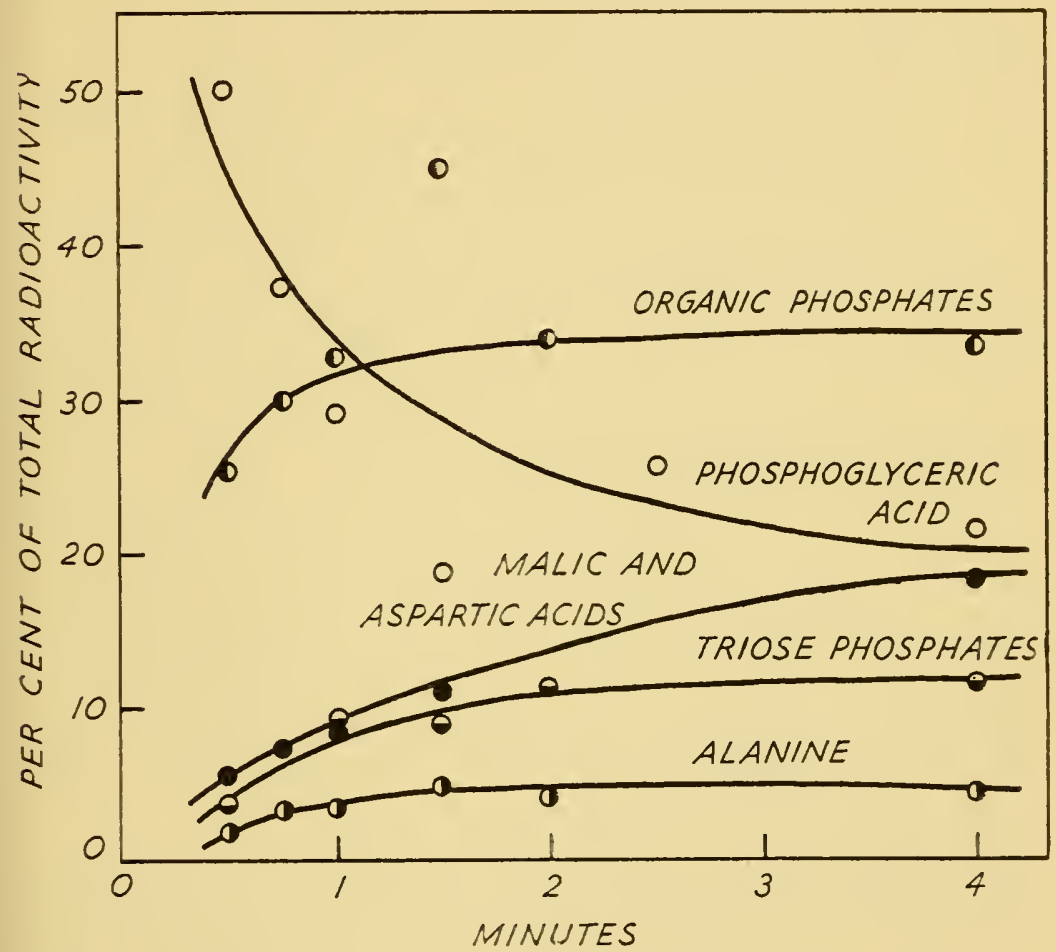

FIG. 8. Distribution of radioactive carbon among products extracted with 80 per cent ethanol from Scenedesmus sp. after varying periods of photosynthesis in the presence of carbon dioxide labelled with radioactive carbon (after ref. 52).

acid, pyruvic acid, malic acid, alanine, triose and hexose phosphates, and sucrose now being the principal substances concerned. 52,114 As the period of exposure of the actively photosynthesizing alga to radioactive carbon dioxide is shortened a greater proportion of the radioactive carbon appears in phosphoglyceric acid (Fig. 8). This and other 
evidence has established that this substance or its immediate precursor is an intermediate in photosynthesis. ${ }^{52,114}$ Evidence that substances such as pyruvic acid and malic acid are directly involved in photosynthetic carbon dioxide fixation is less satisfactory.

Examination of degradation products of the phosphoglyceric acid produced in short periods ( 5 to Io seconds) of photosynthesis with radioactive carbon dioxide shows radioactivity to be almost entirely confined to the carboxyl group. This suggests that the phosphoglyceric acid is formed by the carboxylation of some two carbon $\left(\mathrm{C}_{2}\right)$ compound. As the period of exposure to the labelled carbon dioxide is lengthened radioactive carbon appears to increasing extents in the 2 and 3 positions in phosphoglyceric acid and after about two minutes' exposure the molecule is uniformly labelled. The $\mathrm{C}_{2}$ acceptor thus appears to be itself derived from phosphoglyceric acid. ${ }^{52,114}$

These well-established facts point to the existence of a self-multiplying fixation cycle which, each time it is completed, results in the incorporation of three molecules of carbon dioxide and the formation of another molecule of phosphoglyceric acid for each one initially present. One of these phosphoglyceric acid molecules is necessary to maintain fixation whilst the other may be diverted from the cycle and used for other purposes.

The nature of the $\mathrm{C}_{2}$ acceptor and the manner of its regeneration from phosphoglyceric acid are as yet unknown. There is no evidence that the acceptor is formed by condensation of two $\mathrm{C}_{1}$ molecules, but there are indications that it is derived from $\mathrm{C}_{3}$ or $\mathrm{C}_{4}$ compounds. Thus, if plants are illuminated in the presence of radioactive carbon dioxide for short periods so that labelled $\mathrm{C}_{3}$ and $\mathrm{C}_{4}$ substances are formed, a further period of illumination in the absence of carbon dioxide causes the disappearance of such substances and the appearance of radioactive glycollic acid and glycine, both $\mathrm{C}_{2}$ compounds. This suggests a close relationship between the two latter compounds and the $\mathrm{C}_{2}$ acceptor. ${ }^{52}$ As an example of the type of fixation cycle which may operate, a scheme may be given in which it is supposed 
that the $\mathrm{C}_{2}$ acceptor is derived by splitting and reduction of oxaloacetic acid. ${ }^{30}$ It will be seen from Fig. 9 that in this cycle, which involves two successive carboxylations, the three substances named are interconvertible by known biochemical mechanisms. There is, however, no direct evidence

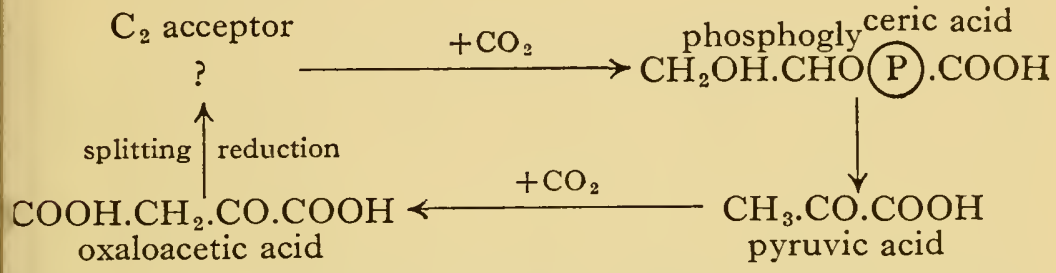

FIG. 9. Scheme showing a possible manner of origin of the $\mathrm{C}_{2}$ acceptor in photosynthesis from phosphoglyceric acid (after ref. 30 ).

for the existence of this cycle and it is open to criticism on various grounds. ${ }^{113}$ The evidence for the various other schemes that have been put forward $52,114,113$ is equally unsatisfactory.

A fundamental problem which is yet unsolved is that of the manner in which the reductions involved in the carbon dioxide fixation cycle take place. Chloroplasts separated by suitable techniques from living cells, or, in the case of algae such as Chlorella, intact cells, are capable of carrying out the 'Hill reaction' in which, under the influence of light, water is split resulting in the evolution of oxygen and the reduction of an appropriate hydrogen acceptor, A, according to the equation:

$$
\mathrm{A}+\mathrm{H}_{2} \mathrm{O} \rightarrow \mathrm{H}_{2} \mathrm{~A}+\frac{1}{2} \mathrm{O}_{2}
$$

Substances such as ferricyanide and quinone can act as direct hydrogen acceptors in this reaction, but carbon dioxide cannot. ${ }^{247}, 291,113$ The reduction potential developed is, in fact, insufficient for the direct reduction of the latter substance to the level of carbohydrate. ${ }^{143}$ However, reduction coupled with carbon fixation by illuminated chloroplast preparations from higher plants has been shown to occur in the presence of a suitable hydrogen carrier. Triphosphopyridine nucleotide (co-enzyme II) is such a. 
substance and its reduction by illuminated chloroplasts may be coupled with a reductive carboxylation such as that of pyruvic acid to malic acid, the sequence of reactions being:

$$
\begin{aligned}
& \mathrm{H}_{2} \mathrm{O}+\text { coenzyme II } \stackrel{\text { light }}{\longrightarrow} \text { coenzyme II. } \mathrm{H}_{2}+\frac{1}{2} \mathrm{O}_{2} \\
& \mathrm{CH}_{3} \cdot \mathrm{CO} \cdot \mathrm{COOH}+\mathrm{CO}_{2}+\text { coenzyme II. } \mathrm{H}_{2} \stackrel{\text { 'malic' enzyme }}{\rightarrow}
\end{aligned}
$$

The so-called 'malic' enzyme which catalyses reaction ( 7 ) has been shown to occur in a number of plant species. ${ }^{288}, 283,15$ Although an extracellular photosynthetic reaction has thus been brought about, it is doubtful whether this particular reaction is concerned in normal photosynthesis. ${ }^{283}, 15$ Malic acid does indeed appear among the products of short-term photosynthesis but photosynthesis has been found to be little affected by the presence of inhibitors such as malonic acid which completely suppress the formation of malic acid. ${ }^{15}, 52$

Further information regarding the link between the photochemical reaction and the reduction of carbon dioxide comes from observations on the enhanced dark fixation which occurs in algae and in other plants immediately following a period of normal photosynthesis or a period of illumination in the absence of carbon dioxide and oxygen. In both cases the enhanced dark fixation shows characteristics of photosynthetic fixation. ${ }^{31,113,114}$ For Chlorella, studies using radioactive carbon dioxide have shown that the products of this dark fixation following illumination are the same as those of short-term photosynthesis. This has been used as evidence in favour of the view that a reducing product, perhaps, for example, reduced coenzyme II, survives from the photochemical reaction and is capable of complete carbon dioxide reduction in the absence of light. Such a substance might be concerned in reductions at more than one point in metabolism, for example in the formation of hexose sugar from phosphoglyceric acid or in the regeneration of the $\mathrm{C}_{2}$ acceptor. ${ }^{30}$ However, it has been pointed out that although the products of dark fixation following illumination are qualitatively the same as those 
of short-term photosynthesis there is an important quantitative difference, phosphoglyceric acid in the former case constituting a much greater proportion of the total. In Scenedesmus the radioactive carbon fixed in the dark immediately following illumination is found almost exclusively in the carboxyl groups of phosphoglyceric and pyruvic acids. Thus it appears that it is only the $\mathrm{C}_{2}$ acceptor that survives after the cessation of illumination and that the reductions concerned in fixation can only occur in the light. This view is supported by the fact that reduction in the Hill reaction likewise ceases immediately in the dark and by the results of experiments with inhibitors. ${ }^{114}$ This implies an intimate association between the reduction required in the fixation cycle and the photochemical reaction. It may be that there is only one specific reduction coupled with the photochemical reaction and that other reductions are accomplished indirectly at the expense of a proportion of the products of photosynthesis which are degraded to provide the necessary energy. ${ }^{114}$ Our knowledge of this most important step in photosynthesis is thus still in an elementary stage.

\section{INTER-RELATIONS BETWEEN THE CARBON DIOXIDE}

FIXATION CYCLE AND OTHER METABOLIC SYSTEMS

The close connexion existing between the metabolic cycles involving sugars, organic acids and proteins has been recognized for some time and the concept has arisen of a 'metabolic pool' of intermediates common to these different processes and through which they are mutually correlated. The one substance now known with a degree of certainty to be an intermediate in photosynthesis, phosphoglyceric acid, is also an intermediate in glycolysis readily transformable into substances involved in other metabolic sequences and may be regarded as a component of this 'pool'. This and other considerations (see ref. I99) make it evident that the photosynthetic fixation of carbon dioxide intermeshes with other metabolic processes at an early stage. This idea, which is contrary to the concept of photosynthesis which prevailed until recently, has received ample 
confirmation from studies with radioactive carbon as tracer.

Since the first recognizable product of photosynthesis is identical with an intermediate in glycolysis, a process which is known to consist of fully reversible steps, it is reasonable to suppose that carbohydrate formed in photosynthesis is elaborated by simple reversal of the normal glycolytic mechanism. Among the products found to be labelled in algae after periods of photosynthesis in the presence of radioactive carbon dioxide of $\mathrm{I} 5$ to 60 seconds duration are triose phosphates, hexose phosphates, hexose diphosphate and sucrose. This rapid appearance of radioactivity in the sugars shows that there is a close connexion between the photosynthetic mechanism and that responsible for the synthesis of these compounds and the fact that several of the labelled phosphate esters are identical with those involved in glycolysis suggests that the pathway of synthesis is the expected one. Furthermore, the distribution of radioactivity in the $3: 4,2: 5$ and the $1: 6$ carbons in the hexose (see formula on p. 9I) corresponds with that found in the carboxyl and in the 2- and 3 -carbons respectively of phosphoglyceric acid as would be expected in hexoses formed by condensation of $\mathrm{C}_{3}$ substances derived from this compound. ${ }^{52}$ In the synthesis of sugars from phosphoglyceric acid a reduction of the carboxyl to an aldehyde group occurs. The source of the hydrogen necessary for this reduction may be the photochemical reaction itself, but, as we have already seen, it is more probable that it is obtained by purely chemical reactions at the expense of a proportion of the products of photosynthesis.

The accumulation of radioactivity in pyruvic and malic acids during short periods of photosynthesis by Scenedesmus and Chlorella in the presence of radioactive carbon dioxide has already been noted. Radioactivity appears more slowly in succinic, fumaric and citric acids. ${ }^{29}, 52$ These acids are all concerned in the tricarboxylic acid cycle (Fig. 2) and this evidence indicates that in these algae carbon fixed in photosynthesis may enter the cycle in the expected way through pyruvic acid (Fig. IO). 
glycine seems to be closely related to the $\mathrm{C}_{2}$ acceptor. Radioactivity accumulates more slowly in other aminoacids, e.g. threonine, phenylalanine, glutamic acid and tyrosine $^{52}$ which are not so readily derived from the immediate products of photosynthesis.

That the first recognizable product of photosynthesis is a phosphorylated compound is evidence of a connexion between this process and the phosphorylation cycles involved in respiration and cell synthesis. It seems unlikely on theoretical grounds that the chemical energy produced by the photochemical reaction can first appear in the form of high energy phosphate linkages ${ }^{247}$ and the phosphorylations involved in photosynthesis are more probably brought about by secondary and purely chemical reactions.

All the substances that have so far been considered occur in the water-soluble fractions of the algae. Considerable proportions of tracer, however, appear in the benzenesoluble and water-insoluble fractions in the course of quite short periods of photosynthesis (Fig. II). This demonstrates the speed with which the products of photosynthesis are incorporated in compounds of high molecular weight. The tracer appearing in protein is probably that in the amino-acids mentioned above as being closely related to the immediate products of photosynthesis.

The radioactivity of the benzene-soluble fraction from cells which have been illuminated for only 40 seconds in the presence of radioactive carbon dioxide has been shown not to be due to contamination with water-soluble substances. ${ }^{56}$ The chlorophylls remain free from tracer but tracer carbon is distributed uniformly between the unsaponifiable materials, the saturated and unsaturated fatty acids, and the water-soluble saponification products. ${ }^{56}$ Fatty acids are probably synthesized from $\mathrm{C}_{2}$ units derived from acetic acid, or a derivative of this, most probably arising by oxidative decarboxylation of pyruvic acid. Evidence for this comes from experiments in which it has been shown that in the light, whether carbon dioxide is present or not, acetate is converted by Scenedesmus to fats as well as to tricarboxylic acid cycle intermediates. ${ }^{52}$ Algal 
ticular consideration because it is important whenever it is necessary to measure the true rate of photosynthesis. There is a certain amount of indirect evidence to show that the view that is commonly held, i.e. that respiration continues at the same rate during photosynthesis as under otherwise comparable conditions in the dark, is correct. Thus, light itself, in the absence of carbon dioxide, has no effect on the rate of respiration of Chlorella. ${ }^{47}$ More direct evidence has been obtained recently in experiments in which oxygen uptake from air containing the heavy isotope of oxygen $\left(\mathrm{O}^{18}\right)$ has been followed while photosynthesis using normal water $\left(\mathrm{H}_{2} \mathrm{O}^{16}\right)$ was taking place. ${ }^{113}$ In Chlorella it was found that respiration continued at the same rate in the dark and during photosynthesis, the labelled oxygen being taken up at the same rate regardless of whether or not oxygen was being produced by photosynthesis at the same time. However, with other algae low light intensities such as produce rates of photosynthesis only a few times as great as that of respiration were found sufficient to inhibit uptake of oxygen from the air to a considerable extent. In Anabaena sp. complete inhibition was observed. ${ }^{113}$ Such inhibition may, however, be only apparent since the oxygen produced in photosynthesis may be used preferentially for respiration and whether or not this occurs might well depend on minor differences in cell or protoplasmic structure.

The results of studies with radioactive carbon dioxide have also been interpreted as showing that respiration is inhibited by photosynthesis. In Chlorella exposed in the dark to radioactive carbon dioxide, iso-citric and glutamic acids, among substances participating in or closely connected with the tricarboxylic acid cycle, acquire high proportions of tracer but even after long periods of photosynthesis in the presence of radioactive carbon dioxide scarcely any radioactivity can be detected in these compounds. ${ }^{29}, 52$ If it is assumed that respiration in Chlorella occurs through the tricarboxylic acid cycle, this suggests that respiration is suppressed by photosynthesis in this organism. However, it must be remembered that other processes than respiration and photosynthesis occur in 
green cells and that, principally through $\alpha$-ketoglutaric acid and glutamine, which forms a reservoir of amino- groups, the tricarboxylic acid cycle is also linked with protein synthesis and breakdown (see Fig. 10). In the dark the tricarboxylic acid cycle is maintained with oxaloacetic acid derived by carboxylation from the pyruvic acid produced in glycolysis. Under these conditions its intermediates rapidly acquire radioactive carbon supplied in carbon dioxide. In the light the carbon dioxide concentration in the cell is reduced by photosynthetic fixation and this carboxylation is suppressed. The tricarboxylic acid cycle is then evidently maintained by deamination of glutamic acid to yield $\alpha$-ketoglutaric acid, the ammonia liberated, together with carbon skeletons provided by photosynthesis, being used for protein synthesis. According to this view the tricarboxylic acid cycle of respiration continues unaffected during photosynthesis, but is then maintained from different sources to those which maintain it in the dark. ${ }^{268}$ This explanation is consistent with the observation that a major portion of the insoluble products formed by algae in short periods of photosynthesis is protein and that glutamic acid only acquires appreciable amounts of tracer after longer times. ${ }^{30}$

There is thus no conclusive evidence to show that the rate of respiration is altered to any great extent when photosynthesis occurs. 


\section{THE CHEMOTROPHIC ASSIMILATION}

\section{OF CARBON}

MANy algae capable of photosynthesis are also able to assimilate substances of high potential chemical energy and certain forms, not possessing photosynthetic pigments, are absolutely dependent upon such substances. These substances evidently do not contribute any chemical groups that are 'essential' in the sense that vitamins are essential in animal nutrition; their function is that of furnishing a readily metabolized source of energy. In considering this chemotrophic mode of nutrition it is again necessary to deal with the assimilation of carbon and of energy together.

\section{CHEMOLITHOTROPHISM IN ALGAE}

When the substance from which it derives its energy is inorganic an organism is said to be chemolithotrophic or, in the older terminology, chemosynthetic. Such organisms are independent alike of light and of organic substances as energy sources and assimilate carbon dioxide by means of energy derived by oxidation of an inorganic substrate.

Examples of chemolithotrophy amongst the algae are less abundant than amongst bacteria. The simultaneous absorption of hydrogen and oxygen coupled with the reduction of carbon dioxide by hydrogen-adapted Scenedesmus has already been mentioned on p. 30. The metabolism of Scenedesmus is here similar to that of Bacillus pantotrophus or $B$. picnoticus, which utilize the energy released by the 'oxyhydrogen' reaction:

$$
\mathrm{O}_{2}+2 \mathrm{H}_{2} \longrightarrow 2 \mathrm{H}_{2} \mathrm{O}+\mathrm{r} 37 \text { k-cal. }
$$

for the reduction of carbon dioxide to bio-organic substances. ${ }^{247}, 267$ The value of the ratio $\Delta \mathrm{H}_{2} / \Delta \mathrm{O}_{2}$ for Scenedesmus carrying out the oxyhydrogen reaction in the 
presence of carbon dioxide shows that for every two molecules of hydrogen transferred to oxygen, up to one molecule is used for the reduction of carbon dioxide, ${ }^{247}$ i.e. the over-all equation is:

$$
6 \mathrm{H}_{2}+2 \mathrm{O}_{2}+\mathrm{CO}_{2} \rightarrow\left(\mathrm{CH}_{2} \mathrm{O}\right)+{ }_{5} \mathrm{H}_{2} \mathrm{O} \text {. }
$$

However, there is no evidence that algae such as Scenedesmus carry out this reaction to any considerable extent under natural conditions and Chlamydomonas moewusii, another species in which the oxyhydrogen reaction occurs, is unable to grow in the dark with this reaction as a source of energy. ${ }^{174}$ Thus, although, as with photoreduction, this inability to grow does not appear to be due to an inherent unsuitability of the products of assimilation, these examples cannot strictly be classed as chemolithotrophic according to the definition given on p. 16 .

The colourless organisms belonging to the genus Beggiatoa, to be found in sewage-contaminated water and sulphur springs, have long been known to be chemolithotrophic but have generally been classed with the bacteria. However, in their morphology and their characteristic method of movement these organisms correspond with blue-green algae of the genus Oscillatoria and there can be little doubt that they should be classified as Myxophyceae. ${ }^{243}$ Species of Beggiatoa oxidize hydrogen sulphide to elementary sulphur which is deposited within the cells:

$$
\mathrm{O}_{2}+2 \mathrm{H}_{2} \mathrm{~S} \rightarrow 2 \mathrm{H}_{2} \mathrm{O}+2 \mathrm{~S}+\mathrm{r} 26 \mathrm{k} \text {-cals. }
$$

When the hydrogen sulphide is exhausted the sulphur is further oxidized to sulphate:

$$
\mathrm{O}_{2}+\frac{2}{3} \mathrm{~S}+{ }_{3}^{2} \mathrm{H}_{2} \mathrm{O} \rightarrow{ }_{3}^{2} \mathrm{SO}_{4}{ }^{--}+{ }_{3}^{4} \mathrm{H}^{+}+98 \mathrm{k} \text {-cal. }
$$

The energy released is used for the reduction of carbon dioxide and Beggiatoa spp. are able by this means to grow in the complete absence of organic substrates. ${ }^{247}, 267$

Chemolithotrophy is obviously analogous to phototrophy, from which it differs apparently only in the source from which energy is derived. Few experimental studies of the mechanism of the process have, however, been made, and it is not known whether a fixation cycle similar to that 
in photosynthetic organisms operates or how the energyyielding reactions are linked with the reduction of carbon dioxide. ${ }^{247}$

\section{FACULTATIVE CHEMO-ORGANOTROPHY}

Many algae possessing photosynthetic pigments are able to utilize preformed organic substances and are thus enabled to grow in the dark or in the absence of carbon dioxide. These are facultative chemo-organotrophs. Other algae, having no photosynthetic pigments, are obligate chemoorganotrophs. It may be noted that, although most experimental work has been carried out on the assimilation of organic substances from solution, certain forms included in the algae can assimilate particulate food, i.e. show holozoic nutrition. ${ }^{106}$ Sometimes, as in Ochromonas, capacities for photosynthesis and holozoic nutrition are present in the same organism. ${ }^{244 a}$

There have been many investigations in which the effects of organic substances on the final amount of growth achieved by algae in culture have been recorded in qualitative or semi-quantitative terms (a historical review of early work is given in ref. 258). Such work has established that many algae possessing photosynthetic pigments are able to grow in darkness upon substrates such as sugars, alcohols, organic acids, amino-acids, peptones and proteins. These same substances also generally stimulate the growth of the algae in the light. The biological advantage of this ability to make use of organic substances to algae inhabiting soils and polluted waters and to symbiotic forms need not be emphasized. So far, investigations of the assimilation of organic compounds by algae have been confined to those forms which are easily obtainable in pure culture and very little information is available about chemoorganotrophy in the larger marine algae although it has been shown that numerous organic substances, especially fatty acids and amino-acids, can serve as substrates for the respiration of several species of Chlorophyceae, Phaeophyceae and Rhodophyceae. ${ }^{295}$ Ulva lactuca, however, does not appear capable of chemotrophic growth. ${ }^{171}$ 
Hexose sugars and acetic acid are the substrates most generally utilized by algae, but individual species differ considerably in the substances which support growth best. For example, fructose supports vigorous growth in the dark of Cystococcus (Trebouxia) sp. but allows only poor growth under the same conditions of Scenedesmus costulatus var. chlorelloides. ${ }^{250,251}$ The range of substrates available to Nostoc punctiforme is very similar to that for members of the Chlorophyceae except that this organism is able to assimilate polysaccharides such as starch and inulin whereas most green algae do not appear able to do this. ${ }^{132}$ Only glucose among a large number of substances tested suffices to support growth in the dark of Navicula pelliculosa. ${ }^{175}$ Flagellates belonging to the Euglenineae, Cryptophyceae and Volvocales grow best when provided with acetate, whereas they grow poorly or not at all upon sugars, and are hence often known as 'acetate organisms'. ${ }^{239}$, 150 Such organisms are abundant in situations in which the decomposition of organic matter liberates fatty acids and alcohols in relatively high concentrations, e.g. in water contaminated with sewage. An extreme example of this type is afforded by Chlorogonium sp., which cannot utilize any organic energy source other than acetic acid. ${ }^{\mathbf{1 8 4}}$ Other acetate organisms, however, are able to make use of a wider variety of substrates. Euglena gracilis can grow in the dark if provided with a salt of a lower fatty acid such as acetic or butyric. Other types of organic acid, tartaric, lactic, pyruvic, succinic and phosphoglyceric for example, are unsuitable. Among the lower fatty acids only those with an even number of carbon atoms and less than seven carbon atoms in all give good growth. ${ }^{185}$ It is to be noted that not all acetate organisms conform to this pattern. For example, other strains of Euglena gracilis are able to utilize succinic acid. ${ }^{150}$ The rule regarding the utilization of fatty acids is not of general application among algae since Prototheca zopfii utilizes fatty acids with even and odd numbers of carbon atoms with equal readiness. ${ }^{22}$

Determinations of the final populations attained in cultures supplied with organic substances cannot give much 
information about the manner in which these substances are utilized. More useful comparisons of the effects of different substrates are possible if growth is followed quantitatively throughout the development of the cultures. A model for investigations of this sort is that of Bristol Roach ${ }^{250,252}$ in which the effect of a number of organic substances on the growth of Scenedesmus costulatus var. chlorelloides was studied. Under the culture conditions used exponential growth lasted for several days and the relative growth constant (see Fig. I 2 and page 107) could be used for the quantitative comparison of growth in the presence of different substances. The results obtained by Bristol Roach are summarized in Table 4 . It is to be noted that in a light intensity which was not saturating for photo-

\section{TABLE 4}

RELATIVE GROWTH CONSTANTS, EXPRESSED AS PERCENTAGES

OF THE MAXIMUM, CHARACTERISTIC OF THE GROWTH OF Scenedesmus costulatus VAR. chlorelloides IN THE PRESENCE OF VARIOUS SUBSTRATES

The light intensity used was not saturating for photosynthesis ${ }^{250}$ Glucose (light). . . 100 Control (light) . . . 60 Maltose ". . . . I00 Glycerol " . . . 43 Galactose ", . . . 94 Glucose (dark) . . . 40 Sucrose ", . . . 84 Mannitol (light) . . . I3 Fructose ", . . . 73 Xylose " . . .

synthesis both hexoses and disaccharides accelerated growth but that certain substances, particularly the pentose sugar xylose, had an inhibitory effect.

It is generally accepted that the reactions in which the intermediates of metabolism are involved are reversible and that intermediates and enzymes together form a complex but flexible system into which material can be introduced at many points and through which material flows in a direction determined rather by the conditions to which the organism is exposed than by the nature of the mechanism itself. Because the respiratory system is intermeshed with other metabolic systems then it would seem that any substance which can serve as a substrate for respiration and so yield energy ought at the same time to be capable of 


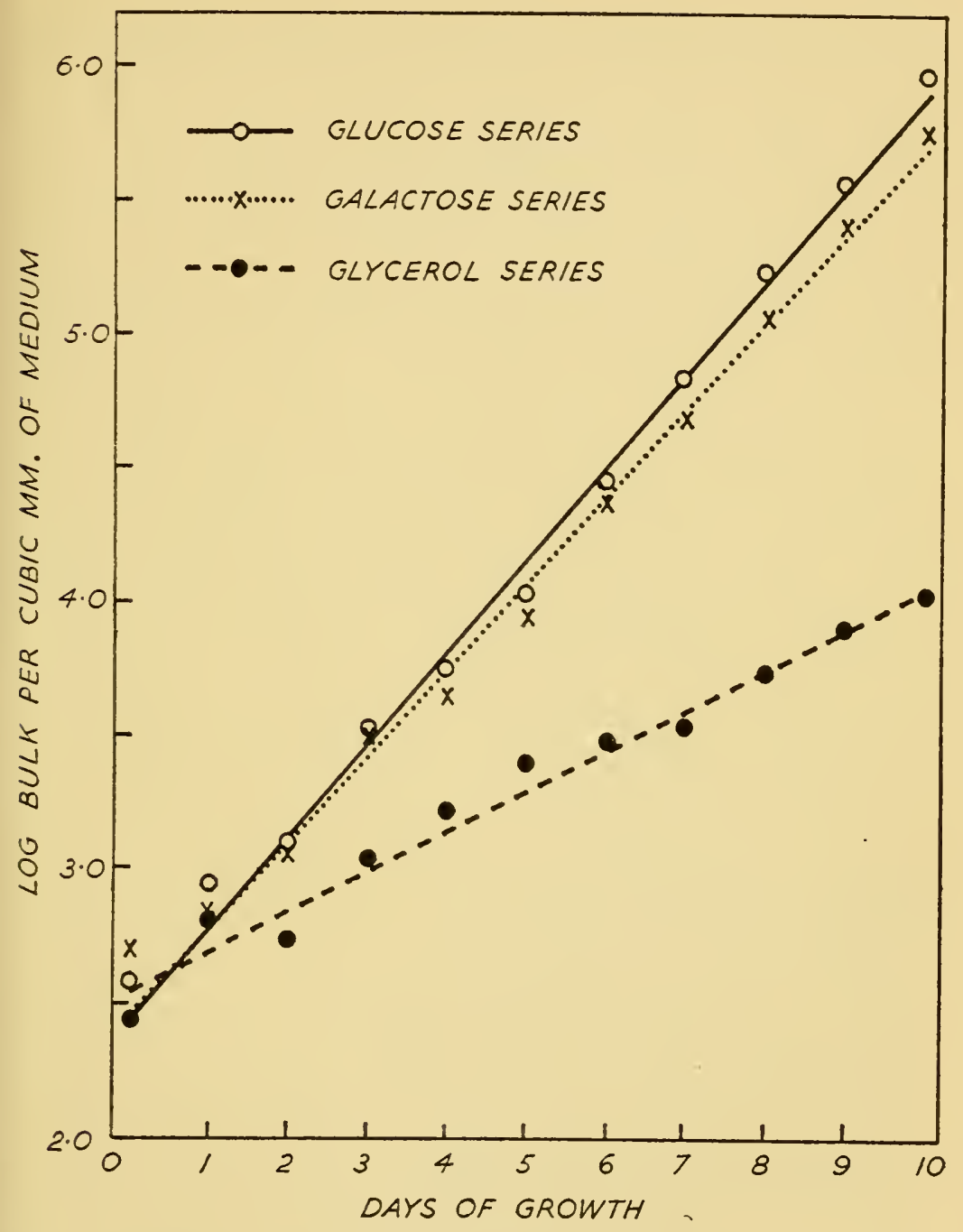

FIG. I2. Growth of Scenedesmus costulatus var. chlorelloides in the light in the presence of various organic substrates. The logarithms of the bulk of alga per unit volume of medium plotted against time lie approximately along straight lines, i.e. growth was exponential during the period of the experiment. In each case the slope of the line is numerically equal to the relative growth constant. Further explanation is given on p. 107 (data from ref. 250). 
providing the carbon skeletons necessary for the synthesis of further protoplasm and thus support chemotrophic growth. There is, in fact, good evidence that this is so in certain algae. In a study of the metabolism of Prototheca, in which about seventy compounds, including fatty acids, other organic acids, carbohydrates, alcohols, ketones and nitrogen-containing compounds were used, a close correlation was found between the growth that could be obtained with a particular substrate and the value of the same substance as a substrate for respiration. ${ }^{22}$ In a more limited investigation with Chlorella a good correspondence has likewise been found between the values as substrates for respiration and for growth of a number of organic acids. ${ }^{82,83}$ It must be noted, however, that such a correlation has not been found in all algae that have been examined. Obligate phototrophs, to be discussed on p. 59, are able to oxidize a number of substances which they are not able to utilize as substrates for chemotrophic growth, and, although Navicula pelliculosa is apparently only able to use glucose for growth in the dark, nevertheless citrate, acetate, pyruvate, succinate and lactate are stimulatory to respiration. ${ }^{175}$

If it is supposed that any substance which is an intermediate in metabolism or readily convertible into one should be utilizable as a substrate for chemotrophic growth provided that it is of sufficient potential chemical energy, then it is necessary to explain how it is that some substances which are apparently of this kind cannot be assimilated by certain algae and how it is that different species vary so considerably in their requirements for chemotrophic growth.

One possibility is that a substance which would otherwise be metabolized may not be able to enter the cell. This is obviously so in the case of bulky molecules, such as those of proteins and polysaccharides, which are unable to penetrate the plasma membrane unless they are first broken down into smaller units. Thus most algae able to assimilate glucose are unable to utilize glucose polymers such as starch or glycogen supplied externally although they may store and utilize the same materials within their cells. The production of extracellular enzymes by means of which such 
substrates may be assimilated appears to be much less common in algae than in bacteria. Certain algae, Scenedesmus costulatus var. chlorelloides ${ }^{250}$ and Nitzschia putrida ${ }^{244}$ for example, are nevertheless able to liquefy gelatine, a property which must be due to the production of an extracellular proteinase (see also ref. 258 ).

Since ions penetrate into cells less readily than undissociated molecules the reaction of the medium is of great importance in determining whether or not ionizable substances can be assimilated. Thus all but the weakest organic acids exist almost entirely as ions in alkaline solution and are then unable to penetrate into cells, whereas penetration of the same acids may occur readily from acid solutions, in which the undissociated molecules predominate. If this is overlooked then it may appear that an organic acid cannot be utilized for chemotrophic growth. For example, from the results of experiments carried out at $\mathrm{pH} 5.0$ to 5.5 it was concluded that pyruvic acid could not be assimilated by Prototheca zopfi ${ }^{22}$ but further work using media adjusted to $\mathrm{pH} 3 \cdot 0$ to 4.5 showed that this substance can be metabolized rapidly by this organism. ${ }^{14}$ Similarly, assimilation of other acids known to be intermediates in metabolism can generally be demonstrated if conditions are adjusted to give a sufficient concentration of the undissociated form in the medium. ${ }^{150}$ The situation may be further complicated if the concentration of a particular acid necessary to ensure adequate penetration reaches the toxic level. Ability to resist high concentrations of free fatty acids is evidently the important characteristic of acetate organisms. Acetic acid may play just as important a part in the metabolism of other algae as it does in that of acetate organisms, but the high concentrations of the free acid which the latter are able to tolerate are toxic to these other forms. ${ }^{150}$

Another possibility is that an enzyme, necessary for the utilization of a particular substrate and regarded as of general occurrence, may nevertheless be absent from a particular species. The clearest example of this is the inability of certain acetate organisms to utilize glucose and other sugars, which results from their lack of hexokinase, the 
enzyme responsible for the phosphorylation of glucose and fructose. 186, 1, 150, 25 Polytomella caeca, for instance, stores a starch-like substance which it is able to synthesize from glucose-I-phosphate but not from glucose, maltose or sucrose. ${ }^{186,25}$ Whereas the hexose phosphates are intermediates in metabolism, the sugars themselves are not and the absence of the enzymes necessary for their phosphorylation does not impair metabolic activity although it prevents direct utilization of these substrates.

It is unlikely that all the vagaries of algae in the assimilation of organic substrates can be accounted for along these lines. The metabolic system of an organism is not infinitely adaptable and the adjustment of the proportions of the different enzymes necessary to cope with a particular substrate may in a given species not be compatible with the general economy of the cell. The limits within which adjustment is possible probably vary considerably from species to species and may be expected to be narrower the greater the morphological complexity of the organism. Adaptation in bacteria has received considerable attention and it has been shown that, within limits, an organism may be trained to attain maximum growth rate on a substrate which the original material was unable to utilize. ${ }^{\mathbf{1 4 5}} \mathrm{A}$ few cases of similar adaptation are known among algae. For example, Scenedesmus costulatus var. chlorelloides exhibits a lag period before beginning exponential growth with maltose as a substrate whereas no such lag is shown in media containing glucose, sucrose or glycerol. This lag period may be interpreted as the period needed for the development of maltase necessary for the conversion of this sugar to glucose. ${ }^{250} \mathrm{~A}$ further example is afforded by a strain of Chlorella vulgaris which has been found to grow slowly at first in the presence of cellobiose in the light but, after several transfers in the light in a medium containing this substance, to grow almost as rapidly as it does under otherwise comparable conditions when supplied with glucose. ${ }^{207}$ Adaptation evidently is dependent upon suitable environmental conditions. Thus Euglena gracilis cannot utilize glucose for growth under the usual conditions of culture, but in an atmosphere containing 
5 per cent of carbon dioxide and with an ammonium salt as the nitrogen source it attains excellent growth upon this substrate after a lag phase. ${ }^{200}$ Certain substances appear sometimes to be utilized more readily in the dark than in the light. The strain of Chlorella vulgaris mentioned above, for example, grows better in the dark than in the light when provided with lactose, cellobiose or methyl- $\beta$-D-glucoside, as substrate. These three compounds are all $\beta$-glucosides and it appears that adaptive enzymes are formed for their utilization and that the rate of adaptation is slower in the light when the photosynthetic products are available as an alternative source of carbon. ${ }^{207}$

\section{THE RELATIONSHIP BETWEEN PHOTOSYNTHESIS AND}

\section{CHEMOTROPHIC ASSIMILATION}

In an organism which is capable of both, phototrophic and chemotrophic assimilations proceed at rates which are mutually dependent. For Scenedesmus costulatus var. chlorelloides it has been found that at high light intensities a maximum rate of growth is attained which cannot be increased by the addition of glucose. ${ }^{252}$ With reduced light intensity the alga absorbs glucose to supply the deficiency due to retarded photosynthesis but only sufficiently to bring the growth rate up to the maximum. At still lower light intensities the growth rate falls, approaching the value attained in complete darkness on glucose (see Table 4). The same relationships have been demonstrated in Chlorella pyrenoidosa. ${ }^{200}$ There are many reports of the growth of algae in light being accelerated by the addition of organic substrates to the medium, but in none of these instances is there satisfactory evidence that the provision of carbon dioxide was sufficient to maintain maximum rates of photosynthesis. No case has yet been found in which an organic carbon source accelerated growth under conditions of lightand carbon dioxide-saturation of photosynthesis. ${ }^{200}$ It thus appears that the photosynthetic mechanism is generally capable of saturating with its products the synthetic systems involved in growth so that under optimum conditions for 
photosynthesis some other factor than carbon assimilation limits the rate of growth.

It is possible that light may have effects on growth other than those arising from photosynthesis. If Chlorella vulgaris is grown in the presence of glucose it is found that a weak light intensity produces a considerable increase in the rate of growth in the exponential phase as compared with that in darkness, but that further increase in light intensity produces comparatively little effect even though carbon dioxide is not in short supply. ${ }^{222}$ These effects may be indirectly due to photosynthesis since in cultures of the type used to obtain these results oxygen is limiting and the amount of growth that can take place in older cultures is dependent on the oxygen evolved in photosynthesis. In the exponential phase the medium initially contains oxygen and it may be that the small amounts produced by photosynthesis at the lowest light intensities are sufficient to supplement this to a level at which the maximum growth rate can be maintained. ${ }^{222}$ However, the effect of light on the growth rate in the exponential phase may equally well be explained in other ways. For example, a substance which in small amounts stimulates growth may be produced by a photochemical reaction other than photosynthesis. Evidence for such an effect may be obtained from studies of the effect of light upon the growth of cultures in the absence of carbon dioxide. For Chlamydomonas pseudococcum and Hormidium nitens it has been found that cultures aerated with carbon dioxide-free air grow better in the light than in complete darkness. ${ }^{151}$ However, really vigorous aeration is needed to remove from a culture the carbon dioxide produced by respiration and it seems probable that in these experiments a small amount of photosynthesis occurred and that this might account for the better growth of the light cultures. ${ }^{200}$ Experiments with Chlorella pyrenoidosa grown in cultures vigorously aerated with carbon dioxidefree air have failed to show any stimulatory effect of light on the rate of growth with glucose or acetate as substrate. On the contrary, light retards the growth of Chlorella on acetate in the absence of carbon dioxide. ${ }^{200}$ Thus there 
THE CHEMOTROPHIC ASSIMILATION OF CARBON 59 appears to be no conclusive evidence for a stimulatory effect of light upon the growth of algae apart from that due to photosynthesis. However, photochemical reactions other than those concerned in photosynthesis are known to occur in plants, e.g. the formation of chlorophyll in higher plants involves such a process, and it is possible that when a greater range of forms has been examined examples of these will be found among the algae.

\section{OBLIGATE PHOTOTROPHY}

From the account that has been given above it would be expected that all photosynthetic algae would also be capable of chemo-organotrophic nutrition. However, although many algae are able to grow in the dark if provided with a suitable organic substrate, there are some which have not so far been grown under these conditions and which appear to be obligate phototrophs. A strain of Chlorella vulgaris, ${ }^{86}$ Chlamydomonas spp., ${ }^{174}$ Prorocentrum micans, Peridinium sp., ${ }^{21}$ Anabaena cylindrica, ${ }^{93}$ and perhaps the majority of diatoms, ${ }^{244}, 175$ for example, are apparently of this type. An analogous situation is met with in the chemolithotrophic bacterium Thiobacillus thio-oxidans in which sulphur and carbon dioxide are required for growth and can be replaced by no other energy or carbon source respectively. ${ }^{267}$ The occurrence of obligate phototrophism is evidently sporadic as far as systematic position is concerned.

Most information about obligate phototrophism is available for Chlamydomonas moewusii. ${ }^{174}$ Some sixty-four organic materials, including acids, alcohols, sugars, phosphate compounds (including phosphoglyceric acid), nitrogen compounds and preparations rich in growth factors, have been tested and found ineffective as substrates for the chemo-organotrophic growth of this flagellatè. Cell extracts and hydrolysates of the organism itself and filtrates from light-grown cultures likewise do not support growth in darkness. A most curious feature is that whereas control cultures without substrate grow on being returned to the light, cultures with substrates are found to be dead although the substrate concentrations used are not toxic in light 
cultures. ${ }^{150}$ No toxic substance inhibitory to the organism when growing in the light has been demonstrated as being produced in the dark. ${ }^{174}$ In the absence of carbon dioxide no growth has been observed on any substrates either in light or darkness; this seems to show that the obligate phototrophy does not in this case depend on a photochemical reaction other than that of photosynthesis. ${ }^{174} \mathrm{It}$ has already been noted (p. 49) that a chemolithotrophic mechanism cannot replace photosynthesis in this species.

It does not seem that substances that would otherwise be suitable substrates for growth are unable to penetrate into the cells of $C$. moezunsii since acetate, pyruvate and succinate are readily oxidized by the organism in the dark. ${ }^{174}$ Thus there is here no correlation between the value of a substance as a substrate for respiration and its ability to support growth such as has been noted for Prototheca and Chlorella (p. 54). It appears, then, that energy released by oxidation of organic substrates is not available for at least one synthetic mechanism essential for the growth of $C$. moewusii. The behaviour of an ultra-violet induced mutant of $C$. moewusii, in which the photosynthetic apparatus is impaired, ${ }^{177}$ is interesting in this connexion. This mutant is incapable of growth in purely inorganic media unless a high concentration of carbon dioxide is maintained, e.g. by aeration with 5 per cent carbon dioxide in air, but it will grow in the light at low carbon dioxide tensions in media supplemented with substances such as citrate, fumarate, succinate, pyruvate, malate, glucose or glycerol, at rates approaching those attained by the wild type. The mutant is able to carry out the Hill reaction ${ }^{177}$ and it may be that the part of the photosynthetic mechanism which is impaired is that responsible for maintaining the concentration of the particular form of carbon dioxide which enters into the fixation cycle, e.g. the enzyme concerned might be carbonic anhydrase. If this is so, then the supplementary carbon sources utilized by this mutant may act merely by being oxidized to give carbon dioxide in a form in which it can be fixed photosynthetically without the intervention of this system. Another possibility is that oxidation of exogenous 
THE CHEMOTROPHIC ASSIMILATION OF CARBON 6I

substrates can be used as a supplementary source of energy for growth, the capacity for photosynthesis of the mutant being then sufficient for an essential step that in obligate phototrophs is specifically associated with the photochemical reaction but which in facultative chemo-autotrophs can be by-passed by dark reactions.

It may be noted that Euglena gracilis, although a facultative chemo-organotroph, responds sluggishly to added organic substrates in the dark after having been cultured phototrophically. ${ }^{65}$ Possibly this condition represents a stage in the development of obligate phototrophy.

\section{OBLIGATE CHEMO-ORGANOTROPHY}

The strains of Chlorella generally used in experimental work are facultative chemo-organotrophs which during growth in darkness produce pigments that are qualitatively the same as those produced in the light and which remain capable of beginning photosynthesis without any markedly prolonged induction period on exposure to light. ${ }^{144,}{ }^{196}$ In these cases the photosynthetic mechanism is stable. Chlorella variegata, however, if cultured in the presence of organic substrates in the dark becomes yellow and only slowly recovers its capacity for phototrophic growth when returned to the light. Some cells may become white and in them the capacity for producing chlorophyll is irrevocably lost. ${ }^{27}$ Similarly, Euglena gracilis, if cultured in the dark loses chlorophyll and on return to the light slowly becomes photosynthetic once more. ${ }^{200}$ With certain strains of this species completely colourless individuals arise during culture in the dark and these do not regain their green colour in the light and are thus permanently chemoorganotrophic. ${ }^{242}$

The loss of photosynthetic pigments which may occur when algae are cultured in the dark is reversible so long as leucoplasts, i.e. the decolorized chromatophores, are retained by the cells. Irreversible loss of pigments, or apochlorosis, takes place when a cell containing no leucoplasts is produced. Production of such cells does not depend on the fortuitous exclusion of leucoplasts from one of the 
products in cell division but is due to disorganization of the leucoplast stroma while the cell remains capable of growth and division. ${ }^{242}$ This disorganization has the appearance of resulting from a gene-mutation. ${ }^{27,} 242$

Spontaneous apochlorosis has been noted only rarely, but chlorophyll-less forms have been induced in Chlorella vulgaris by irradiation with $\mathrm{X}$-rays ${ }^{118}$ and in Euglena gracilis by treatment with streptomycin or by exposure to high temperatures. ${ }^{246}, 150,245$ Streptomycin appears to be unique among antibiotic substances in exerting this effect. ${ }^{150}$ Streptomycin-induced apochlorosis, like that which occurs spontaneously, results from disintegration of the chromatophores.

There exists in nature a large number of colourless and therefore obligatorily chemotrophic forms which can readily be recognized as related to pigmented algae because of similarities in mophology and in storage products. ${ }^{240}$ These forms have apparently been derived from pigmented species by processes similar to those investigated in laboratory experiments. Since streptomycin-producing actinomycetes are common in soils it is possible that this substance may play an important part in inducing apochlorosis in nature. The pigmented species concerned are readily able to utilize organic substrates so that colourless forms derived from them would evidently stand a good chance of survival under natural conditions. Only a few of the colourless algae that have been described can be mentioned here. Species of the genus Astasia are similar, except for the absence of pigments, to species of Euglena. A. longa in fact, is identical with a colourless strain of $E$. gracilis obtained in culture experiments and has been renamed $E$. gracilis forma hyalina. ${ }^{242}$ Polytoma spp. resemble Chlamydomonas spp. except in the matter of pigmentation and similarly Polytomella corresponds to Tetrachloris. ${ }^{240}$ Prototheca is evidently a colourless Chlorella. ${ }^{27}, 106$ Colourless species have been assigned to nearly every class of algae with unicellular representatives (see refs. 106, 240, 243, 244). Besides those obviously related to pigmented species there is a considerable number of forms which may have had an algal origin 
THE CHEMOTROPHIC ASSIMILATION OF CARBON 63

but in which scarcely any indication of affinity is to be found. ${ }^{240}$ Among the morphologically more complex algae certain parasitic species of Rhodophyceae, e.g. Harveyella, show complete absence of photosynthetic pigments. ${ }^{107}$

There is no evidence of any significant alteration in growth or dark metabolism occurring in apochlorosis. The requirements for chemotrophic nutrition and the storage products are the same in corresponding colourless and pigmented forms. ${ }^{240,} 242$

\section{OXIDATIVE ASSIMILATION}

The organic substrate used in chemo-organotrophic growth must serve as a source both of energy and of carbon and therefore is partly oxidized in respiration and partly built up into cell material. The mechanism of such oxidative assimilation of organic substances must now be considered.

Oxidative assimilation was first studied in Prototheca..$^{22,23}$ Under aerobic conditions the supply of glucose to this organism stimulates respiration, but the amount of oxygen consumed for a given amount of glucose is sufficient to account for complete oxidation to carbon dioxide and water of only part of the glucose, the rest, about 30 per cent, apparently being converted to cell material. Other substances, including glycerol, ethyl alcohol, acetic acid and propionic acid, can be partly oxidized and partly assimilated by Prototheca in a similar manner. Under anaerobic conditions glucose cannot be used for building cell material but is fermented, yielding lactic acid in almost exactly the amount required by the equation:

$$
\mathrm{C}_{6} \mathrm{H}_{12} \mathrm{O}_{6} \rightarrow 2 \mathrm{CH}_{3} \text {. } \mathrm{CH}(\mathrm{OH}) \text {. } \mathrm{COOH} \text {. }
$$

Oxidative assimilation has also been investigated in Chlorella pyrenoidosa, ${ }^{198}$ C. vulgaris ${ }^{274}$ and Scenedesmus quadricauda. 281

In investigations with Prototheca the amounts of substrate decomposed and oxygen consumed have been found to be in agreement with the hypothesis that a carbohydrate is the principal product of oxidative assimilation, being formed according to a simple over-all equation such as:

$$
\mathrm{CH}_{3} \cdot \mathrm{COOH}+\mathrm{O}_{2} \rightarrow\left(\mathrm{CH}_{2} \mathrm{O}\right)+\mathrm{CO}_{2}+\mathrm{H}_{2} \mathrm{O}
$$


in the case of acetic acid. ${ }^{23}$ Similarly, results have been obtained in experiments on the oxidative assimilation of glucose by Chlorella pyrenoidosa in accord with the following equation: ${ }^{198}$

$$
\mathrm{C}_{6} \mathrm{H}_{12} \mathrm{O}_{6}+\mathrm{O}_{2} \rightarrow{ }_{5}\left(\mathrm{CH}_{2} \mathrm{O}\right)+\mathrm{CO}_{2}+\mathrm{H}_{2} \mathrm{O} \text {. }
$$

These equations, implying a definite relationship between oxidation and assimilation, suggest that the nature of the intermediate products of the decomposition of the substrate may be more important in determining the proportion which is oxidized than the energy relationships involved. ${ }^{14}$

However, the proportion of substrate which is oxidized is not as fixed as these results suggest. Not only does the proportion vary from species to species but it may alter in the same organism according to its physiological condition ${ }^{64}$ or the reaction of the medium. ${ }^{281}$ If it is supposed that a substrate for oxidative assimilation is first converted into fragments which can enter the metabolic pool then in most cases these fragments will be of one sort and the proportions oxidized and used for synthesis will depend on energy requirements and the conditions to which the organism is exposed. For example, it is to be expected that in the oxidative assimilation of glucose the normal glycolytic pathway will be followed and that this substance after phosphorylation to yield hexose phosphates may then be used in polysaccharide synthesis or be further degraded and enter the metabolic pool as phosphoglycerate. The various pathways by which phosphoglycerate may be metabolized are indicated in Fig. 10. There is no evidence that glucose is assimilated by algae in any other way; the possibility suggested by equation I4, for example, that in oxidative assimilation it is converted to pentose by oxidation and decarboxylation receives no support from analytical data. ${ }^{281}$

A further example that may usefully be discussed is that of acetate, a substrate which, as we have already seen, is the most generally utilized by algae. There are several possible ways in which this substance might enter into metabolism. Acetate, by reductive carboxylation, might yield pyruvic acid. However, the oxidative decarboxylation of 
THE CHEMOTROPHIC ASSIMILATION OF CARBON 65

pyruvic acid appears to be an irreversible process and it has been found that, whereas the oxidation of glucose, glycerol and pyruvate, by thiamine-deficient Prototheca is markedly stimulated by the addition of thiamine (which is necessary for the carboxylation and decarboxylation of pyruvic acid, see p. 9), that of acetate is stimulated to a much smaller extent. This shows that pyruvate is not an intermediate in the oxidation of acetate as it is in the cases of glucose and glycerol. ${ }^{14}$ Another possible pathway, involving glycollic acid, $\mathrm{CH}_{2} \mathrm{OH}$. $\mathrm{COOH}$, as an intermediate, seems unlikely because glycollate has a catalytic effect on the respiration of Prototheca whereas acetate does not. ${ }^{14}$ In yeast, acetate has been found to undergo condensation with oxaloacetate to form citric acid:

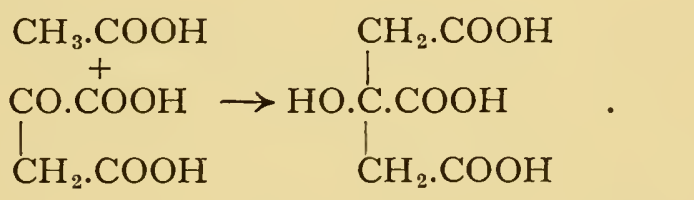

Acetic acid seems not to take part directly in this reaction but must first be converted to 'activated acetate', probably an acetylcoenzyme $A .{ }^{19}$ It has not been established that acetate is oxidized by yeast through the tricarboxylic acid cycle but that this may take place in Scenedesmus is suggested by the appearance of radioactivity in citric acid and other tricarboxylic acid cycle intermediates following supply of acetate labelled with radioactive carbon. ${ }^{52}$ This mechanism can, however, only account for the oxidation of acetate since the operation of the cycle will result in the liberation as carbon dioxide of the two carbon atoms of acetate and the regeneration of the original oxaloacetate (Fig. 2). Assimilation to more complex substances must follow other pathways. In certain species and under certain conditions at least, e.g. in Scenedesmus in the light, acetate is most readily assimilated to fats, ${ }^{52}$ a synthesis that most probably takes place directly from 'activated acetate' by successive condensations and reductions. ${ }^{19,}{ }^{41}$ Carbohydrate could be derived from acetate if this were first transformed 
to pyruvate. The condensation of two molecules of acetic acid to give succinic acid:

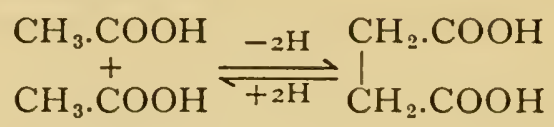

has been demonstrated in certain micro-organisms ${ }^{267,19}$ and if a similar reaction occurs in algae pyruvic acid could be formed via oxaloacetate produced by the operation of the tricarboxylic acid cycle (Fig. IO). It is to be noted that the effects observed in thiamine-deficient Prototheca (see above) do not exclude the possibility that assimilation of acetate occurs in this way.

Some indication of the manner in which oxidation and assimilation are related is given by the effects upon them of cyanide. ${ }^{274}$ In Chlorella vulgaris low concentrations of cyanide have been found to stimulate endogenous respiration. In the absence of cyanide one-eighth to one-ninth of added glucose may be completely oxidized, most of the remainder being assimilated to di- or polysaccharide. Low concentrations of cyanide reduce the rate of oxidation of added glucose to a level which does not, however, fall below that of endogenous respiration under the same conditions, but at the same time produce an increase in the amount of oxygen taken up for a given amount of this substance. That is, in the presence of low cyanide concentrations more of the added glucose is oxidized and less is synthesized to more complex substances. The facts seem best explained on the assumption that glucose may be oxidized by either of two mechanisms, one of which is unaffected, the other blocked, by cyanide. The assimilation of glucose appears to be coupled with the cyanide-sensitive system in such a way that for every molecule which is oxidized by this path a certain fixed number of molecules are synthesized to more complex substances. ${ }^{274}$ This cyanidesensitive system is presumably one involving a cytochrome, evidence for the presence of which in Chlorella has already been mentioned (p. 10), with a phosphorylation cycle as a means of energy transfer between the reactions of oxidation and synthesis. 
THE CHEMOTROPHIC ASSIMILATION OF CARBON 67

Under the conditions of carbohydrate deficiency usually used in experimental studies of oxidative assimilation the products formed by Chlorella and Scenedesmus are chiefly polysaccharides, the exact nature of which has not been established. ${ }^{274,} 281$ These products may subsequently be broken down to provide for the synthesis of other cell materials. ${ }^{22}$ Under other circumstances oxidative assimilation presumably results directly in the production of lipides or proteins. 


\section{AUTOTROPHIC ASSIMILATION WITH SPECIAL REFERENCE TO NITROGEN METABOLISM}

Given a suitable source of energy and of carbon, autotrophic organisms are able to synthesize all their cell constituents from inorganic materials. Something has already been said of the synthesis of carbon compounds and this chapter must be chiefly concerned with the autotrophic assimilation of nitrogen. This emphasis is justified since the most characteristic components of living matter are nitrogenous and since departure from the autotrophic mode of life is most frequently manifest as an inability to synthesize some essential nitrogenous metabolite.

Nitrogen may be assimilated by autotrophic algae as the element, as nitrate or as ammonia.

\section{NITROGEN FIXATION BY ALGAE}

The ability to assimilate, or ' $\mathrm{fix}$ ', the elementary nitrogen of the atmosphere is restricted to a comparatively few organisms and has as yet been demonstrated with certainty only in certain bacteria, i.e. Azotobacter spp., Clostridium spp., Rhizobium spp. in symbiotic association with leguminous plants, and some photosynthetic bacteria, and in certain Myxophyceae. ${ }^{285}, 301 a$

That some algae are able to fix nitrogen was first reported by Frank in $1889,{ }^{101}$ four years before the first isolation of a nitrogen-fixing bacterium was announced by Winogradsky. Frank's cultures were, however, impure and must have contained numerous organisms other than algae to which the observed nitrogen fixation might be attributed. The isolation of blue-green algae in pure culture is not easy and it was not until 1928 that satisfactory evidence of nitrogen 
fixation by these organisms was published. ${ }^{70}$ In the many subsequent studies in which a capacity for nitrogen fixation has been demonstrated in Myxophyceae the Kjeldahl method has generally been used for the determination of combined nitrogen but nitrogen fixation has also been established for Nostoc muscorum ${ }^{49}$ and Calothrix parietina ${ }^{300}$ using the heavy isotope of nitrogen as a tracer.

There is now satisfactory evidence of a capacity for nitrogen fixation in some twenty-one species distributed among the following genera of Myxophyceae: Nostoc, Anabaena, Cylindrospermum, Aulosira (for references see 89), Calothrix, ${ }^{297},{ }^{300}$ Tolypothrix, Anabaeniopsis, ${ }^{297}$ Mastigocladus.${ }^{91}$ Further research will no doubt reveal many more nitrogenfixing species in this class but it is certain that not all bluegreen algae possess the property. Evidence that species belonging to the Chroococcales and to the Oscillatoriaceae are nitrogen-fixing is unsatisfactory ${ }^{91}$ and certain forms, e.g. Phormidium spp. ${ }^{66,300}$ Gloeocapsa spp., Microcystis (Diplocystis) aeruginosa and Aphanizomenon flos-aquae, 300 have been found to be incapable of growth in media free from combined nitrogen.

Work with pure cultures of members of the Chlorophyceae has generally shown that these algae cannot fix nitrogen. A report that a number of species of unicellular green algae, including a Chlorella, possess the property ${ }^{289}$ has been shown to be based on results obtained with an unsuitable analytical technique. ${ }^{44}$ Nevertheless, the suggestion that Chlorella may, under certain circumstances, fix elementary nitrogen has been revived as a result of an observation that old cultures of this alga with a high lipide content contained substantially more combined nitrogen as determined by the absolute method of Dumas than that originally supplied.264 So far this finding has not been substantiated. ${ }^{200}$

While there is no evidence to suggest that algae belonging to classes other than the Myxophyceae and Chlorophyceae include species capable of nitrogen fixation it is well to remember that very few forms have as yet been investigated critically from this point of view. 
It is evident that in its physiology nitrogen fixation by blue-green algae resembles that in other organisms. Thus nitrogen fixation can only occur concurrently with growth and is suppressed in the presence of readily available combined nitrogen such as an ammonium salt. ${ }^{87}$ Nitrate inhibits nitrogen fixation in Anabaena cylindrica only if the alga is adapted to utilize this form of combined nitrogen. ${ }^{93}$ Traces of molybdenum are essential for the achievement of maximum rates of fixation in blue-green algae as in other nitrogen-fixing organisms. ${ }^{42}, 90,308$ In Nostoc muscorum assimilation of free nitrogen does not occur in media of $\mathrm{pH}$ below approximately $5 \cdot 7 \cdot{ }^{11}$ Nitrogen fixation in blue-green algae may occur either during phototrophic growth or in the dark if a suitable carbon source is provided.11, 66 In Nostoc muscorum growing in the dark, Io to $12 \mathrm{mg}$. of nitrogen have been found to be fixed per gm. of glucose utilized. ${ }^{11}$

The properties of the nitrogen-fixing enzyme system in Nostoc muscorum appear to be very similar to those of Azotobacter and of the Rhizobium-legume system. ${ }^{50}$ The half maximum rate of fixation occurs at a partial pressure of nitrogen of about 0.02 atmosphere, a value of the same order as those for Azotobacter ( 0.02 atmosphere) and Trifolium pratense $(0.05$ atmosphere). Like those of other nitrogen-fixing organisms the enzyme system of Nostoc is specifically inhibited by hydrogen and by carbon monoxide. In bacteria there appears to be some correlation between the presence of hydrogenase and the capacity to fix nitrogen ${ }^{178}$ but this correlation does not hold in the algae, for Nostoc muscorum cannot be adapted to hydrogen (Table 3) and those algae possessing a hydrogenase system seem to be incapable of nitrogen fixation. ${ }^{200}$

The mechanism by which nitrogen fixation is accomplished in living organisms is still unknown, but it is generally agreed that ammonia is the first recognizable product although in some organisms in certain circumstances this may be replaced by hydroxylamine. ${ }^{285}$ Nitrogen fixed in experiments of short duration accumulates principally in glutamic and aspartic acids in Nostoc muscorum, as it does in other nitrogen-fixing organisms. ${ }^{301 a}$ These two amino-acids 
are abundant in nitrogen-fixing blue-green algae $95,297,300,98$ and it appears that through them the nitrogen fixed enters into general metabolism.

Nitrogen-fixing blue-green algae appear to be of great importance in contributing to the fertility of certain habitats, tropical soils in particular and possibly some types of freshwater. ${ }^{66}, 89,300$ A capacity for nitrogen fixation may be important to certain species of Myxophyceae in enabling them to colonize unpromising substrata. Blue-green algae are often found in symbiotic association with other types of organisms and, in certain of these at least, nitrogen fixation may contribute to the success of the partnership. ${ }^{89}, 142$

\section{THE ASSIMILATION OF NITRATE}

The majority of algae are able to utilize nitrogen supplied in the form of nitrate for the synthesis of cell material. Exceptions are to be found among colourless flagellates, in the chemotrophic growth of certain pigmented flagellates, ${ }^{150}$ and in Euglena gracilis var. bacillaris, which will not grow phototrophically with nitrate as the sole nitrogen source. ${ }^{200}$

The nitrogen of nitrate must undergo reduction before it can be incorporated into amino-acids, nitrogenous bases and their derivatives. This process of reduction was first investigated by Warburg and Negelein using Chlorella pyrenoidosa. ${ }^{292}$ In order to obtain a reduction of nitrate at a rate comparable to those of photosynthesis and respiration, these workers used an acid medium, of $\mathrm{pH}$ about $2 \cdot 0$, from which undissociated nitric acid might be expected to penetrate rapidly into the cells. Chlorella in this medium in the dark was found to evolve carbon dioxide extra to that produced by respiration under comparable conditions in the absence of nitrate and at the same time to liberate ammonia into the medium. The ratio of the amounts of extra carbon dioxide and ammonia was not constant, evidently because some of the ammonia was utilized by the cells. When the cells used were not nitrogen deficient this ratio was found to approach $2: \mathrm{I}$, in agreement with the equation:

$$
\mathrm{HNO}_{3}+2\left(\mathrm{CH}_{2} \mathrm{O}\right) \rightarrow \mathrm{NH}_{3}+2 \mathrm{CO}_{2}+\mathrm{H}_{2} \mathrm{O}
$$


where $\left(\mathrm{CH}_{2} \mathrm{O}\right)$ represents a carbohydrate or similar substrate.

Chlorella placed in the acid nitrate solution in the light was found by Warburg and Negelein to evolve, not extra carbon dioxide, but oxygen extra to that produced by photosynthesis in the absence of nitrate but under otherwise comparable conditions. This was explained by supposing that the carbon dioxide evolved in reaction 17 is in illuminated cells used for the production of more $\left(\mathrm{CH}_{2} \mathrm{O}\right)$ :

$$
2 \mathrm{CO}_{2}+2 \mathrm{H}_{2} \mathrm{O} \rightarrow 2\left(\mathrm{CH}_{2} \mathrm{O}\right)+2 \mathrm{O}_{2}
$$

However, the discrepancy was noticed that the amount of extra oxygen produced in the light was greater than the amount of extra carbon dioxide evolved in the dark.

The possibility must be borne in mind that, under the acid conditions used by Warburg and Negelein, the metabolism of Chlorella may have been abnormal. However, subsequent work with less extreme treatment of the alga has confirmed their principal results. It appears that in media of low pH the penetration of nitrate into the cells is not increased but that the liberation of ammonia is favoured. ${ }^{63}$ In media of $\mathrm{pH}_{4} \cdot 5$ no ammonia is produced by Chlorella supplied with nitrate but the gas exchanges taking place are similar to those observed by the earlier workers. For example, the photosynthetic quotient of Chlorella in the presence of nitrate has been found to be 1.47 as compared with the value of $\mathrm{r} \cdot 06$ obtained with an ammonium salt as the nitrogen source but under otherwise similar conditions. ${ }^{63}$ The situation is complicated, however, since the extent of nitrate reduction and consequently the gas exchanges observed are dependent on the previous history of the cells employed in the experiment and on the conditions to which they are exposed (Table 5). At high light intensities there is proportionately less nitrate assimilation and the value of the photosynthetic quotient approaches unity indicating that the chief product of photosynthesis is carbohydrate. The same effect is achieved if the cells are previously depleted of carbohydrate by starvation. If, on the other hand, the concentration of carbohydrates in the cells 
is already high, as after a period in bright light, then there is no restriction on the use of the products of photosynthesis for the synthesis of nitrogenous substances and the rate of nitrate assimilation is high with a corresponding value of the photosynthetic quotient. Since no nitrate reduction occurs when ammonia is available it is evident that nitrate is only reduced in a manner intimately related to the requirements of subsequent nitrogenous synthesis. ${ }^{63}$

\section{TABLE 5}

PHOTOSYNTHETIC QUOTIENTS $\left(Q_{P}=\Delta \mathrm{O}_{2} /-\Delta \mathrm{CO}_{2}\right)$ of Chlorella pyrenoidosa IN THE PRESENCE OF NITRATE ${ }^{199}$

\begin{tabular}{l|c|c}
\hline \multirow{2}{*}{ Previous history of cells } & \multicolumn{2}{|c}{ Observed $Q_{P}$} \\
\cline { 2 - 3 } & Low light & High light \\
\hline Grown at low light intensity & $\mathrm{I} \cdot 47$ & $\mathrm{I} \cdot \mathrm{I} 4$ \\
Exposed for 4 hr. to high light intensity & $2 \cdot 50$ & $\mathrm{I} \cdot$ \\
Starved for 3 days in darkness & $\mathrm{I} \cdot \mathrm{I} O$ & $\mathrm{I} \cdot 04$ \\
\hline
\end{tabular}

Warburg and Negelein ${ }^{292}$ considered nitrate assimilation to be a process not directly connected with photosynthesis and explained the increase in nitrate reduction on illumination as due to the effects of light on cell permeability. Nevertheless it is possible that nitrate reduction is closely linked with the photosynthetic mechanism. Thus, nitrate might be reduced by a substance which can be produced by respiratory processes but which is closely related to a primary product of photosynthesis and which is available in greater amounts when photosynthesis is taking place. ${ }^{199}$ It is also possible that in the light a sensitized photochemical reduction of nitrate by water occurs, i.e: photosynthesis with nitrate substituted for carbon dioxide: ${ }^{247}$

$$
\mathrm{HNO}_{3}+\mathrm{H}_{2} \mathrm{O} \rightarrow \mathrm{NH}_{3}+2 \mathrm{O}_{2}
$$

Evidence that this takes place is provided by the observation that Chlorella can evolve oxygen in the light in the absence of carbon dioxide if nitrate is present. ${ }^{164}$ Nitrate cannot, however, act as the hydrogen acceptor in the Hill 
reaction. Since nitrate reduction can also occur in the dark in Chlorella it is necessary, if it is accepted that photochemical reduction occurs, to suppose that there are two distinct mechanisms for the reduction of nitrate. Confirmation that some organisms are able to utilize nitrate under phototrophic conditions but not when growing chemotrophically would give strong support to this idea.

Reduction of nitrate to ammonia takes place in plants in several stages. Under certain conditions nitrite is liberated instead of ammonia when Chlorella ${ }^{292}$ or Ankistrodesmus ${ }^{158}$ reduce nitrate in an acid medium. Both nitrite and hydroxylamine appear to be intermediates in the reduction, the sequence being:

$$
\mathrm{NO}_{3}{ }^{-} \rightarrow \mathrm{NO}_{2}{ }^{-} \rightarrow \mathrm{NH}_{3}(\mathrm{OH})^{+} \rightarrow \mathrm{NH}_{4}{ }^{+}
$$

It may be noted here that nitrite can serve as a source of nitrogen for some algae, although it is toxic except in low concentrations, ${ }^{238}, 180$ and that, in low concentrations, hydroxylamine is available as a nitrogen source for certain organisms and may, indeed, be the form in which the nitrogen of nitrate enters into the general metabolism of the organism. ${ }^{285,} 286$

Nitrate assimilation by green algae is inhibited by low concentrations of cyanide, an indication that heavy metals are concerned in the process. ${ }^{292}, 158,218$ As in higher plants, manganese appears to play a specific part in the reduction of nitrate by algae ${ }^{167}$ and traces of molybdenum have been found to be essential for the achievement of maximum rates of nitrate assimilation by Anabaena. ${ }^{308}$

\section{THE ASSIMILATION OF AMMONIUM NITROGEN}

A mmonium salts can be utilized as sole source of nitrogen by most algae and are generally more readily assimilated than is nitrate. If the two forms are supplied together, the ammonium nitrogen is utilized preferentially and the nitrate is only consumed when the ammonia is exhausted. ${ }^{54,180,235}$ If Chlorella growing in a medium containing nitrate is supplied with an ammonium salt the rate of gas exchange alters immediately, showing no adaptation to this latter source of nitrogen to be necessary. ${ }^{63}$ The obvious explana- 
tion of these facts is that nitrate must be reduced before its nitrogen can be utilized in cell synthesis whereas the nitrogen in ammonia, being already at the same level of reduction as that in bio-organic compounds, can participate immediately in metabolism. The fact that an organism able to utilize nitrate must possess some mechanism extra to that required for ammonia assimilation is recognized in the distinction drawn between autotrophs sensu stricto, which are able to reduce oxidized inorganic nutrients, and mesotrophs, which require one or more reduced inorganic nutrients such as ammonia (see p. I6).

Secondary effects of ammonia absorption make it a less favourable source of nitrogen than nitrate. Ammonium nitrogen enters living cells most readily as undissociated ammonium hydroxide, with the result that the medium surrounding the cells becomes more acid and may eventually reach a $\mathrm{pH}$ sufficiently low to inhibit growth. ${ }^{235}$ While absorption of nitrate causes a medium to become more alkaline, the change is relatively less and this form of nitrogen is generally used in preference to ammonium salts in making up media for algae. Only if $\mathrm{pH}$ changes are reduced by buffering or by some other means, is growth. with ammonium salts as good as that with nitrate. Ammonium nitrogen, even in slight excess, may have a profound influence on the course of metabolism and can exert effects, which may or may not be deleterious, apart from those attendant upon changes in hydrogen ion concentration. Even concentrations of the order of $0.5 \times 10^{-4} \mathrm{M}$ of an ammonium salt suppress the formation of heterocysts by Anabaena cylindrica ${ }^{90}$ and although growth of Prorocentrum spp. and Peridinium spp. is possible in the presence of $0.2 \times 10^{-5} \mathrm{M}$ ammonium chloride, it is inhibited by a concentration of $0.2 \times 10^{-3} \mathrm{M}^{21}$

As with nitrate, the uptake of ammonium nitrogen by algal cells depends on the previous history of the cells and on the conditions to which they are exposed. ${ }^{275}$ The addition of an ammonium salt to a suspension of nitrogenstarved Chlorella vulgaris is followed immediately by a rapid assimilation of ammonia which continues until either the 
ammonia in the medium or some carbon reserve within the cells becomes exhausted. Ammonia uptake by cells not initially deficient in nitrogen is much less marked but is increased, although to a level lower than that of nitrogendeficient cells, if glucose is supplied in the medium. The supply of glucose to nitrogen-deficient cells does not increase their rate of ammonia assimilation. These observations were made with cell suspensions kept in the dark; light has little effect on the rate of ammonia assimilation by nitrogen-deficient cells but doubles the assimilation rate of normal cells.

\section{TABLE 6}

RATES OF OXYGEN ABSORPTION (MM. ${ }^{3} /$ MG. DRY WT./HR.) BY Chlorella vulgaris ${ }^{275}$

\begin{tabular}{|c|c|c|}
\hline & $\begin{array}{l}\text { Before addition } \\
\text { of }\left(\mathrm{NH}_{4}\right)_{2} \mathrm{SO}_{4}\end{array}$ & $\begin{array}{l}\text { After addition } \\
\text { of }\left(\mathrm{NH}_{4}\right)_{2} \mathrm{SO}_{4}\end{array}$ \\
\hline $\begin{array}{ll}\begin{array}{l}\text { Nitrogen-starved } \\
\text { cells }\end{array} & \left\{\begin{array}{l}\text { no glucose } \\
+1 \% \text { glucose }\end{array}\right. \\
\text { Normal cells } & \left\{\begin{array}{l}\text { no glucose } \\
+1 \% \text { glucose }\end{array}\right.\end{array}$ & $\begin{array}{r}2 \cdot 74 \\
7 \cdot 75 \\
3 \cdot 05 \\
12 \cdot 48\end{array}$ & $\begin{array}{c}16 \cdot 08 \\
16 \cdot 66 \\
8 \cdot 52^{*} 2 \cdot 32 \\
17 \cdot 53\end{array}$ \\
\hline
\end{tabular}

* This rate was maintained for ro minutes only.

The assimilation of ammonia by nitrogen-starved Chlorella is accompanied by a marked increase in respiration rate. When the addition of an ammonium salt to a cell suspension is not followed by very rapid ammonia assimilation respiration is not stimulated in this manner (Table 6). The assimilation of ammonia and the respiration accompanying it are both cyanide-sensitive. Fermentation, in cell suspensions in an atmosphere of nitrogen, is not affected by addition of ammonia. There is thus a close correlation between the rates of ammonia assimilation and of aerobic respiration. ${ }^{275}$

The ammonia assimilated by nitrogen-starved Chlorella is converted largely into soluble organic compounds. At first, most of the ammonia which disappears from the medium can be accounted for as free or combined aminonitrogen and amide nitrogen within the algal cells (Fig. I3). 


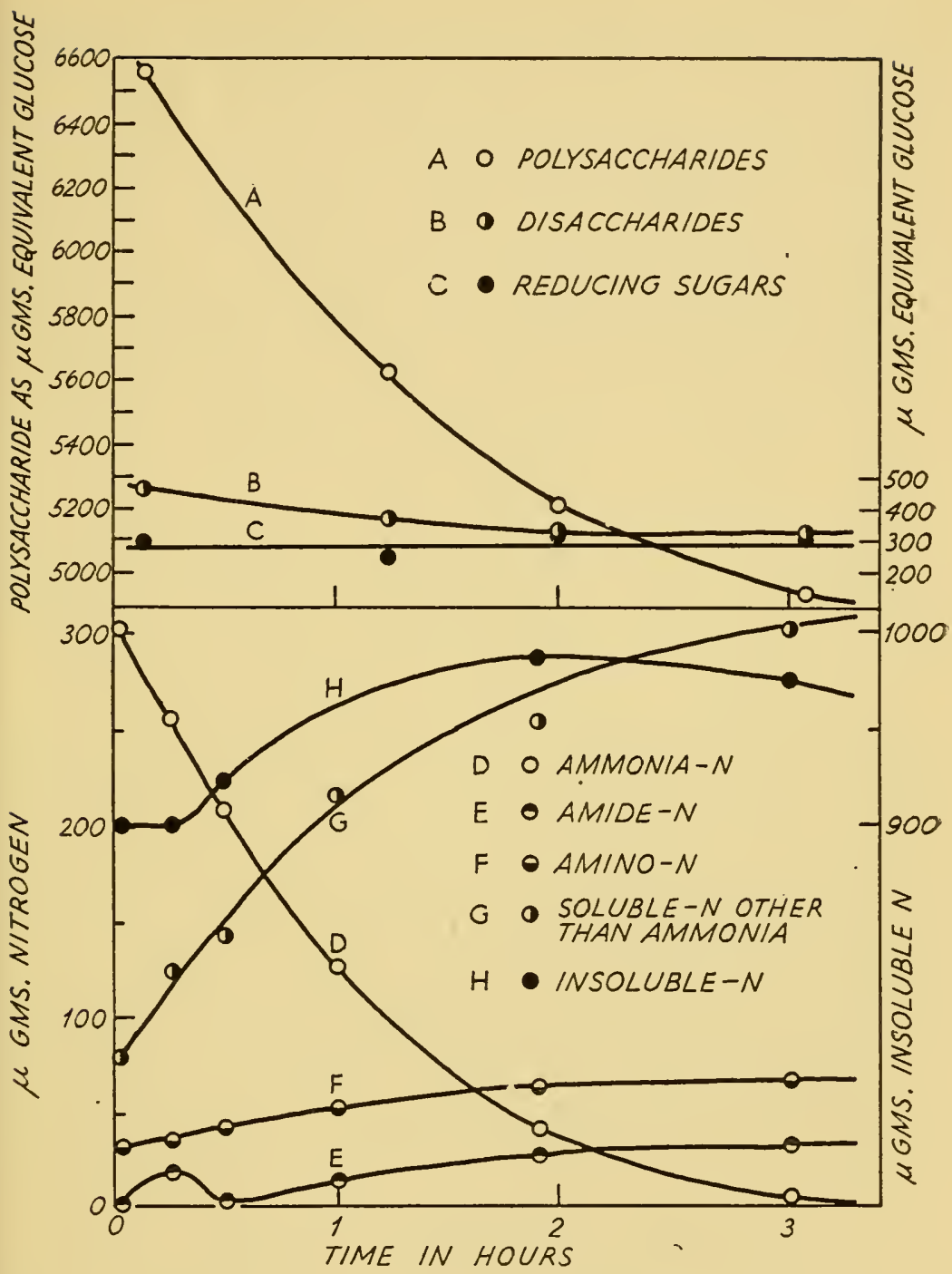

FIG. 13. Changes in the amounts of various chemical fractions in Chlorella vulgaris following the supply of ammonia to nitrogendeficient cells (after ref. 276). 
As assimilation continues, these fractions account for less of the ammonia taken up, basic amino-acids, particularly arginine, lysine and ornithine, being formed instead.276, 278 Corresponding with the assimilation of ammonia there is a disappearance of non-reducing sugar and of polysaccharide from the cells (Fig. I3) and it is evident that the carbon skeletons for the nitrogenous compounds formed are derived from these substances. ${ }^{276}$ When glucose is supplied, all the ammonia nitrogen added to the cells is eventually converted to insoluble nitrogen and the cells return to the nitrogenstarved condition. When no glucose is supplied a large proportion of the ammonia-nitrogen assimilated remains in the cells in a soluble organic form. ${ }^{278}$

The mechanisms whereby ammonia is incorporated into organic substances in algae have not yet been investigated in detail. In higher plants supplied with ammonia labelled with heavy nitrogen, heavy nitrogen appears more rapidly and extensively in glutamic acid than in any other aminoacid, suggesting that there is ready exchange between ammonia and its amino-group and that this is the principal route of entry of ammonia into metabolism. ${ }^{41}$ Glutamic acid, which evidently occurs in substantial proportions in most algae (see Table 8 ) and which is more readily assimilated than other amino-acids by algae such as Scenedesmus $^{8}$ and Euglena spp., ${ }^{150}$ appears to occupy a similar special position in the nitrogen metabolism of these organisms and that this is so for Nostoc muscorum has been confirmed using heavy nitrogen as a tracer. ${ }^{301 a}$ Glutamic acid is formed in plant tissues from $\alpha$-ketoglutaric acid by a reversible process involving a reduction catalysed by glumatic dehydrogenase: ${ }^{41}$

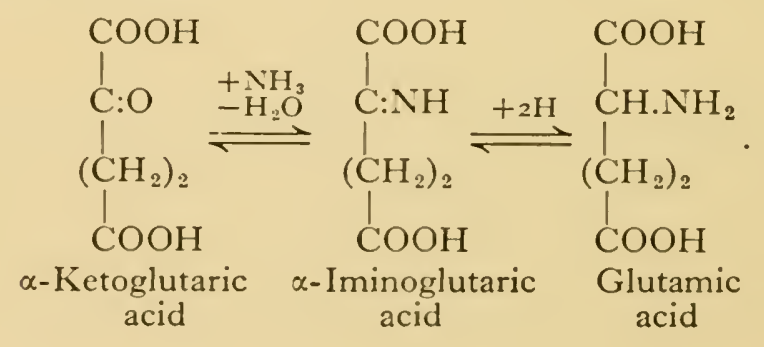


$\alpha$-Ketoglutaric acid may be derived through the tricarboxylic acid cycle from carbohydrate or from the primary products of photosynthesis by the pathways indicated in Fig. Io. A corresponding mechanism for the formation of the related aspartic acid from oxaloacetic acid is unknown ${ }^{41}$ and aspartic acid does not appear to occupy a similar central position in the metabolism of Chlorophyceae to that of glutamic acid.6, 7 There is evidence that in algae other amino-acids are formed from glutamic and aspartic acids by transamination processes such as have been found to occur in other organisms, ${ }^{10,}{ }^{193 a}$ e.g.:

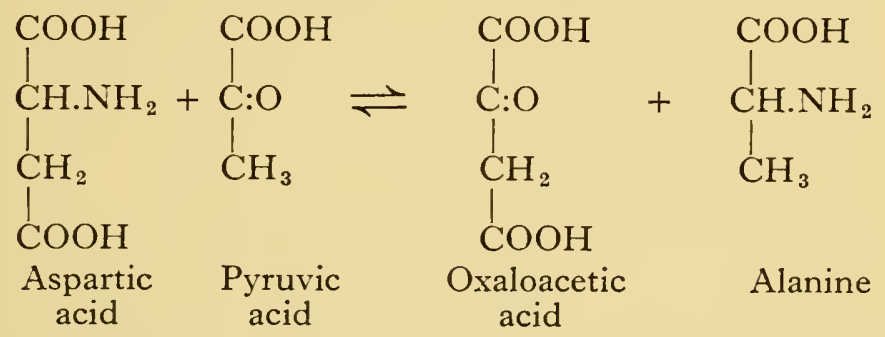

The necessary keto-acid in this particular example may be provided directly either by glycolysis or by photosynthesis. Transaminase systems catalysing the transfer of the aminogroup from aspartic acid, alanine and leucine to $\alpha$-ketoglutaric acid and from aspartic acid, glutamic acid and leucine to pyruvic acid have been demonstrated in Chlorella vulgaris. ${ }^{193 a}$ The synthesis of the basic amino-acids, arginine, lysine and ornithine, which appear to be of particular importance in $C$. vulgaris, ${ }^{278}$ has been studied in detail in other organisms 19,41 but there is nothing to indicate whether or not the mechanisms that have been found occur in algae also.

Amide formation is of general occurrence in plants ${ }^{41}$ and the observed increase in amide in Chlorella supplied with ammonia $^{276}$ is in agreement with expectation. Glutamine formation in animal tissues, higher plants and bacteria, has been found to be dependent on aerobic respiration and evidently involves a phosphorolytic reaction, the energy necessary for the formation of the amide linkage being derived from adenosine triphosphate: ${ }^{19,}{ }^{41}$ 


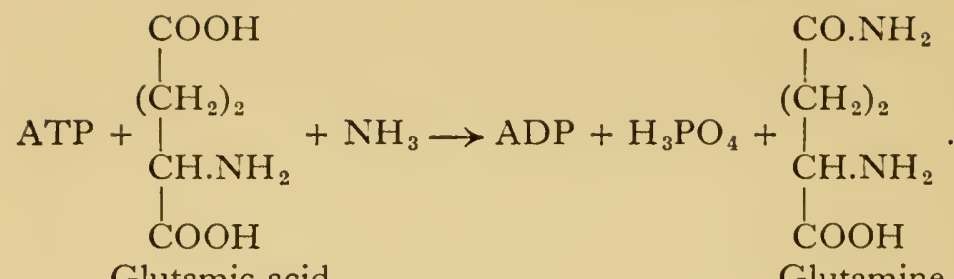

The mechanism of amide formation in algae must be supposed to be essentially similar.
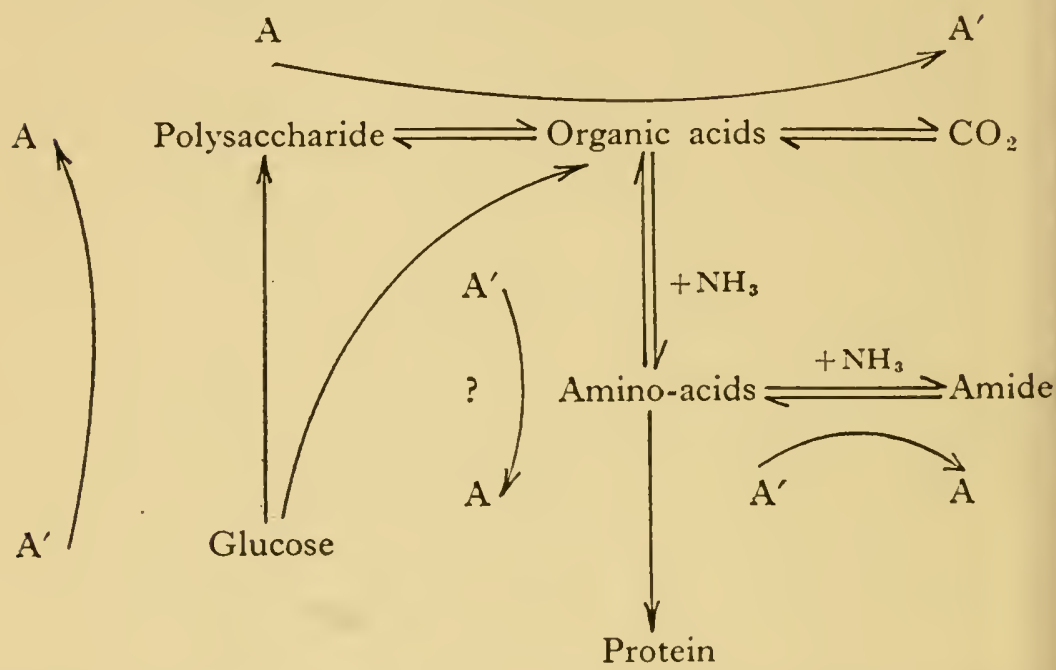

FIG. I 4. Scheme showing the probable inter-relationships between the processes involved in ammonia assimilation in Chlorella vulgaris. A represents a substance such as adenosine diphosphate and $\mathrm{A}^{\prime}$, a substance such as adenosine triphosphate (after ref. 277).

It will be evident from the preceding paragraphs that the mechanisms of ammonia assimilation and respiration are interdependent. The correlation existing between the rates of the two processes may be explained if it is assumed that the rate of respiration is normally limited by the amount available of some substance, such as adenosine diphosphate, which can act as an acceptor for the high energy phosphate groups produced in this process. ${ }^{276}$ It has been pointed out 
above that the synthesis of amides requires energy which can be supplied from high energy phosphate groups and it seems likely that the synthesis of amino-acids and proteins must involve the consumption of energy from a similar source. ${ }^{19,}{ }^{41}$ Upon addition of ammonia to nitrogen-starved cells the synthesis of nitrogenous substances presumably results in the disappearance of high energy phosphate groups and makes more acceptor available so that respiration may proceed more rapidly. In normal cells, in which synthesis of organic nitrogenous substances from ammonia does not occur, no high energy phosphate groups are utilized and so the respiration rate is not increased. This mechanism is represented in Fig. I4, in which A stands for a substance such as adenosine diphosphate and $\mathrm{A}^{\prime}$ for a substance such as adenosine triphosphate. In agreement with this hypothesis it has been found that addition of adenylic acid or of dinitrophenol, which promotes breakdown of adenosine triphosphate, increases the respiration rate of nitrogen-starved Chlorella, and that the soluble organic phosphorus fraction in the cells decreases after addition of ammonia. ${ }^{277}$

\section{THE ASSIMILATION OF NITROGEN IN ORGANIC}

\section{COMBINATION}

The reactions by which nitrogen is transferred from one carbon residue to another during nitrogen metabolism are evidently reversible in the majority of cases and, just as in the case of carbon metabolism, we are justified in imagining a flexible system into which material may be introduced at several points. The expectation that any substance which is an intermediate in nitrogen metabolism, or readily convertible into such, can serve as a nitrogen source if it is able to penetrate the plasma membrane, appears to be borne out by the observed facts. Thus there are many records of autotrophic algae being able to utilize various organic nitrogenous substances as their only source of nitrogen (e.g. ${ }^{180,167,3,4,5,6,7,9,10}$ ). Since this form of nitrogen assimilation is facultative and does not involve any loss 
in synthetic ability it is more appropriately considered here rather than under the heading of heterotrophism.

The first step in the assimilation of $\alpha$-amino-acids, such as glycine and alanine, is evidently deamination, so that their nitrogen enters into metabolism as ammonia. ${ }^{3}, 5$ Thus during the growth of Scenedesmus obliquus in the light in a medium containing glycine, which forms a good source of nitrogen for this alga, considerable amounts of ammonia are liberated. ${ }^{3}$ Since $S$. obliquus is able to grow slowly in the dark with glycine as its sole source of carbon, it might be that this excess ammonia is produced because the rate of deamination of the glycine is high as a result of the utilization of the carbon residue under conditions of carbon deficiency. Evidently this cannot be so, since if glucose is supplied together with glycine to illuminated cultures the rate of deamination per cell remains the same, although less ammonia appears in the medium because of the more rapid growth of the alga. It appears, therefore, that deamination of glycine by $S$. obliquus is independent of carbon metabolism and is in excess of requirements. ${ }^{3}$ In Chlorella vulgaris the rate of deamination of this amino-acid is relatively slower than in Scenedesmus and limits the rate of growth of the alga with the result that no ammonia is liberated provided that the medium is neutral. ${ }^{4}$ Similarly Chlorella, Haematococcus and Zygnema spp. deaminate alanine relatively slowly so that no ammonia is liberated from the cells, whereas Ankistrodesmus, Stichococcus and Hormidium, are of the same type as Scenedesmus and give off an excess of ammonia to the medium when supplied with these amino-acids. ${ }^{5}$ Bacterial deaminases have a maximum rate of reaction at about $\mathrm{pH} 8.0$ but the optimum for these algal deaminases is on the acid side of neutrality, between $\mathrm{pH} 5$ and $6 .^{3,4}$ The algae in which deamination has been demonstrated frequently occur in waters contaminated with organic matter and must play a considerable part in the degradation of nitrogenous substances in such situations.

Aspartic acid, glutamic acid, asparagine, succinamide and glutamine, have also been found to be suitable as sole nitrogen sources for various green algae. $6,7,9$ Aspartic acid 
does not appear to be deaminated during assimilation, its amino-group evidently being utilized by transamination ${ }^{8}$ as in reaction 22 . In media containing amides, ammonia may be liberated in small quantities during the growth of Chlorophyceae, evidently as a result of deamidation taking place independently of deamination and transamination. ${ }^{7}$ 


\section{HETEROTROPHIC ASSIMILATION}

Heterotrophic organisms are unable to synthesize the full range of organic substances necessary for life and are consequently dependent on exogenous sources for one or more essential metabolites. In the algae autotrophism is evidently the primitive condition, the heterotrophic habit being derived from it by specialization leading to loss of particular synthetic mechanisms.

There are many indications that a requirement for specific organic growth factors is of frequent occurrence among algae but few definite instances have been recorded. Partly, this is because the isolation of algae has usually involved 'enrichment culture'* in a mineral medium, a procedure which tends to select species without organic growth substance requirements and which results in our present knowledge of algal metabolism being biased in favour of completely autotrophic forms. ${ }^{176}$ There is also the technical difficulty of establishing requirements for substances which may be active at exceptionally high dilutions. ${ }^{150}$ Many reports of growth factor requirements among flagellates cannot be confirmed ${ }^{183}$ and these will not be discussed here.

\section{THE AMINO-ACID REQUIREMENTS OF ALGAE}

Twenty or more different $\alpha$-amino-acids appear to be essential in living matter and, if any part of the mechanism for the synthesis of these from ammonia and appropriate carbon residues is absent, the organism concerned must obtain the particular amino-acids from exogenous sources.

Euglena deses can only grow if provided with a suitable amino-acid such as aspartic acid. ${ }^{131}$ Here the requirement

* An enrichment culture is one, inoculated with a mixture of species, in which particular conditions favour the development of certain organisms whilst hindering that of others (see ref. 24I). 
is evidently not for a specific amino-acid and it appears that the mechanism which is lacking is one which forms aminogroups from ammonia, for example that represented in equation $2 \mathrm{I}$. Given an amino-acid which can participate in transamination reactions (equation 22) then synthesis of other amino-acids is possible. Glycine and phenylalanine are not suitable nitrogen sources for Euglena deses ${ }^{131}$ and it may be significant that of these the former apparently does not participate in transamination reactions in other organisms.

Chlamydomonas chlamydogama, an obligate phototroph, provides an example of an alga with specific amino-acid requirements, viz. for histidine and aspartic acid. ${ }^{150}$ Here the missing mechanisms lie towards the end of synthetic sequences rather than on the main track of synthesis as in Euglena deses.

\section{THE VITAMIN REQUIREMENTS OF ALGAE}

If an organism is unable to synthesize for itself a component of an enzyme system, only minute amounts of the metabolite concerned need to be supplied from exogenous sources to permit growth to take place. Growth factors of this type are generally known as vitamins.

Most algae are able to synthesize for themselves vitamin $\mathrm{B}_{1}$ or thiamine, the importance of which in metabolism has already been discussed (p. 9), in quantities sufficient for their needs. ${ }^{2}$ However, a requirement for this substance has been demonstrated in a number of algae. It may be noted that the amounts of dissolved thiamine present in natural waters are evidently enough to support the growth of these forms. ${ }^{149,177}$ The thiamine molecule consists of thiazole and pyrimidine portions and synthetic disabilities may result in an organism being unable to synthesize either or both of these portions or to unite them to give thiamine. A requirement for thiamine as such has not yet been demonstrated in an alga. The thiazole portion only is required by Polytoma ocellatum whereas Euglena gracilis can manufacture this for itself but requires an exogenous supply of the pyrimidine portion. ${ }^{183}$ Both the pyrimidine and thiazole portions must be supplied for the growth of Polytomella 
caeca, Chilomonas paramoecium ${ }^{183}$ and Prototheca zopfii. ${ }^{13}$ A mutant requiring thiamine of Chlamydomonas moewusii has been induced by ultra-violet irradiation and responds to as little as $10^{-10} \mathrm{gm} . / \mathrm{ml}$. of the substance. Here it is the pyrimidine portion alone which is required, the ability to synthesize thiazole remaining unimpaired. ${ }^{177}$

The requirement of Euglena gracilis for thiamine is of particular interest in that this substance has been found to be necessary for phototrophic growth but not when glutamate is supplied either in the light or the dark. ${ }^{65}$ The significance of these facts is not clear since although it is possible for the decarboxylation of pyruvic acid, for which thiamine is essential, to be by-passed if glutamate is the carbon source (see Fig. I0), thiamine appears to be just as necessary for the oxidative decarboxylations occurring in the tricarboxylic acid cycle, which presumably operates in Euglena. Possibly the inability of Euglena gracilis to synthesize thiamine is not absolute and glutamate exerts sufficient thiamine-sparing action to enable growth to take place.

Traces of vitamin $B_{12}$, the anti-pernicious anaemia factor of animals, are necessary for the growth of Euglena gracilis, E. stellata and Astasia spp. It has been suggested that the requirement is characteristic of species of Euglenineae in general, but it can also occur in representatives of other classes, e.g. Chlamydomonas chlamydogama. ${ }^{150}$ Vitamin $B_{12}$, like folic acid, may be concerned in the synthesis of desoxyribosenucleic acid. ${ }^{150}$ The vitamin $\mathrm{B}_{12}$ requirement of Euglena gracilis is the same whether growth takes place in the light or in the dark. ${ }^{65}$

A constituent of folic acid, $p$-amino-benzoic acid, has been recognized as an essential metabolite as a result of the observation that it antagonizes the inhibition of the growth of micro-organisms by its analogue, sulphanilamide. ${ }^{267}$ p-Amino-benzoic acid evidently plays as important a rôle in the metabolism of some algae as it does in that of other organisms since it has been found to neutralize the inhibitory effects of sulphanilamide on the growth of Nitzschia spp. ${ }^{299}$ and of Chlamydomonas moerwusii. ${ }^{177}$ While $p$-aminobenzoic acid has been found to be a growth factor for several 
bacterial species, ${ }^{267}$ a requirement for it in an alga appears so far only to have been found in an artificially induced mutant of Chlamydomonas moewusii. ${ }^{176,177}$ In the nutrition of this mutant $p$-amino-benzoic acid may be replaced by aniline at an efficiency of about I per cent, but it is remarkable that aniline does not have a corresponding neutralizing effect on the inhibition of the wild-type cells by sulphanilamide. ${ }^{176,177}$

\section{UNIDENTIFIED GROWTH FACTORS}

Besides these few instances in which growth factors have been identified, it may be as well to mention briefly examples in which a requirement for less completely characterized growth factors has been found, as an indication of the extent to which heterotrophism occurs among the algae.

There are several reports indicating that the growth of marine algae may in some cases depend on organic substances present in seawater. ${ }^{136}$ Thus, Ditylium brightwelli has been found to require for vigorous growth in artificial seawater two organic substances, or groups of substances, in addition to mineral salts. One of these factors may be replaced by organic compounds containing sulphur in the grouping, $-\mathrm{S}-\mathrm{CH}_{2} \cdot \mathrm{CH}\left(\mathrm{NH}_{2}\right) \mathrm{COOH}$. The other substance, or group of substances, is present in extracts of algae and of yeast. ${ }^{135}$ Seawater from the surface, particularly that from the littoral zone, has been found to contain substances necessary for the germination of sporelings of Enteromorpha and Ulva spp., which do not appear to be of an inorganic nature and which are absent from water taken from a depth of 35 to 40 metres. ${ }^{168}$ A marine dinoflagellate, Gymnodinium sp., cannot be subcultured indefinitely in the absence of an organic factor or factors occurring in soil extract. ${ }^{273}$ The addition of soil extract is frequently necessary to obtain growth of soil and freshwater algae in culture. ${ }^{241}$ Thus, Cryptomonas ovata and Synura uvella will not grow in a medium found suitable for other planktonic algae, until an extract of soil or lake sediment is added. Ashing destroys the activity of these extracts. ${ }^{254}$ Soil extract presumably contains a wide variety of substances 
which may act as growth factors and different factors may be concerned in different cases. ${ }^{150}$ There is some evidence that Gloeotrichia echinulata requires a thermolabile growth factor present in garden soil. ${ }^{254}$ It is commonly observed that algae which have grown well in impure culture cease to thrive after isolation in bacteria-free culture. Gloeotrichia natans, for example, is of this type. ${ }^{93}$ This is an indication that such species require organic growth factors. 


\section{THE PRODUCTS OF METABOLISM}

In the previous chapters the pathways by which materials assimilated by algae enter into metabolism have been traced as far as possible. Now, the nature of the final products of metabolism must be considered. Something of the nature of the transformations which the intermediates that have so far been identified must undergo before these final products appear can be inferred by analogy with processes that have been discovered in other organisms, but information obtained by experiment with algae themselves is for the most part lacking as yet. For present purposes it seems best, after noting the existence of this gap in our knowledge, to review briefly that which is known of the chemical nature of the major products of algal metabolism without speculation as to the pathways by which they are synthesized.

\section{SOLUBLE EXTRACELLULAR PRODUCTS}

Algae, in general, inhabit aquatic environments. As we have seen, it is possible for organic substances to enter algal cells from the environment and so the possibility must be considered that the passage of similar substances can take place equally readily in the opposite direction with the result that appreciable proportions of the products of metabolism are liberated in extracellular form from healthy algal cells.

In pure cultures of species of Chlorophyceae, such as Scenedesmus, Chlorella and Coccomyxa spp., from 2 to 12.5 per cent of the total carbon àssimilated has been found to appear in a soluble form in the external medium. ${ }^{166}, 253,264,203,200$ The amount of such extracellular carbon increases as cultures age and proportions as high as 12.5 per cent have only been observed in old cultures $^{253}$ in which, it may be suspected, autolysis may have occurred to some extent. The nature of the extracellular 
compounds of the Chlorophyceae has not been determined but Anabaena cylindrica has been found to liberate extracellular pentose in amounts of up to $\mathrm{I} \cdot 4$ per cent of its dry weight as well as nitrogenous substances which may represent a considerably greater proportion of the total carbon fixed by the alga. ${ }^{92}$ It is to be noted that the dissolved organic matter to be found both in freshwater and seawater consists principally of substances of a nitrogenous nature and of pentosans. ${ }^{165}$ Organic acids, alcohols and other extracellular products commonly found in cultures of bacteria and fungi have never been found in appreciable quantities in filtrates from algal cultures.

Extracellular nitrogenous products in cultures of nitrogen fixing algae have been noted frequently $12,66,87,91,142$ and it appears that the liberation of such substances may be characteristic of most members of the Myxophyceae, whether they fix nitrogen or not. ${ }^{92}$ For Anabaena cylindrica the total amount of extracellular substances is relatively greatest in young cultures, in which they may account for over 50 per cent of the nitrogen assimilated, and the substances concerned are evidently not produced by autolysis of dead cells. The liberation of extracellular combined nitrogen appears invariably to accompany growth although its relative extent varies according to culture conditions. The substances concerned are principally polypeptides but in young cultures a considerable proportion of the nitrogen may be present as amide. ${ }^{92}$ It is not known whether similar substances are liberated by algae belonging to other groups but such excretion easily escapes notice in the usual culture media made up with ample amounts of nitrate or ammonium salts.

It may be agreed that "conservation of carbon and a minimal level of excretion is probably generally characteristic of the green algae' and that in addition to their rôle in raising the energy level of carbon 'they also provide the mechanism of carbon accumulation and can ill afford wasteful luxuries of excretion'.200 'This generalization, however, does not necessarily apply to species belonging to other groups of algae and even the low levels of excretion reported 
for members of the Chlorophyceae may become important where growth of these algae takes place on a large scale. The direct nutritional value to most other organisms of algal excretion products is probably slight ${ }^{165}, 92$ but their indirect effects on organic production are perhaps sometimes considerable. ${ }^{92}$

\section{CARBOHYDRATES AND RELATED SUBSTANCES}

Carbohydrates may occur in considerable proportions in algae either as intracellular reserve materials or as cell wall constituents and more is known of this class of algal product than of any other. Most of the carbohydrates that will be mentioned are built up from units containing a heterocyclic six-membered, or pyranose, skeleton. It may be helpful to the reader of this section to note that, in order that the spatial relationships of the atoms may be shown, this ring is conventionally represented thus:

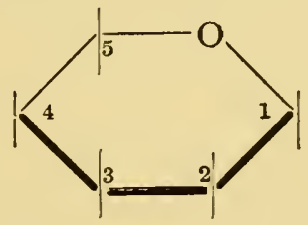

the plane of the ring being supposed to be at right angles to that of the paper, with the thickened edge foremost. The formation of this ring from a simple chain results in a further carbon atom, that numbered I, becoming asymmetric. Thus there are two optical isomers of the pyranose form of D-glucose:

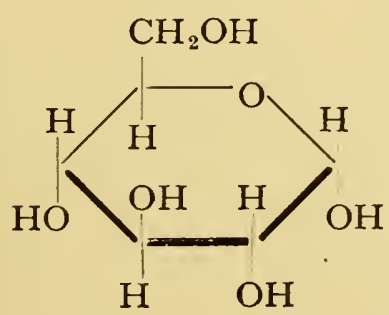

$\alpha$-D-glucopyranose

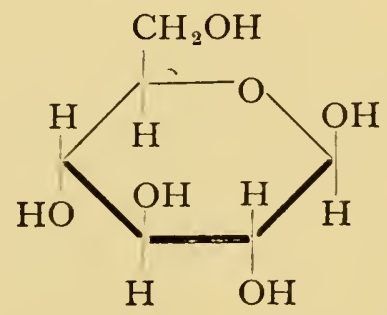

$\beta$-D-glucopyranose 
Further information on the structure and nomenclature of carbohydrates may be found in a number of books. e.g. ${ }^{226}$

Glucose or other reducing sugars occur in low concentrations in species of Chlorophyceae $225,172,260$ but are present only in traces or are absent in demonstrable quantity in representatives of the Bacillariophyceae, ${ }^{20}$ Phaeophyceae, ${ }^{121}, 127,173$ Rhodophyceae ${ }^{59}, 138,169$ and Myxophyceae. ${ }^{221}, 170$ Free pentoses, like hexoses, are evidently of little quantitative importance in algae. Mannitol, a hexahydric alcohol which may be derived by reduction from mannose or fructose, occurs in considerable quantity in species of Phaeophyceae, in which it may sometimes form more than 30 per cent of the dry weight. ${ }^{33}$ Mannitol is to be found in only a few higher plants but appears to be of general occurrence in the Phaeophyceae. ${ }^{122}, 127,173$ It is absent from those representatives of the Rhodophyceae in which it has been sought ${ }^{127}$ and does not appear to have been recorded as occurring in any other algal class.

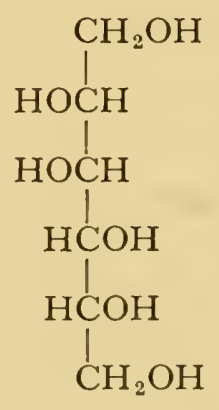

D-mannitol

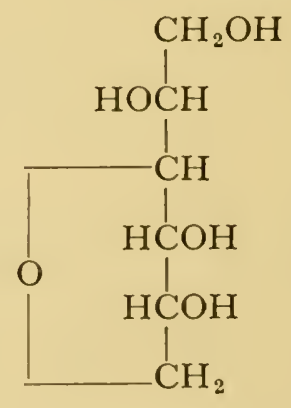

D-mannitan

An anhydride of mannitol, mannitan, has been reported as occurring in Pelvetia canaliculata. ${ }^{122}$ Dulcitol and sorbitol, which are isomeric with mannitol, have been found in Bostrychia scorpioides and Iridaea laminarioides but not in a number of other species of Rhodophyceae. ${ }^{123,} 125,138$ Floridoside, which is evidently glycerol $\alpha$-D-galactoside, is abundant and generally distributed in the Rhodophyceae. ${ }^{59,127,169} \mathrm{It}$ is remarkable among naturally occurring glycosides in belonging to the $\alpha$-series. In many species of 
Ceramiales, Gigartinales and Cryptonemiales, sodium mannoglycerate is more abundant than floridoside. ${ }^{17}$

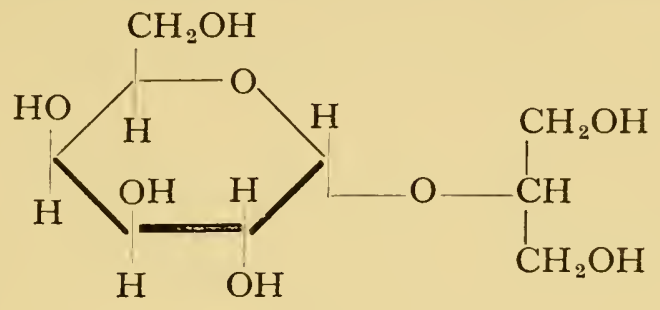

Floridoside

Among oligosaccharides, sucrose occurs in appreciable quantities in Chlorella and Scenedesmus ${ }^{52}$ but does not appear to have been found in more than traces in representatives of classes of algae other than the Chlorophyceae. Trehalose, I-[ $\alpha$-D-glucopyranosido]- $\alpha$-D-glycopyranoside, which is commonly to be found in fungi but not in higher green plants, is present in various species of Myxophyceae $^{221}, 170$ and in freshwater species of Rhodophyceae. ${ }^{58}$

Glucose polymers form the principal intracellular reserve products in several classes of algae. The starch of the Chlorophyceae stains blue or purple with iodine and appears to be essentially similar to that of higher plants. Starch contains two principal constituents, i.e. amylose, which consists of long unbranched chains of $\alpha$-D-glucopyranose units united by I : 4 linkages, and amylopectin, also consisting of $\alpha$-D-glucopyranose units but having branched chains. The starch of Polytomella caeca contains 84 to 87 per cent of amylopectin. ${ }^{43}$ Floridean starch, which occurs in the form of small grains staining brown with iodine or, on swelling, violet, is the characteristic reserve product of the Rhodophyceae. ${ }^{107}$ It consists entirely of glucose residues but is structurally different from normal starch in containing a large proportion of $\mathrm{I}: 3$ linkages and is resistant to attack by $\beta$-amylase. ${ }^{24}$ Paramylum (paramylon), the characteristic reserve product of the Euglenineae, does not stain with iodine but yields mostly glucose upon hydrolysis ${ }^{150}$ and is evidently related to starch. A starch-like product giving a blue colour with iodine either directly ${ }^{106}$ or on 
boiling ${ }^{148}$ occurs in the Cryptophyceae and in Chilomonas paramoecium appears to consist of about equal parts of amylose and amylopectin. ${ }^{148} \mathrm{~A}$ polysaccharide, the presence of which causes the chromatoplasm to stain reddish brown with iodine, generally occurs in the Myxophyceae ${ }^{107}$ although it is not always demonstrable in these algae. ${ }^{221}$ This polysaccharide, which has been generally considered to be glycogen but which is perhaps better designated as Myxophycean starch, evidently occurs in the cells in the form of submicroscopic granules. ${ }^{170}$ Oscillatoria princeps has been found to contain an enzyme synthesizing a glycogenlike polysaccharide having it to I 6 glucose residues, which may or may not be identical with Myxophycean starch, from glucose-I-phosphate. ${ }^{102}$ Starch and similar substances appear to be absent from the Phaeophyceae.

Another type of glucose polymer is represented by laminarin, a soluble reserve product giving no colour with iodine and occurring in the Phaeophyceae, e.g. in Ascophyllum, Fucus and Laminaria spp. to the extent of up to 25 per cent on a dry weight basis. ${ }^{33}$ Laminarin has been reported as being absent from certain members of the Phaeophyceae, e.g. Pelvetia canaliculata and Chorda and Ectocarpus spp. ${ }^{173}$ but this has been shown to be incorrect in the case of the Pelvetia. ${ }^{35}$ Normal laminarin is built up of $\beta$-D-glucopyranose units linked through $\mathrm{C}_{1}$ and $\mathrm{C}_{3}$ Upon hydrolysis with mineral acid it yields a disaccharide, laminaribiose or $3-\beta$-D-glucosyl D-glucose. ${ }^{18}$ Laminarin probably has the following constitution: ${ }^{61}$

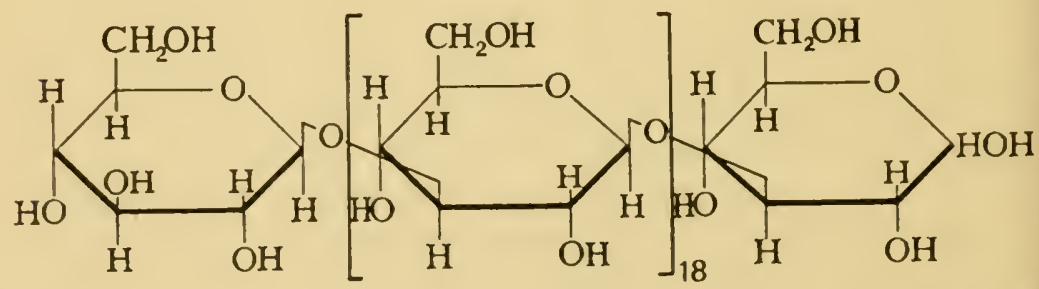

Laminarin may occur in another modification, the relation of which to the normal form is not known. ${ }^{230}$ 
Leucosin, the characteristic reserve product of the Chrysophyceae and perhaps also of the Bacillariophyceae, occurs as rounded glistening granules, soluble in water, which do not stain with iodine. ${ }^{105,270}$ Nothing is known of its chemical structure but it is evidently a polysaccharide. ${ }^{260,270,244 a}$

Cellulose is composed of $\beta$-D-glucopyranose units linked into long chains through the $\mathrm{C}_{1}$ and $\mathrm{C}_{4}$ positions. As in the higher plants it is the characteristic cell wall component in the Chlorophyceae and many studies, made by X-ray analysis and other physical methods, of cell wall structure have utilized members of this class, particularly Valonia spp., as material e.g., ${ }^{236}$ Cellulose is not, however, invariably present in members of the Chlorophyceae. ${ }^{208 a}$ Cellulose, as demonstrated by microchemical tests, is prominent in the envelopes of Dinophyceae. ${ }^{106}$ It occurs generally in the Phaeophyceae and Rhodophyceae, amounting to 2 to 15 per cent of the dry weight in these algae ${ }^{206}$ and its fundamental similarity in the Phaeophyceae and in the higher plants has been confirmed by chemical and X-ray examination. ${ }^{228}$ Cellulose occurs sporadically in the Myxophyceae and appears to be generally lacking in the Xanthophyceae, Chrysophyceae and Bacillariophyceae, ${ }^{106,107}$ although X-ray evidence shows its presence in Tribonema. ${ }^{208 a}$

Algin, the characteristic intercellular substance of the Phaeophyceae, of which it generally forms about 25 per cent on a dry weight basis, ${ }^{33}$ is a calcium-magnesium salt of alginic acid, a polymer of $\beta$-D-mannuronic acid having the following probable constitution: ${ }^{16}$

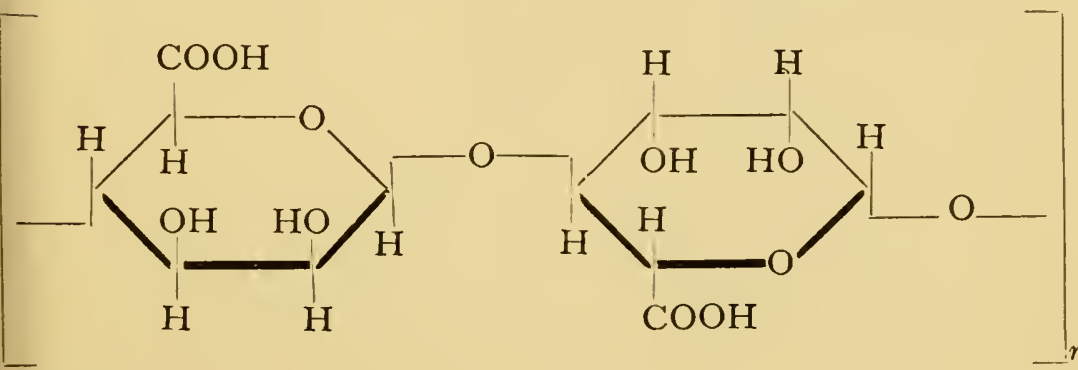


Because of its special colloidal properties alginic acid finds considerable use in industry. ${ }^{208}$

A polysaccharide yielding only xylose upon hydrolysis has been reported as present in Rhodymenia palmata. This xylan contains both $I: 3$ and $I: 4$ linkages. ${ }^{227}$

Other polysaccharides constituting the intercellular material of marine algae are composed of residues esterified by sulphuric acid. Because of this, a considerable proportion of the ash constituents of marine algae are present in the living plants in chemical combination with the intercellular material. ${ }^{130}$ Such sulphuric esters have so far only been found in the Rhodophyceae and Phaeophyceae and in animals and have not been reported as occurring in the bacteria or Myxophyceae. It has been suggested that the sulphate group plays a similar part in the synthesis of these polysaccharides as does the phosphate group in the synthesis of $\operatorname{starch}^{156}$ but there is as yet no evidence to show whether this is actually so.

Agar, or, more properly, agar-agar, is the most familiar polysaccharide of this type, being extensively used as a substratum for the culture of micro-organisms and for a variety of medical and industrial purposes. ${ }^{208}$ Its structure has not yet been fully elucidated. Many, but not all, Rhodophyceae yield extracts which gel ${ }^{189}$ and the tendency is to apply the term agar to all the substances concerned although they certainly differ in chemical constitution. A commercial agar, probably derived from Gelidium sp., has been found to contain D-galactopyranose units linked by I : 3 linkages together with $\mathrm{L}$-galactose residues linked with the others through $\mathrm{C}_{1}$ and $\mathrm{C}_{4}$ and esterified by sulphuric acid at $\mathrm{C}_{6} .{ }^{156}$ These two components are respectively:
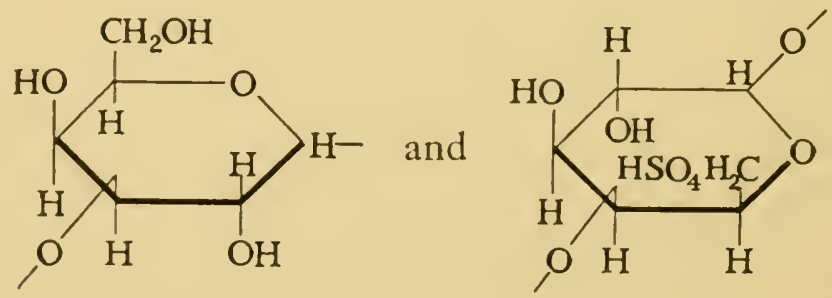
The ratio of $\mathrm{D}$ - to $\mathrm{L}$-galactose residues has been variously reported as $9: \mathrm{I}^{156}$ and $\mathrm{I}_{5}: 2^{231}$ and the exact constitution of the polysaccharide is not yet agreed upon. ${ }^{231}$

Chondrus crispus, carragheen, which is now used as a source of agar, ${ }^{208}$ yields two principal colloidal substances, one more soluble in cold water than the other and giving a viscous solution, and another forming a gel more readily. ${ }^{119}$ The difference in physical properties between these two appears to be due to the former being a mixture of sodium and potassium salts, whereas the latter is chiefly a calcium salt, the polysaccharide concerned, carragheenin, being evidently the same in both. ${ }^{46}$ The principal constituents of carragheenin are $\mathrm{D}$-galactose residues linked through $\mathrm{C}_{1}$ and $\mathrm{C}_{3}$ and each having a sulphate residue on $\mathrm{C}_{4}$. Carragheenin also contains $\mathrm{L}$-galactose and other residues. ${ }^{155}$ Gigartina stellata ${ }^{69}$ and Iridaea laminarioides ${ }^{137}$ evidently contain polysaccharides of a similar nature.

Fucoidin ${ }^{107,173}$ is a mucilaginous material extractable

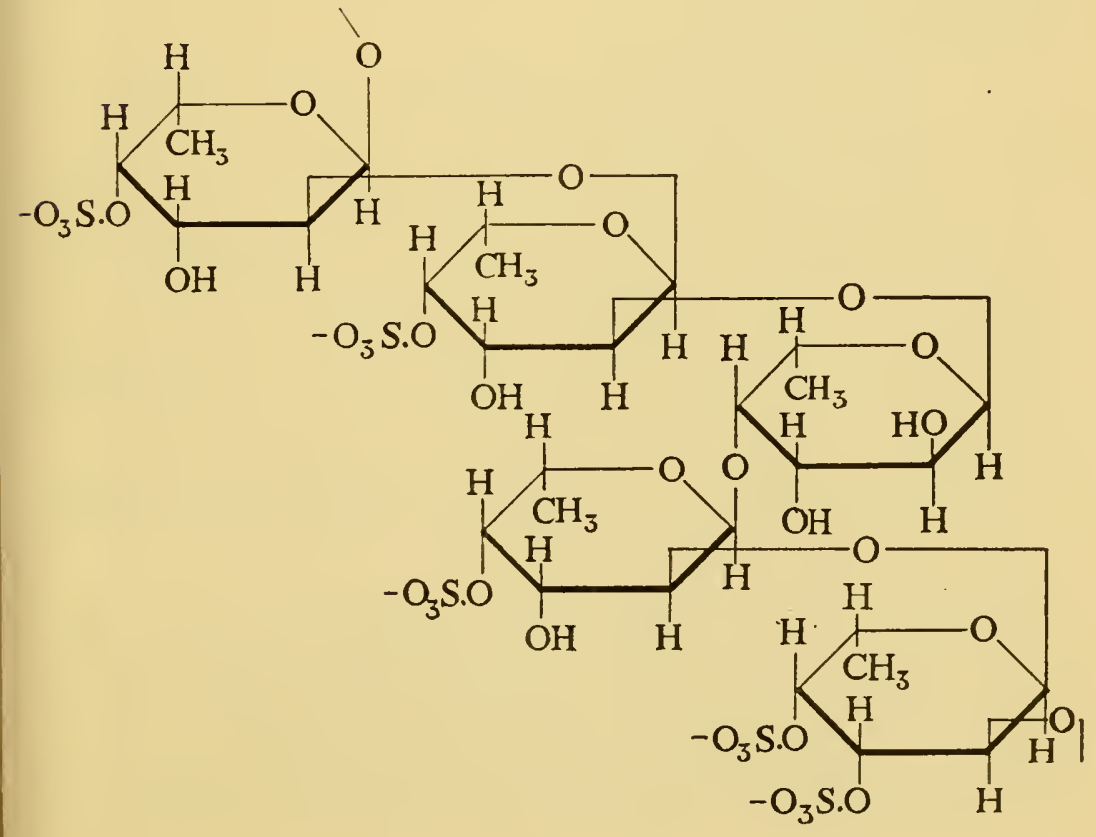


from many Phaeophyceae, e.g. Fucus spp. and Laminaria cloustoni. The principal constituents of this polysaccharide are L-fucose (a methyl pentose) residues esterified by sulphuric acid. These residues are evidently united chiefly by I : $2-x$ links; for a possible constitution see p. $97 .{ }^{229,60}$

There is some evidence that chitin, which is composed of $\mathrm{N}$-acetylglucosamine residues and which is a characteristic component of the cell wall of fungi and of the exoskeleton of insects, occurs in the cell walls of certain species of Xanthophyceae. ${ }^{208 a}$

Many other substances of a carbohydrate nature, variously described as pectins, mucilages and hemicelluloses, are to be found in algae but have not as yet been adequately characterized (see refs. I06, I07, 22 I, I I 7, I69, I70).

\section{LIPIDES}

Table 7 summarizes results of fatty acid analyses of various algae. These results are in general agreement with those of less extensive analyses made on other algae representative of the same classes. ${ }^{127}, 55,157$

The $\mathrm{C}_{16}$ acid, palmitic acid, appears to be the most generally abundant of the saturated acids. In algae of all classes, unsaturated acids predominate, principally those having 16, I 8 and 20 carbon atoms. An exception to this is found in the fructifications of higher marine algae such as Alaria crassifolia, of which over 50 per cent of the fatty acids are saturated. ${ }^{279}$ Having regard to the considerable variations in the composition of the fatty acid fraction that may occur in a single species (see p. I I 8 ) it does not appear that there are any consistent differences between the fatty acids produced by algae of different classes and higher plants growing in similar habitats.

The fatty acids of Chlorella sp., Scenedesmus sp. and Nitzschia palea are present as triglycerides ${ }^{157}$ but it has been reported that freshly collected marine diatoms, e.g. $N$. closterium, may contain considerable proportions of free fatty acids, apparently irrespective of species. ${ }^{55}$ An explanation of this difference has not yet been put forward and 


\section{TABLE 7}

FATTY ACIDS, EXPRESSED AS PERCENTAGES BY WEIGHT OF TOTAL FATTY ACIDS, OF ALGAE REPRESENTATIVE OF VARIOUS CLASSES AND OF A HIGHER PLANT

Degrees of unsaturation are given in parenthesis

\begin{tabular}{|c|c|c|c|c|c|c|c|c|}
\hline \multirow{2}{*}{ Class and species } & \multicolumn{3}{|c|}{ Saturated } & \multicolumn{5}{|c|}{ Unsaturated } \\
\hline & $\mathrm{C}_{14}$ & $\mathrm{C}_{16}$ & $\mathrm{C}_{18}$ & $\mathrm{C}_{14}$ & $\mathrm{C}_{16}$ & $\mathrm{C}_{18}$ & $\mathrm{C}_{20}$ & $\mathrm{C}_{22}$ \\
\hline $\begin{array}{l}\text { CHLOROPHYCEAE } \\
\text { Chlorella pirenoidosa }{ }^{194}\end{array}$ & - & 8 & 4 & - & $\begin{array}{c}27 \\
(-4 \cdot 4 \mathrm{H})\end{array}$ & $\begin{array}{c}6 \mathrm{I} \\
(-3.4 \mathrm{H})\end{array}$ & - & 一 \\
\hline Oedogonium sp. ${ }^{179}$ & 2 & 20 & I & 一 & $\left(\begin{array}{c}32 \\
-3 \cdot \mathrm{I} H)\end{array}\right.$ & $\left(\begin{array}{c}35 \\
(-4.6 \mathrm{H})\end{array}\right.$ & 9 & I \\
\hline Cladophora sauteri ${ }^{178}$ & 12 & 10 & 2 & trace & $\left(\begin{array}{c}19 \\
-4 \cdot 7 \mathrm{H})\end{array}\right)$ & $\left(\begin{array}{c}49 \\
-3 \cdot 8 \mathrm{H})\end{array}\right.$ & $\left(\begin{array}{c}8 \\
(-\tau \cdot I H)\end{array}\right.$ & - \\
\hline Nitella opaca $a^{179}$ & 6 & 18 & 3 & $\left(\begin{array}{c}3 \\
-2 \mathrm{H}\end{array}\right)$ & $(-2 \cdot 5 \mathrm{H})$ & $\left(\begin{array}{c}23 \\
-4 \cdot 5 \mathrm{H})\end{array}\right.$ & $\left(\begin{array}{c}13 \\
5 \cdot 8 \mathrm{H})\end{array}\right.$ & - \\
\hline $\begin{array}{l}\text { BACILLARIOPHYCEAE } \\
\text { Nitzschia closterium }^{179}\end{array}$ & 8 & 17 & 2 & I & $\left(\begin{array}{c}36 \\
-3 \cdot 4 \mathrm{H})\end{array}\right.$ & $\left(\begin{array}{c}20 \\
-5 \cdot 3 \mathrm{H})\end{array}\right.$ & $\left(\begin{array}{c}16 \\
(-7 \cdot \circ \mathrm{H})\end{array}\right.$ & - \\
\hline $\begin{array}{l}\text { PHAEOPHYCEAE } \\
\text { Fucus iesiculosus } 179\end{array}$ & 9 & 7 & 2 & I & $\stackrel{5}{5}(-2 \cdot 0 \mathrm{H})$ & $\left(\begin{array}{c}63 \\
-3 \cdot 0 H)\end{array}\right.$ & $\left(\begin{array}{c}13 \\
(-7 \cdot 3 \mathrm{H})\end{array}\right.$ & 一 \\
\hline Laminaria digitata $^{179}$ & 6 & I 4 & I & 2 & $\left(\begin{array}{c}\text { I I } \\
-2 \cdot 0 \mathrm{H})\end{array}\right)$ & $\left(\begin{array}{c}42 \\
-4 \cdot 2 \mathrm{H})\end{array}\right.$ & $(-8 \cdot 1 \mathrm{H})$ & 一 \\
\hline Alaria crassifolia ${ }^{279}$ & 5 & 19 & $\circ$ & - & $\mid \begin{array}{c}4 \\
(-2 \mathrm{H}) \\
\mathrm{I} 2 \\
(-4 \mathrm{H})\end{array}$ & $\begin{array}{c}\text { I I } \\
(-4 \mathrm{H}) \\
3 \\
(-6 \mathrm{H}) \\
\text { I } 9 \\
(-8 \mathrm{H})\end{array}$ & - & 一 \\
\hline $\begin{array}{l}\text { RHODOPHYCEAE } \\
\text { Rhodymenia palmata }{ }^{179}\end{array}$ & 4 & I 9 & I & trace & $\left(\begin{array}{c}6 \\
(-2 \cdot 9 \mathrm{H})\end{array}\right.$ & $\left(\begin{array}{c}20 \\
(-4 \cdot 5 \mathrm{H})\end{array}\right.$ & $\begin{array}{c}3^{6} \\
\left(-9^{\cdot} \cdot 2 \mathrm{H}\right)\end{array}$ & 13 \\
\hline $\begin{array}{l}\text { HIGHER PLANT } \\
\text { Elodea (Anacharis) } \\
\text { canadensis } 179\end{array}$ & I & I 5 & 5 & 2 & $\left(\begin{array}{r}25 \\
(-3 \cdot 0 \mathrm{H})\end{array}\right.$ & $\left(\begin{array}{l}39 \\
-4 \cdot 9 \mathrm{H})\end{array}\right.$ & $(-\stackrel{12}{6 \cdot \circ \mathrm{H})})$ & 一 \\
\hline
\end{tabular}

there would otherwise appear to be no difference between the fats of marine and freshwater algae. ${ }^{179}$

In addition to fats, a fat solvent extract of any organism contains lesser amounts of other materials, such as photosynthetic pigments, sterols and hydrocarbons, which are unrelated chemically to the true lipides and which are generally classed as lipoids. Of these, the photosynthetic pigments have already been discussed in an earlier chapter. 
The unsaponifiable lipoid fractions of all algae appear to contain small amounts of the paraffin hydrocarbon hentriacontane, $\mathrm{C}_{31} \mathrm{H}_{64}{ }^{140,55}$ Sterols, similar to those of higher plants which are grouped under the generic name of sitosterol, have been found in the Chlorophyceae, Xanthophyceae and Rhodophyceae. ${ }^{140,53} \mathrm{~A}$ more well-defined compound, fucosterol, occurring in representatives of most algal classes but not in higher plants, is the only sterol produced by the Phaeophyceae. ${ }^{53}$ The Chlorophyceae are somewhat variable in the sterols which they contain; thus Oedogonium sp. contains only sitosterol, ${ }^{40}$ Cladophora sauteri and Nitella opaca contain both sitosterol and fucosterol; ${ }^{140}$ the principal sterol of Chlorella pyrenoidosa is ergosterol, a sterol which is otherwise known only from fungi and lichens; ${ }^{161}$ and Scenedesmus obliquus contains chondrillasterol amounting to about 23 per cent of the unsaponifiable fraction, apparently to the exclusion of other sterols. ${ }^{32}$
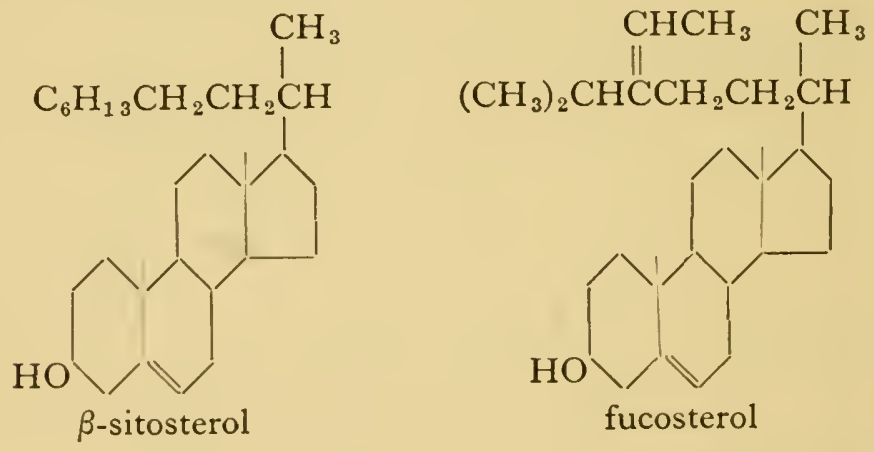

$\left(\mathrm{CH}_{3}\right)_{2} \mathrm{CHCH}\left(\mathrm{CH}_{3}\right) \mathrm{CH}: \mathrm{CHCH}\left(\mathrm{CH}_{3}\right) \quad\left(\mathrm{CH}_{3}\right)_{2} \mathrm{CHCHCH}: \mathrm{CHCH}$
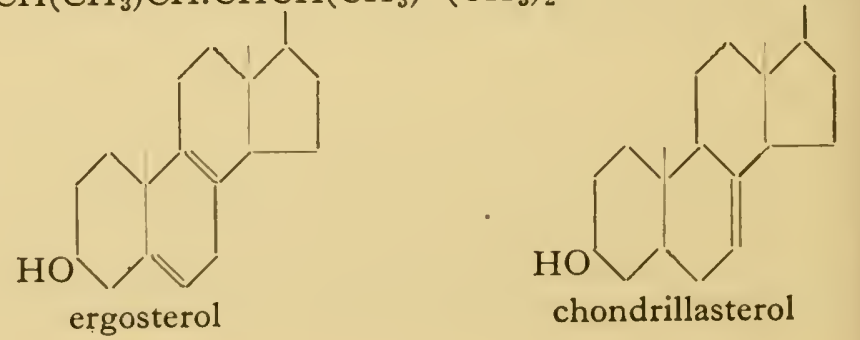

chondrillasterol 
Sterols appear to be totally lacking in the Myxophyceae. ${ }^{53}$

\section{NITROGENOUS SUBSTANCES}

Little is known of the proteins of algae and as yet only amino-acid analyses of the bulk proteins of certain species are available. $190,191,95,96,98,300$ The analytical results presented in Table 8 are not all of equal value. In Ulva, Laminaria, Chondrus, Microcystis and Phormidium, not all the protein nitrogen is accounted for and the protein fractions examined may not have been representative of the whole. It is thus possible that the amino-acids reported as absent in these algae were, in fact, present and in this

\section{TABLE 8}

THE AMINO-ACID COMPOSITIONS OF THE BULK PROTEINS OF VARIOUS ALGAE COMPARED WITH SIMILAR DATA FOR HIGHER PLANTS Amounts are given as $\mathrm{g}$. amino-acid $\mathrm{N} / \mathrm{ro0}$ g. protein $\mathrm{N}$

\begin{tabular}{|c|c|c|c|c|c|c|c|c|c|c|}
\hline & 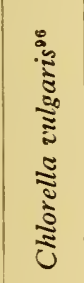 & 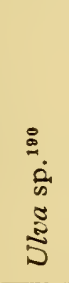 & 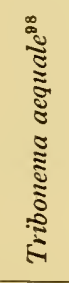 & 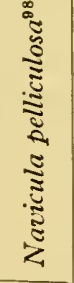 & 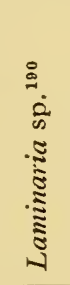 & 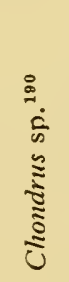 & 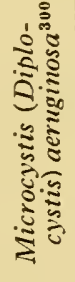 & 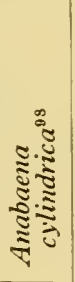 & 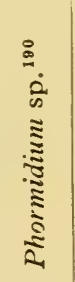 & 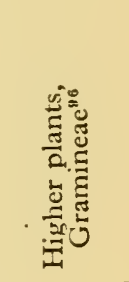 \\
\hline Aspartic acid & $6 \cdot 4$ & $4^{\circ} \mathrm{I}$ & $5 \cdot 1$ & $6 \cdot 4$ & $I \cdot 9$ & $2 \cdot 5$ & $4 \cdot 6$ & $6 \cdot 9$ & 0.9 & $4.9-5.4$ \\
\hline Glutamic acid & $7 \cdot 8$ & $7 \cdot 6$ & $4 \cdot 6$ & 4.9 & $7 \cdot 3$ & $8 \cdot 2$ & $6 \cdot 5$ & $5 \cdot 6$ & 4.4 & $6 \cdot 6-7 \cdot 8$ \\
\hline Serine & $3 \cdot 3$ & 一 & $2 \cdot 4$ & $4 \cdot 2$ & - & 一 & $3 \cdot 3$ & $2 \cdot 4$ & - & - \\
\hline $\begin{array}{l}\text { Threonine } \\
\text { Glycine }\end{array}$ & $2 \cdot 9$ & - & 4.0 & $4 \cdot 2$ & - & - & $3 \cdot 2$ & $5 \cdot 7$ & - & 3.0 \\
\hline Glycine & $6 \cdot 2$ & 0.8 & $6 \cdot 2$ & $6 \cdot 1$ & $2 \cdot 7$ & $2 \cdot I$ & $4 \cdot 9$ & $5 \cdot 5$ & $\mathrm{I} \cdot 6$ & 0.4 \\
\hline $\begin{array}{l}\text { Alanine } \\
\text { Valine }\end{array}$ & $7 \cdot 7$ & $6 \cdot 5$ & $8 \cdot 4$ & $6 \cdot 5$ & $6 \cdot 4$ & $3 \cdot 7$ & 5.4 & $6 \cdot 0$ & $5 \cdot 2$ & $4 \cdot 4-5 \cdot I$ \\
\hline $\begin{array}{l}\text { Valine } \\
\text { Leucine }\end{array}$ & $5 \cdot 5$ & $5^{2} 2$ & $7 \cdot 5$ & $7 \cdot 5$ & $5 \cdot 1$ & $2 \cdot 8$ & $4 \cdot 1$ & $7 \cdot 0$ & 6.7 & $3 \cdot 3-4 \cdot 2$ \\
\hline $\begin{array}{l}\text { Leucine } \\
\text { Isoleucine }\end{array}$ & $\begin{array}{l}6.1 \\
3.5\end{array}$ & $5^{\cdot 2}$ & $\begin{array}{l}0.4 \\
4 \cdot I\end{array}$ & $\begin{array}{l}7 \cdot 2 \\
3 \cdot 5\end{array}$ & $2 \cdot 5$ & 5.3 & $\begin{array}{l}4 \cdot 2 \\
2 \cdot 2\end{array}$ & $\begin{array}{l}0.2 \\
3.9\end{array}$ & $2 \cdot 11$ & $7 \cdot x-8 \cdot 8$ \\
\hline Phenylalanine & $2 \cdot 8$ & $2 \cdot 3$ & $2 \cdot 8$ & $3 \cdot 4$ & $x \cdot 0$ & $I \cdot 5$ & 4.4 & $2 \cdot 9$ & $I \cdot I$ & $2 \cdot 5-2 \cdot 6$ \\
\hline Tyrosine & $2 \cdot 8$ & 0.0 & $3 \cdot 0$ & $\mathrm{I} \cdot 9$ & I.9 & $2 \cdot 3$ & - & $1 \cdot 6$ & $\mathrm{I} \cdot 8$ & $2 \cdot 3-2 \cdot 5$ \\
\hline Proline & $7 \cdot 2$ & $7 \cdot 0$ & $6 \cdot 1$ & $6 \cdot 2$ & $7 \cdot 6$ & $7 \cdot 1$ & $3 \cdot 2$ & $5 \cdot 0$ & $7 \cdot 0$ & $3 \cdot r$ \\
\hline Tryptophane & $2 \cdot I$ & 0.3 & $\mathrm{I} \cdot 8$ & $I \cdot I$ & $I \cdot I$ & $I \cdot 6$ & - & $I \cdot O$ & 0.2 & $I \cdot 8-2 \cdot I$ \\
\hline Methionine & $I \cdot 4$ & 0.0 & $\mathrm{I} \cdot 4$ & $I \cdot 2$ & 0.0 & 0.0 & $I \cdot 7$ & $x \cdot 2$ & $2 \cdot 0$ & $1 \cdot 4-1 \cdot 6$ \\
\hline Cystine & 0.2 & I. 8 & - & - & $3 \cdot 4$ & $x \cdot 6$ & - & - & 0.0 & $I \cdot 3-1 \cdot 5$ \\
\hline Arginine & I $5 \cdot 8$ & $7 \cdot 5$ & 15.9 & $9 \cdot 2$ & $16 \cdot 1$ & 10.2 & - & I I 7 & $9 \cdot 2$ & $13 \cdot 7-14 \cdot 3$ \\
\hline Histidine & $3 \cdot 3$ & $I \cdot 2$ & $3 \cdot 7$ & $2 \cdot 8$ & $1 \cdot 6$ & $\mathbf{I} \cdot 8$ & - & $2 \cdot 5$ & $3 \cdot 8$ & $3 \cdot 6-3 \cdot 7$ \\
\hline Lysine & $10 \cdot 2$ & 0.0 & $9 \cdot 0$ & $8 \cdot 3$ & 0.0 & 4.0 & - & $6 \cdot 6$ & 0.0 & $6 \cdot 3-6 \cdot 6$ \\
\hline Amide $N$ & $6 \cdot I$ & - & $6 \cdot 5$ & $7 \cdot 1$ & - & - & & $8 \cdot 0$ & 一 & $4 \cdot 7-5 \cdot 3$ \\
\hline Total N & $101 \cdot 3$ & $49^{\circ} 5$ & $98 \cdot 9$ & $91 \cdot 7$ & $5^{8 \cdot 6}$ & $54 \cdot 7$ & $47 \cdot 7$ & $89 \cdot 7$ & $46 \cdot 0$ & $\left(\begin{array}{c}74^{4} 4 \\
\text { (mean) }\end{array}\right.$ \\
\hline
\end{tabular}


connexion it should be noted that lysine, methionine and tyrosine, reported as absent in Ulva, are present in Chlorella vulgaris, the other species of Chlorophyceae examined, and similarly cystine and lysine, reported as absent in Phormidium, are present in another member of the Myxophyceae. ${ }^{95}$ It thus seems most probable that there is a general similarity in amino-acid composition between the proteins of the various classes of algae and of higher plants. This similarity cannot, of course, be taken as implying that the individual proteins of these various forms are similar.

Certain amino-acids other than those mentioned in Table 8 may be characteristic of particular classes. All representatives of the Myxophyceae which have been so far examined, i.e. Anabaena cylindrica, Oscillatoria sp. and Mastigocladus laminosus, have been found to contain $\alpha$ - $\varepsilon$-diaminopimelic acid, $\mathrm{COOH} \cdot \mathrm{CH}\left(\mathrm{NH}_{2}\right) \cdot\left(\mathrm{CH}_{2}\right)_{3} \cdot \mathrm{CH}\left(\mathrm{NH}_{2}\right) \cdot \mathrm{COOH}$. This amino-acid appears to occur otherwise only in certain bacteria and has not been found in representatives of the Chlorophyceae, Xanthophyceae, Bacillariophyceae, Euglenineae, Phaeophyceae and Rhodophyceae in which it has been sought. ${ }^{309}$ The presence of diiodotyrosine has been demonstrated in Laminaria spp. Diiodotyrosine accounts for only a small proportion of the iodine to be found in these brown seaweeds, the bulk evidently being in inorganic form. ${ }^{253 a}$

Water-soluble peptides occur in certain marine species of Chlorophyceae, Phaeophyceae and Rhodophyceae, in amounts comprising up to 0.73 per cent of the dry weight of the alga. ${ }^{124}, 126,129,120,67$ It is not clear whether these substances are comparable in origin with the extracellular polypeptides produced by blue-green algae (see p. 90). They are not present in all marine algae and there is evidence that they may arise as a result of lack of balance between carbon and nitrogen metabolism. ${ }^{128}$ The composition of these peptides varies from species to species, e.g. in Corallina officinalis a pentapeptide of aspartic acid is present ${ }^{126,129}$ whereas $C$. squamata contains a peptide containing alanine and arginine. ${ }^{129}$ Only for Pelvetia fastigiata has the constitution of the peptide been established, the 
material isolated being L-pyrrolidonoyl- $\alpha$-glutaminyl-Lglutamine: ${ }^{67}$

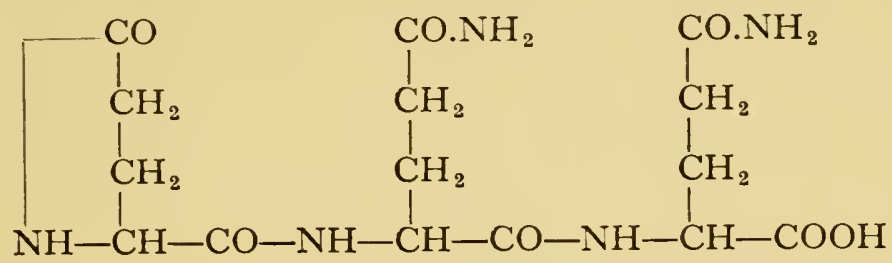

It appears possible that the pyrrolidonoyl ring may have been formed after extraction of the substance and that in the living alga there is present tri-L-glutamine. ${ }^{67}$

Other nitrogenous products of algae have received little attention. From their staining reactions it is evident that algal cells contain nucleic acids but only for Polytomella caeca, in which the proportion of ribonucleic acid to protein is as high as 6 to Io per cent in actively growing cells, ${ }^{153}$ do quantitative investigations appear to have been made. Cyanophycin, a conspicuous reserve product of the Myxophyceae, is generally stated to be proteinaceous ${ }^{107}$ but has not yet been examined in anything more than a superficial manner.

THE BIOCHEMICAL CLASSIFICATION OF THE ALGAE

Many, but not all, of the chemical components of algae are characteristic of classes rather than of individual species and the existence of biochemical peculiarities confirms to a remarkable extent the classification derived on morphological grounds. ${ }^{106,107,} 259$ The photosynthetic pigments, in particular, are of great taxonomic value, often affording the simplest and most certain means of recognizing representatives of different classes (see Table 2). The regular occurrence of its characteristic pigments in different species belonging to a given class has been confirmed in several investigations. ${ }^{53},{ }^{272}$ Although the Chlorophyceae has been found to show greater variation in pigmentation than has generally been supposed, the variation occurs between orders and closely related species contain the same pigments. ${ }^{272}$ 
Although often chemically ill-defined, polysaccharides sometimes have a characteristic appearance or staining reaction which assists in the identification of a species. In some cases the characteristics of the carbohydrate metabolism of algal classes can be defined more precisely. The Phaeophyceae and Rhodophyceae, for example, are characterized

\section{TABLE 9}

BIOCHEMICAL CHARACTERISTICS OF THE ALGAL CLASSES (see refs. 106, 107 and references in the text)

\begin{tabular}{|c|c|c|c|}
\hline Class & $\begin{array}{l}\text { Reserve } \\
\text { products }\end{array}$ & $\begin{array}{l}\text { Cell wall } \\
\text { constituents }\end{array}$ & Sterols \\
\hline Chlorophyceae & $\begin{array}{l}\text { starch } \\
\text { fat }\end{array}$ & $\begin{array}{l}\text { cellulose } \\
\text { pectin }\end{array}$ & $\begin{array}{l}\text { sitosterol } \\
\text { fucosterol } \\
\text { chondrillasterol } \\
\text { ergosterol }\end{array}$ \\
\hline Xanthophyceae & fat & $\begin{array}{l}\text { pectin } \\
\text { silica } \\
\text { cellulose } \\
\text { chitin (?) }\end{array}$ & sitosterol \\
\hline Chrysophyceae & $\begin{array}{l}\text { leucosin } \\
\text { fat }\end{array}$ & $\begin{array}{l}\text { pectin } \\
\text { silica }\end{array}$ & $\begin{array}{l}\text { fucosterol } \\
\text { unidentified } \\
\text { sterols }\end{array}$ \\
\hline $\begin{array}{l}\text { Bacillario- } \\
\text { phyceae }\end{array}$ & $\begin{array}{l}\text { fat } \\
\text { leucosin(?) }\end{array}$ & $\begin{array}{l}\text { silica } \\
\text { pectin }\end{array}$ & $\begin{array}{l}\text { fucosterol } \\
\text { unidentified } \\
\text { sterols }\end{array}$ \\
\hline Cryptophyceas & starch & cellulose(?) & - \\
\hline Dinophyceae & $\begin{array}{l}\text { starch } \\
\text { fat }\end{array}$ & $\begin{array}{l}\text { cellulose } \\
\text { pectin }\end{array}$ & - \\
\hline Euglenineae & paramylum & none & - \\
\hline Phaeophy & $\begin{array}{l}\text { mannitol } \\
\text { laminarin }\end{array}$ & $\begin{array}{l}\text { algin } \\
\text { fucoidin } \\
\text { cellulose }\end{array}$ & fucosterol \\
\hline Rhodophyceae & $\begin{array}{l}\text { floridoside } \\
\text { mannoglycerate } \\
\text { floridean } \\
\quad \text { starch }\end{array}$ & $\begin{array}{l}\text { polygalactose- } \\
\text { sulphate esters } \\
\text { cellulose }\end{array}$ & $\begin{array}{l}\text { fucosterol } \\
\text { sitosterol } \\
\text { unidentified } \\
\text { sterols }\end{array}$ \\
\hline Myxophyceae & $\begin{array}{l}\text { myxophycean } \\
\text { starch } \\
\text { cyanophycin }\end{array}$ & $\begin{array}{l}\text { pectin } \\
\text { cellulose }\end{array}$ & none \\
\hline Higher plants & $\begin{array}{l}\text { starch } \\
\text { fat }\end{array}$ & $\begin{array}{l}\text { cellulose } \\
\text { pectin } \\
\text { lignin }\end{array}$ & $\begin{array}{l}\text { sitosterol } \\
\text { chondrillasterol } \\
\text { stigmasterol }\end{array}$ \\
\hline
\end{tabular}


by, (I) a tendency to form $I: 3$ linkages between monosaccharide residues rather than $I: 4$ linkages such as are found in other algal groups and higher plants and animals; this is apparent in laminarin, floridean starch, agar and carragheenin; and (2) a tendency to form polysaccharide sulphate esters as in fucoidin, agar and carragheenin. In view of differences in morphology and in other chemical products, this correspondence between the two classes cannot be taken as evidence of phylogenetic affinity and perhaps only reflects the similarity of the environments in which the two types have evolved. Other noteworthy peculiarities of the carbohydrate metabolism of these two groups are the formation of a reserve polyglucose with $\beta$-linkages in the Phaeophyceae and the presence of an $\alpha$-glycoside, floridoside, in the Rhodophyceae. Lack of ability to synthesize certain carbohydrates is characteristic of some classes. For example, starch evidently does not occur in the Xanthophyceae, Chrysophyceae or Bacillariophyceae, and the same three classes have a general tendency to store fats as reserve materials rather than polysaccharides.

These and other biochemical characteristics are summarized in Table 9. It will be seen from this table and that giving the characteristic pigments of the algal classes (Table 2) that there are resemblances between certain of the classes. These biochemical similarities, together with morphological evidence, indicate an affinity between the Xanthophyceae, Chrysophyceae and Bacillariophyceae, which are consequently grouped together as the Chrysophyta, and between the Dinophyceae and Cryptophyceae, which are grouped together as the Pyrrophyta. ${ }^{259}$ 


\section{GROWTH AND METABOLISM}

Metabolism and growth are interdependent. It has already been noted that ability to assimilate a particular substrate may depend on the previous history of an alga, but the clearest examples of this interdependence are to be found in the relation which exists between the physiological condition of the organism and the products of its metabolism and it is with this relationship that this chapter must be chiefly concerned.

An alga varies in chemical composition, most notably in its content of major fractions such as protein, fat and carbohydrate, according to the stage of growth which it has reached and to the conditions under which growth has taken place. Growth and multiplication in any organism are contingent upon the development of particular structures which in turn depends on particular chemical conditions which are likely to be more circumscribed the more complex the structures involved. The greatest variation in chemical composition is accordingly found in the simplest organisms. In the fungi and bacteria this variation is less evident than it otherwise might be because products of metabolism which are not required for protoplasmic synthesis may be liberated into the surrounding medium. In algae, in which excretion appears generally to be reduced to a minimum, changes in intracellular and extracellular conditions are reflected to a greater extent in the composition of the cell material. In Chlorella, for example, growth of which is possible under a wide range of conditions, the chemical composition of the cells may vary to an extreme extent (see Table I I). In the structurally more complex algae the range within which variation of this sort is possible is reduced as requirements for growth and reproduction become more exacting. The cases of simple and structurally complex algae are for I06 
this and other reasons most conveniently considered separately.

\section{GROWTH AND METABOLISM IN SIMPLE ALGAE}

Many studies have been made of the growth of simple algae in laboratory culture (e.g. ${ }^{250}, 225,88,254,302,148$ ) and it is possible to give a generalized picture of the growth cycle under these conditions. Following inoculation of an appropriate medium with the alga and its exposure to suitable conditions of light and temperature, growth in cell numbers may begin immediately, as is generally the case in Chlorella spp. and other Chlorophyceae, ${ }^{250,} 225$ or after a lag period, as in Anabaena cylindrica ${ }^{88}$ Growth is usually exponential in the first few days, the cell numbers per unit volume of medium $\left(n_{t}\right)$ at any time $(t)$ being given by the expression:

$$
n_{t}=n_{0} e^{r t} .
$$

where $n_{0}$ is the number of cells per unit volume of medium at zero time, $e$ the base of natural logarithms, and $r$ the relative growth constant. This expression may be converted to the form:

$$
\log n_{t}=\log n_{0}+r t \text {. }
$$

and the accuracy with which it represents experimental results may be demonstrated by the closeness of fit of the points to a straight line when $\log n_{t}$ is plotted against $t$. Following the exponential phase is a period in which the relative growth constant declines continuously and finally a stationary phase is reached in which there is no further increase in cell numbers (Fig. 15). When other measures of growth, such as bulk or dry weight of alga per unit volume of medium, are used, the pictures obtained are generally similar to that just described but differ in detail since cell volume and relative dry weight are not constant throughout the growth cycle (Figs. 12 and I5).

Algae growing under natural conditions show phases of growth similar to that observed in culture, for example the growth of phytoplankton populations during the spring 'outburst' in lakes generally follows a nearly exponential 


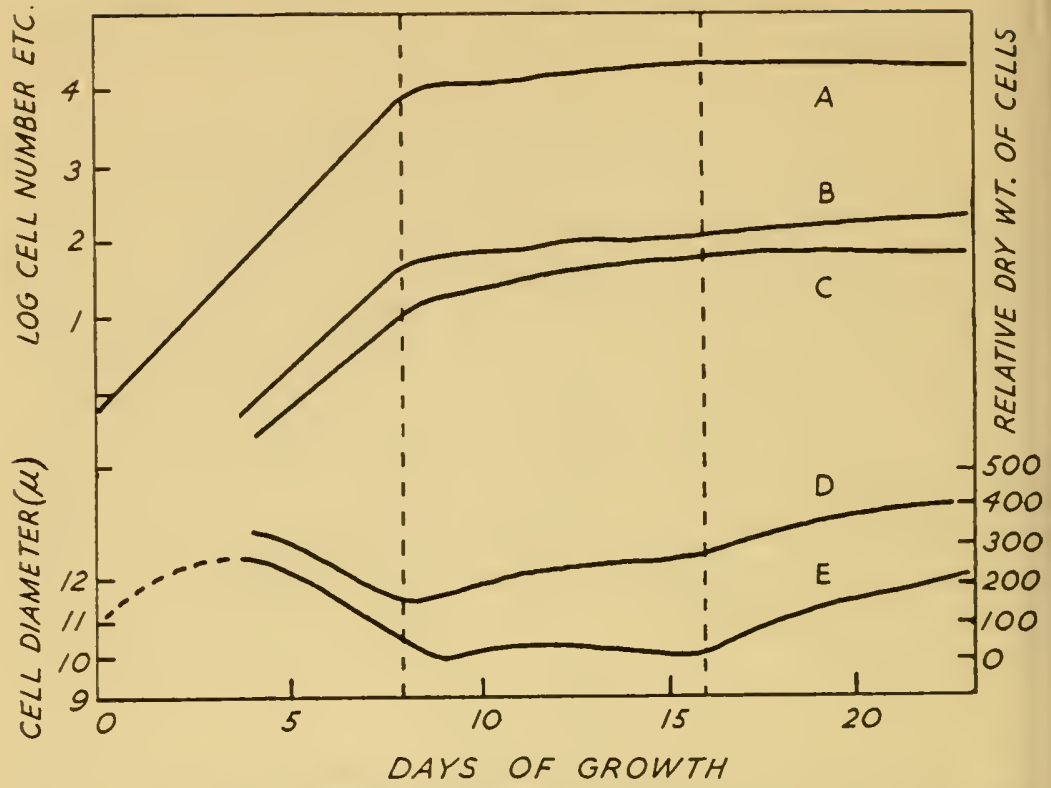

FIG. 15. Growth of Chlorella vulgaris in culture. A, log. cell number per mm. ${ }^{3}$ of medium; B, log. volume of cells $\left(\mathrm{mm} .^{3}\right)$ in $10 \mathrm{ml}$. of medium; C, log. dry weight of cells as $\mathrm{mg}$. per $10 \mathrm{ml}$. of medium; D, relative dry weight as $\mathrm{mg}$. per $10^{9}$ cells; $\mathrm{E}$, mean cell diameter in $\mu$ (after ref. 225).

course, ${ }^{224}$ but growth rates may alter in response to changes in conditions other than those occurring as a result of growth of the algae themselves. ${ }^{181}$

A general feature of the growth of microscopic algae which requires comment is that its rate is generally less than that of the growth of non-photosynthetic microorganisms. For example, even after allowing for the effects of differences in optimum temperatures, the maximum relative growth rate recorded for Chlorella pyrenoidosa, one of the most rapidly growing algae used in experimental studies, is less than one half as great as that of a yeast or a bacterium of the same order of size. ${ }^{200}$ It is evidently not carbon assimilation which thus limits the growth rate of an alga. ${ }^{200}$ The explanation may perhaps lie in the fact that the photosynthetic apparatus of an alga, which, as simple microscopical examination shows, represents a considerable 
proportion of the protoplast, contains a high proportion of materials such as pigments and other lipoids, which are inert in so far as they are directly concerned in growth. The relative growth rate of $C$. pyrenoidosa, for example, depends on the protein content of the cells, not upon lipoid. ${ }^{1 a}$ Thus, whereas under optimum conditions the substances assimilated by a non-photosynthetic cell are largely used for the synthesis of more material capable of growth (i.e. 'autosynthetic', see ref. I45), a large part of the synthetic capacity of an alga is diverted to the production of the non-growing material of the chromatophore and it may be because of this that the alga has the lower rate of growth under otherwise comparable circumstances. However, were the situation as simple as this, it would be expected that colourless algae would show higher growth rates than the pigmented species from which they are derived but this does not appear to be so.

The chemical kinetics underlying the growth sequence in simple algae are presumably similar to those which have been postulated to occur in bacteria. ${ }^{145}$ In material which is not actively growing, enzymes may have denatured and the concentrations of essential metabolites may have fallen, so that a period of reconstitution is necessary before exponential growth can begin. In agreement with this view it has been found that in Anabaena cylindrica a marked increase in the amount of nitrogenous substances per unit volume of algal material occurs during the lag and that the length of this phase increases with the age of the inoculum. ${ }^{88}$ The duration of the lag in A. cylindrica is dependent upon light intensity, being longer the higher the intensity. ${ }^{90} \mathrm{It}$ is possible that the establishment of the level of concentration of nitrogenous constituents necessary for exponential growth is directly retarded as carbon assimilation becomes more intense but other explanations of this phenomenon are possible, e.g. photo-oxidation of some essential metabolite may occur at higher light intensities. Cases in which exponential growth of algae evidently awaits the development of enzymes adapted to particular substrates have already been mentioned (p. 56). 
It would appear that during exponential growth the different enzyme systems concerned must increase at equal rates. ${ }^{145}$ This does not necessarily mean that the chemical composition of an alga should remain the same as long as the relative growth factor remains constant. In fact, the chemical composition of Chlorella vulgaris may vary during exponential growth ${ }^{225}$ and during exponential growth of Anabaena cylindrica the nitrogen content per unit volume of cell material falls considerably. ${ }^{88}$ Such variation may be partly due to changes in amount of substances not directly concerned in growth, particularly reserve products and cell wall constituents. The variations both in the total amount and in the relative proportions of various fractions of ribonucleic acid which have been found to occur during exponential growth of Polytomella caeca are less easily explained, particularly since it has been reported that in yeast there is a linear relationship between relative growth rate and ribonucleic acid content. ${ }^{153}$ However, when exponential growth is continued for long periods then a constant chemical composition of cell material is approached. In an apparatus in which a constant cell population per unit volume of medium is maintained indefinitely in exponential growth by continuous automatic dilution with fresh medium, cells are produced having nearly constant chemical and physiological characteristics. ${ }^{201,} 202$ The type of algal cell characteristic of exponential growth that has continued for some time is small, with thin cell walls and little reserve material, and having vacuoles in the protoplast either absent or inconspicuous and the chromatophores relatively undeveloped. Such cells have a high nitrogen content and it is evident that their metabolism is chiefly directed to protein and protoplasmic synthesis. ${ }^{225}$ Chlorella pyrenoidosa in this state growing under a set of conditions in which light intensity was limiting has been found to have the following elementary composition: $\mathrm{C} 53 \cdot 0$ per cent, $\mathrm{H} 7 \cdot 5$ per cent, $\mathrm{O} 28 \cdot 5$ per cent, $N$ ro. 8 per cent; ${ }^{199}$ this corresponds to a protein content of about 67.5 per cent of the dry organic matter of the cells. From this analysis, a 'formula' for Chlorella may be obtained and, since extracellular organic products are negli- 
gible, an over-all equation for the metabolism at this stage can be written as follows:

$$
\begin{aligned}
& \mathrm{I} \cdot 0 \mathrm{NH}_{4}++5 \cdot 7 \mathrm{CO}_{2}+3 \cdot{ }_{4} \mathrm{H}_{2} \mathrm{O} \rightarrow \\
& \mathrm{C}_{5.7} \mathrm{H}_{9 \cdot 8} \mathrm{O}_{2 \cdot 3} \mathrm{~N}_{1 \cdot 0}+6 \cdot 2 \mathrm{O}_{2}+\mathrm{I} \cdot 0 \mathrm{H}^{+}
\end{aligned}
$$

The value of the photosynthetic quotient required by this equation, i.e. $\mathrm{I} \cdot \mathrm{IO}$, is in good agreement with that observed, i.e. I·06.199 The relative growth rate and composition of cells in exponential growth alter, of course, according to the conditions of culture, e.g. increase in light intensity produces an increase in the proportion of protein. ${ }^{197,} 1 a$

Cells of the type just described show characteristic changes in metabolism when subjected to conditions other than those under which growth was taking place. ${ }^{200}$ Chlorella pyrenoidosa cells starved of carbohydrate by aerobic incubation in a complete inorganic nutrient medium in the dark lose all detectable starch in the course of about ten hours and corresponding with this the rate of respiration falls and approaches a constant value. The respiratory quotient characteristic of such starved cells indicates that carbohydrate rather than protein or fat forms the substrate for respiration. The rate of photosynthesis in starved cells is only about 20 per cent less under conditions of light and carbon dioxide saturation than it is under similar conditions in normal cells. ${ }^{64}$ It is algae in this starved condition that have usually been used in studies on oxidative assimilation and further information regarding their reactions may be found under this heading in Chapter III. Cells starved of carbohydrate are incapable of assimilating nitrate or ammonium nitrogen (see pp. 72 and 76 ) and on return to conditions permitting growth only show nitrogen assimilation after a period of photosynthesis which presumably restores the original carbon/nitrogen balance. ${ }^{202}$

Nitrogen-deficient cells of Chlorella may be produced by exposure to intensities of light saturating photosynthesis or, more effectively, by transference to a medium containing no source of nitrogen. Such cells, although showing a reduced capacity for photosynthesis ${ }^{\mathbf{1 4 4}}$ continue to increase in dry weight if exposed to light and come to have a low 
nitrogen content. ${ }^{159}$ On return to a medium suitable for growth nitrogen-starved cells show an unusually high rate of nitrogen assimilation $159,202,232,275$ a phenomenon that has already been discussed in Chapter IV.

Cells of various species of Chlorella and Scenedesmus have been found to show abnormally high respiratory quotients, i.e. $\Delta \mathrm{CO}_{2} /-\Delta \mathrm{O}_{2}=\mathrm{I} \cdot 2$ to $2 \cdot 0$, when transferred from a medium containing glucose and an ample nitrogen supply, in which they were growing, to one deficient in available nitrogen. ${ }^{108}$ There is no evidence that these high values result from the oxidation of organic acids but they may be the result of the formation of more reduced products, such as fats, from stored carbohydrate. This behaviour is evidently similar to that of diatoms such as Pinnularia spp., which accumulate conspicuous amounts of fat in the course of 48 hours following transference from a natural environment to glucose or sucrose solutions. ${ }^{146}$

Determinations of photosynthetic quotient have generally been made with material transferred from growing cultures to conditions of higher light intensity and the values available in the literature give some indication of the direction of metabolism in nitrogen-starved cells as well as providing evidence that algae of different classes show similar metabolic behaviour under these conditions. The values given in Table 10 are all close to unity, indicating that a

\section{TABLE 10}

PHOTOSYNTHETIC QUOTIENTS $\left(Q_{p}=\Delta \mathrm{O}_{2} /-\Delta \mathrm{CO}_{2}\right)$, WITH THEIR STANDARD DEVIATIONS, OF VARIOUS ALGAE EXPOSED TO HIGH LIGHT INTENSITIES

Class

Species

Chlorophyceae . . . Chlorella sp. ${ }^{163}$

C. pyrenoidosa ${ }^{199}$

Hormidium flaccidum ${ }^{219}$

Bacillariophyceae . . Nitzschia closterium $^{20}$

N. palea 20

Euglenineae

Euglena gracilis var. bacillaris ${ }^{65}$

Dinophyceae. . . . Peridinium sp. ${ }^{21}$

Rhodophyceae : . Gelidium cartilagineum $^{284}$

Myxophyceae

- Synechococcus sp. ${ }^{104 a}$

$$
\begin{aligned}
& \quad Q_{P} \\
& I \cdot 09 \pm 0.008 \\
& I \cdot 09 \pm 0.05 \\
& I \cdot 0 I \pm 0.034 \\
& I \cdot 04 \pm 0.03 \\
& I \cdot 03 \pm 0.03 \\
& I .085 \\
& I .03 \pm 0.01 \\
& 0.95 \pm 0.049 \\
& I .08 \pm 0.03
\end{aligned}
$$


carbohydrate or similar compound is the principal product of metabolism. A photosynthetic quotient corresponding to the production of fat only, e.g. $Q_{P}$ for the formation of glycerol tripalmitate $=\mathrm{I} \cdot 42$, has apparently never been observed in this type of experiment, ${ }^{232}$ but the tendency for the observed values to exceed unity suggests that a small proportion of fat or protein is normally produced. Only one of the values given in Table Io, that for Chlorella sp., differs by a statistically significant amount from the mean value, $\mathrm{I} \cdot 045$, of all those given and it is clear that this deviation is not one characteristic of the Chlorophyceae generally. Table Io shows that representatives of classes having quite different storage products (see Table 9) nevertheless form photosynthetic products of similar composition when exposed to similar conditions. This provides further evidence for the view that the mechanism of photosynthesis is fundamentally the same in all types of algae.

Nitzschia and Chlorella spp. when deprived of phosphate show a pattern of behaviour similar to that characteristic of nitrogen deficiency. Carbon assimilation continues in phosphorus-deficient cells and on return to a complete medium there is an enhanced rate of phosphorus uptake. ${ }^{159}$ Phosphorus-deficient cells of Polytomella caeca have been found to show accelerated protein synthesis immediately following addition of excess of phosphate to the culture. This is accompanied by a decrease in ribonucleic acid content but subsequently there is an increase in ribonucleic acid content the rate of which far exceeds that of protein synthesis. ${ }^{154}$ These effects are perhaps to be interpreted as the result of inorganic phosphate being immediately available for the energy transfer mechanisms of protein synthesis whereas its incorporation into nucleotides is a slower process.

In cultures made in a limited volume of medium exponential growth of algae sooner or later ceases. The factors bringing this about are various, the following being the more important: (I) Exhaustion of a nutrient substance from the medium; culture media generally contain all essential nutrient substances in quantities sufficient for luxuriant growth 
but trace elements such as iron may be precipitated in an unavailable form in alkaline media and frequently it is shortage of this element which brings the growth of algae in culture to a standstill. If precautions are taken to maintain trace elements in an available form by means of complexforming agents, much higher population densities may be achieved in culture. ${ }^{204}$ In species with unrecognized requirements for trace elements or organic growth factors growth may cease after a short time as the traces of the particular substance concerned introduced with the inoculum or by contamination become exhausted. (2) Preferential absorption of a particular ion may result in the reaction of the medium becoming inimical to growth. Effects of this sort produced by ammonium nitrogen have already been mentioned, another example is that of Chilomonas, which by absorption of weak organic acids without equivalent intake of cations causes the medium in which it is placed to become too alkaline to support growth. ${ }^{147}$ (3) Accumulation of growth inhibiting products of metabolism; autoinhibition of growth by metabolic products accumulating in the medium has been demonstrated for Nostoc punctiforme, ${ }^{132}$ a strain of Chlorella vulgaris ${ }^{234}$ and Nitzschia palea. ${ }^{68}$ The autoinhibitor of Chlorella, 'chlorellin', may be a product of the photo-oxidation of fatty acids but rigorous proof of this is lacking. ${ }^{265}$ Those of Nostoc and Nitzschia do not appear to have been studied in detail. (4) The increasing density of the culture may reduce the penetration of light into the bulk of the medium so that photosynthesis becomes insufficient to maintain exponential growth.

In natural environments interactions between different species almost invariably occur and it is rarely possible to ascribe the cessation of growth of a particular alga to the operation of any single physico-chemical factor. However, in an example which has been examined with particular thoroughness, that of Asterionella formosa - in the English lakes, it appears that it is depletion of silica in the water which usually limits growth in the spring. ${ }^{182}$

When exponential growth ceases the course of metabolism of an alga alters considerably. An example which may be 
conveniently taken first is that of Chlorella vulgaris growing under conditions in which neither carbon nor nitrogen assimilation is limited. ${ }^{225}$ The changes occurring in the amounts of various components in cultures of this alga are shown in Fig. I6. At the end of the exponential phase (8

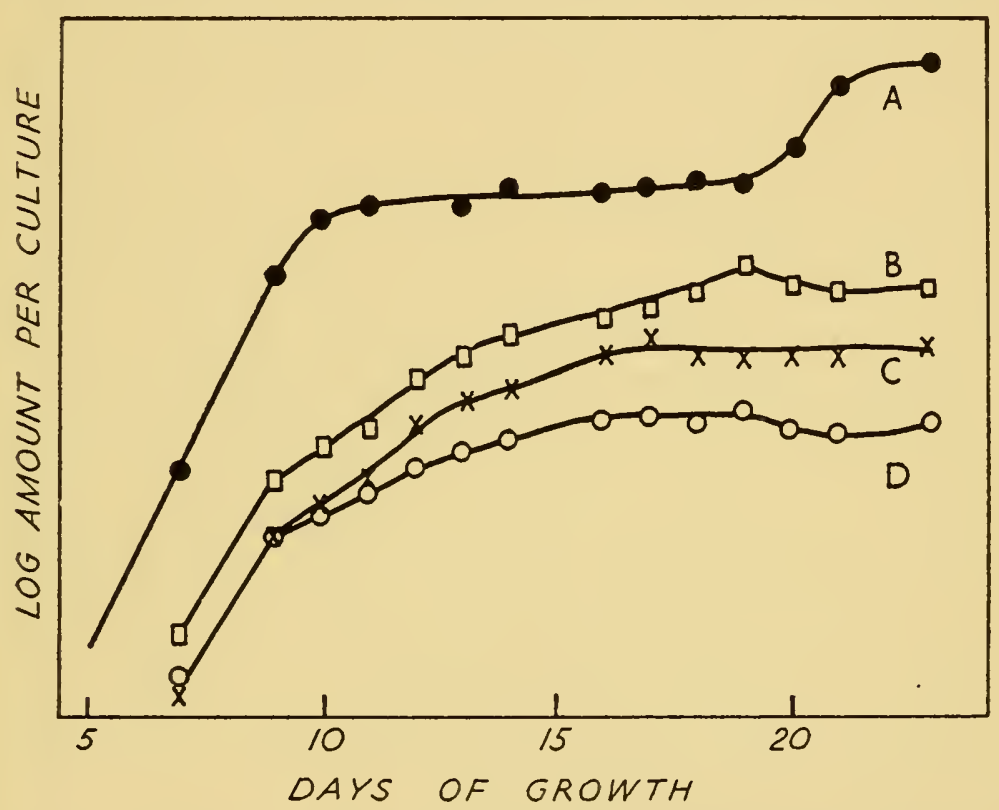

FIG. I6. Amounts per culture of different components of Chlorella vulgaris, plotted logarithmically and adjusted as to level for comparative purposes. $\mathrm{A}$, disaccharide; $\mathrm{B}$, starch; $\mathrm{C}$, insoluble carbohydrate; D, protein (after ref. 225).

days) the relative rates of accumulation of both protein and carbohydrate decline but the former decreases more than the latter. Later, when the stationary phase is reached (I6 days), protein synthesis ceases altogether but starch continues to be accumulated. As a result, cells harvested in the stationary phase are of different chemical composition to those taken at the end of the exponential phase, e.g. at 20 days $15 \cdot 3$ per cent of the dry matter is protein and $2 I^{\circ} 5$ per cent is starch as compared with $24^{\circ} 4$ per cent of protein and 15.5 per cent of starch at 7 days. Corresponding with 
this, the microscopical appearance of the cells changes, the characteristic form at the beginning of the stationary phase being large, with vacuolated protoplasm, extensive dark green chromatophore, and thick walls. The composition as well as the total amounts of the major chemical fractions may show changes. Thus the end of the exponential phase is marked by a replacement of hexose by disaccharide in the soluble carbohydrate fraction and in senescent cultures there is a tendency towards hydrolysis of starch with a corresponding increase in disaccharide (see Fig. I6). The composition of the protein of $C$. vulgaris growing under the same conditions does not change to any great extent after the cessation of exponential growth; the most marked effect being an increase in histidine content as cultures age. ${ }^{97}$

Similar changes have been observed in other algae. In Chlorella pyrenoidosa, growing in a purely mineral medium which in the later stages of growth became nitrogen deficient, the protein content has been observed to fall from over 60 per cent of the dry weight in the exponential phase to less than ro per cent in the post-exponential phase. ${ }^{1 a}$ In another organism, Polytomella caeca, exponential increase in ribonucleic acid continues for a while after the cessation of exponential increase in protein with the result that cells at the beginning of the stationary phase have a high ribonucleic acid content. ${ }^{153}$

The accumulation of lipide in algae which have ceased active growth has been noted frequently. Beijerinck first showed by qualitative methods that deficiency of nitrogen is the principal factor promoting fat accumulation in diatoms ${ }^{28}$ but detailed quantitative information is so far available only for Chlorella pyrenoidosa. ${ }^{264}, 306,1 a$ The lipide content of this alga can be varied experimentally by changes in any one of several environmental conditions, but the extent of the variation is limited primarily by the concentration of available nitrogen in the medium. The effect of the initial concentration in the medium of ammonium nitrogen on the lipide content of $C$. pyrenoidosa is shown in Fig. I7; only if this concentration becomes reduced below $0.00 \mathrm{I} \mathrm{M}$ in the course of growth is lipide accumulation considerable. 
Somewhat more lipide is accumulated if ammonium rather than nitrate nitrogen is supplied and high light intensities and low concentrations of free oxygen also favour fat formation. Other factors, e.g. phosphate concentration, temperature and carbon dioxide supply, are without great

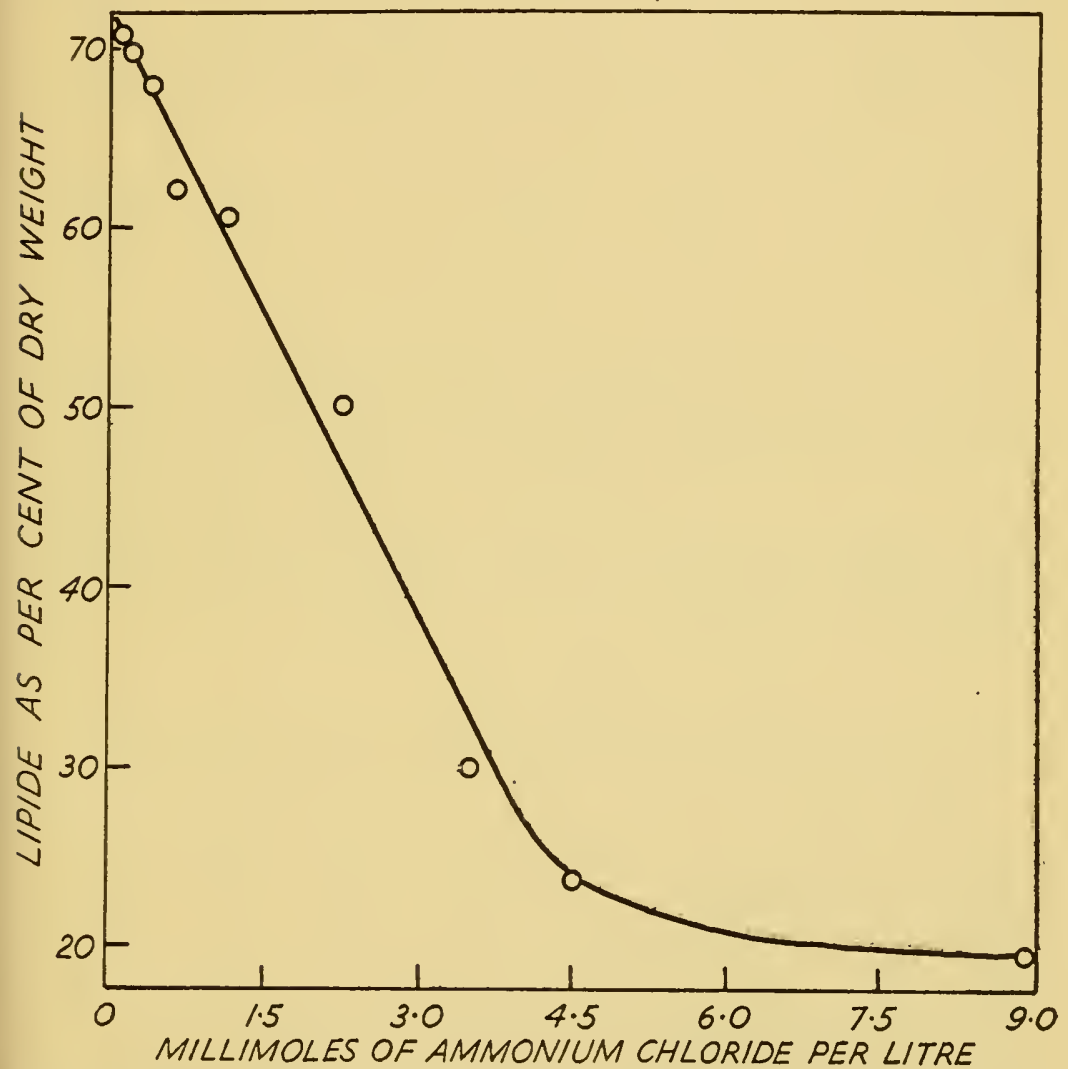

FIG. I7. Effect of the initial nitrogen concentration in the culture medium on the lipide content of Chlorella pyrenoidosa (after ref. 264).

effect. ${ }^{264}$ Extremely high proportions of lipide are stored in cells subjected to prolonged incubation under conditions of nitrogen deficiency, as is shown in Table II, but such cells are not degenerate and will resume growth if transferred to a suitable medium. ${ }^{307}$ 
TABLE 11

COMPOSITION OF Chlorella pyrenoidosa GROWN UNDER DIFFERENT CONDITIONS

(data from ref. 264)

\begin{tabular}{|c|c|c|c|c|}
\hline \multirow{2}{*}{$\begin{array}{l}\text { Initial conc. } \\
\text { of } N^{\top} \text { available } \\
\text { in medium }\end{array}$} & \multirow{2}{*}{$\begin{array}{c}\text { Age in } \\
\text { days }\end{array}$} & \multicolumn{3}{|c|}{$\%$ of dry weight } \\
\hline & & Protein & Carbohydrate & Lipide \\
\hline- & 17 & $5^{8}$ & 37 & 5 \\
\hline $0.0250 \mathrm{M}$ & 15 & 50 & 32 & 18 \\
\hline $0.00225 \mathrm{M}$ & 15 & 26 & 25 & 49 \\
\hline $0.00308 \mathrm{M}$ & 63 & 9 & 6 & 85 \\
\hline
\end{tabular}

The proportion which fatty acids form of the total lipide increases as the lipide content of $C$. pyrenoidosa increases and there is a corresponding decrease in the proportion of unsaponifiable material (Table 12). Chlorophyll degradation products account for about half the water-soluble saponification products from the samples with the lower

\section{TABLE 12}

ANALYSIS OF LIPIDE FRACTIONS OF SAMIPLES OF Chlorella pyrenoidosa OF DIFFERENT TOTAL LIPIDE CONTENTS ${ }^{194}$

Lipide as \% of dry wt.

Fatty acids as \% of lipide

Unsaponifiable material as \% of lipide

Water-soluble saponification products as $\%$ of lipide

\begin{tabular}{r|r|r|r}
\hline 23.4 & 33.2 & 63.0 & 75.5 \\
28.0 & 49.5 & 83.0 & 86.8 \\
12.0 & 7.7 & 3.3 & 3.3 \\
60.0 & 42.8 & 13.7 & 9.9
\end{tabular}

total lipide contents but the chlorophyll content of Chlorella decreases rapidly as the lipide content increases. As the lipide content of Chlorella increases there is a decrease in the degree of unsaturation of the fatty acids. ${ }^{191}$

The conclusion based upon microscopical examination that fat accumulation is characteristic of certain classes of algae is borne out by the little quantitative information that 
is available. High lipide contents have been recorded for representatives of the Xanthophyceae ${ }^{94}$ and the Bacillariophyceae ${ }^{134}$ whereas the Phaeophyceae, ${ }^{255}, 279,187$ Rhodophyceae $^{187}$ and Myxophyceae ${ }^{94}$ rarely have a total lipide content of more than 5 per cent. In view of the results obtained with Chlorella pyrenoidosa and since various species of Chlorophyceae and a diatom have been found to contain approximately equal amounts of lipide after growth under similar conditions, ${ }^{160}$ it has been suggested that the accumulation of lipide which is regarded as characteristic of classes such as the Bacillariophyceae is dependent more on the environmental conditions under which such species habitually grow than on genetically determined peculiarities of metabolism. ${ }^{200}$ That inherent differences in capacity to accumulate lipide do, nevertheless, exist among the algae is shown by the fact that certain Myxophyceae do not accumulate lipide even under conditions of nitrogen deficiency. ${ }^{94}$

The general explanation of the phenomena just described lies in the fact that carbon assimilation may continue in an alga after cell division has been brought to a standstill. This much was pointed out by Beijerinck in $1904^{28}$ but it is now possible to put forward more detailed evidence in support of this idea and to suggest mechanisms for some of the observed effects.

Many of the factors acting to bring about the cessation of exponential growth are without direct effects on photosynthesis or on the chemotrophic assimilation of carbon. Thus, synthesis of fresh protoplasm cannot occur in the absence of a sufficient supply of nitrogen whereas chemotrophic assimilation of carbon can continue under these conditions. Photosynthesis is reduced but not totally inhibited by nitrogen deficiency. ${ }^{144,159,} 232$ Similarly deficiency of most other nutrient substances except carbon dioxide or the organic carbon source affects protoplasmic synthesis more directly than carbon assimilation. Photosynthesis has been found not to be directly affected by changes in reaction within widely separated limits, ${ }^{76}, 213,52$ whereas the growth of many algae can only take place within 
a more restricted range of hydrogen ion concentration (e.g. ${ }^{11,}{ }^{21}$ ). The autoinhibitor produced by Nitzschia palea appears specifically to block mitosis without affecting assimilation. ${ }^{68}$ This does not mean that the capacity to assimilate carbon does not decrease as cultures age. A continuous increase in the minimum quantum requirement has, in fact, been shown to occur as cultures of Chlorella age $^{163}$ and the maximum rate of photosynthesis of which Chlorella cells, taken in the stationary phase, are capable has been found to be from a quarter to less than one-tenth of that which cells in exponential growth can achieve. ${ }^{144,303}$ A water-soluble substance inhibiting photosynthesis, which may perhaps be the agent bringing about this decrease in efficiency, has been extracted from cells from old cultures of Chlorella. ${ }^{233}$ Nevertheless, the results of many different workers (e.g. ${ }^{225}, 68,303,264$ ) show that photosynthesis and chemotrophic assimilation of carbon continues in cultures in which all cell-division has ceased.

It has already been emphasized that assimilated carbon enters directly into a system of intermediates common to the major metabolic cycles and that therefore it may be used directly for the synthesis of carbohydrate, lipide or protein. When cell-division is no longer possible, carbon which would otherwise be used for the synthesis of protoplasmic constituents will flow along other channels and accumulate as reserve products. In cells in which growth has ceased as a result of deficiency of nitrogen, the reserve materials formed will necessarily be carbohydrate or lipide rather than protein and, in general, protein synthesis appears to be more sensitive to adverse conditions than synthesis of lipide or carbohydrate.

It may be supposed in the first instance that in those forms which characteristically store lipide, lipide-synthesizing enzymes are more effective in competing for the primary products of photosynthesis than are those which synthesize carbohydrate. Nevertheless, there is the contradictory fact, already commented upon (p. II 3 ), that the photosynthetic quotient under conditions of relative nitrogen deficiency of algae of this type, e.g. diatoms, 
corresponds to the formation of carbohydrates as the principal photosynthetic products. Because of this it has been supposed that lipide formation does not take place directly from the primary products of photosynthesis ${ }^{20}$ but, as we have already seen (p. 44), this does not appear to be so. Measurements of photosynthetic quotients appear never to have been made using material known with certainty to be capable of accumulating lipide in quantity and it seems likely that the explanation of the apparently discrepant values is that diatoms transferred from growing cultures to a medium deficient in nitrogen are not in a condition for the immediate rapid synthesis of lipide. It is to be expected that in a growing organism the enzymic equipment will be adapted to produce protoplasmic constituents and that this system, if transferred to conditions under which growth cannot take place, will not immediately be reorganized and will meanwhile produce such temporary reserve products as can be synthesized with the enzymes available. This supposition is not necessarily inconsistent with the idea that the high respiratory quotient of growing cells tranşferred to nitrogen deficient conditions indicates fat formation (p. I I2). Fat formation might proceed at the same rate in photosynthesizing cells but at high light intensities its effect on the photosynthetic quotient would be slight. On prolonged incubation under nitrogen deficient conditions or when the transition to conditions under which growth cannot occur is less abrupt, as during the ageing of a culture, there is opportunity for the enzymic equipment to be reorganized for the production of high proportions of lipide from excess primary products of photosynthesis.

This hypothesis receives support from the finding that different nitrogen fractions, including enzymes, in microorganisms are affected to different extents by nitrogenstarvation $^{287}$ and from determinations of the relationship between the lipide and total nitrogen contents of various algae. ${ }^{94}$ In Fig. I 8 the fatty acid contents of six species have been expressed as a percentage of the total content of reserve material (taken as dry material other than protein) and plotted as a function of nitrogen content. From this it 


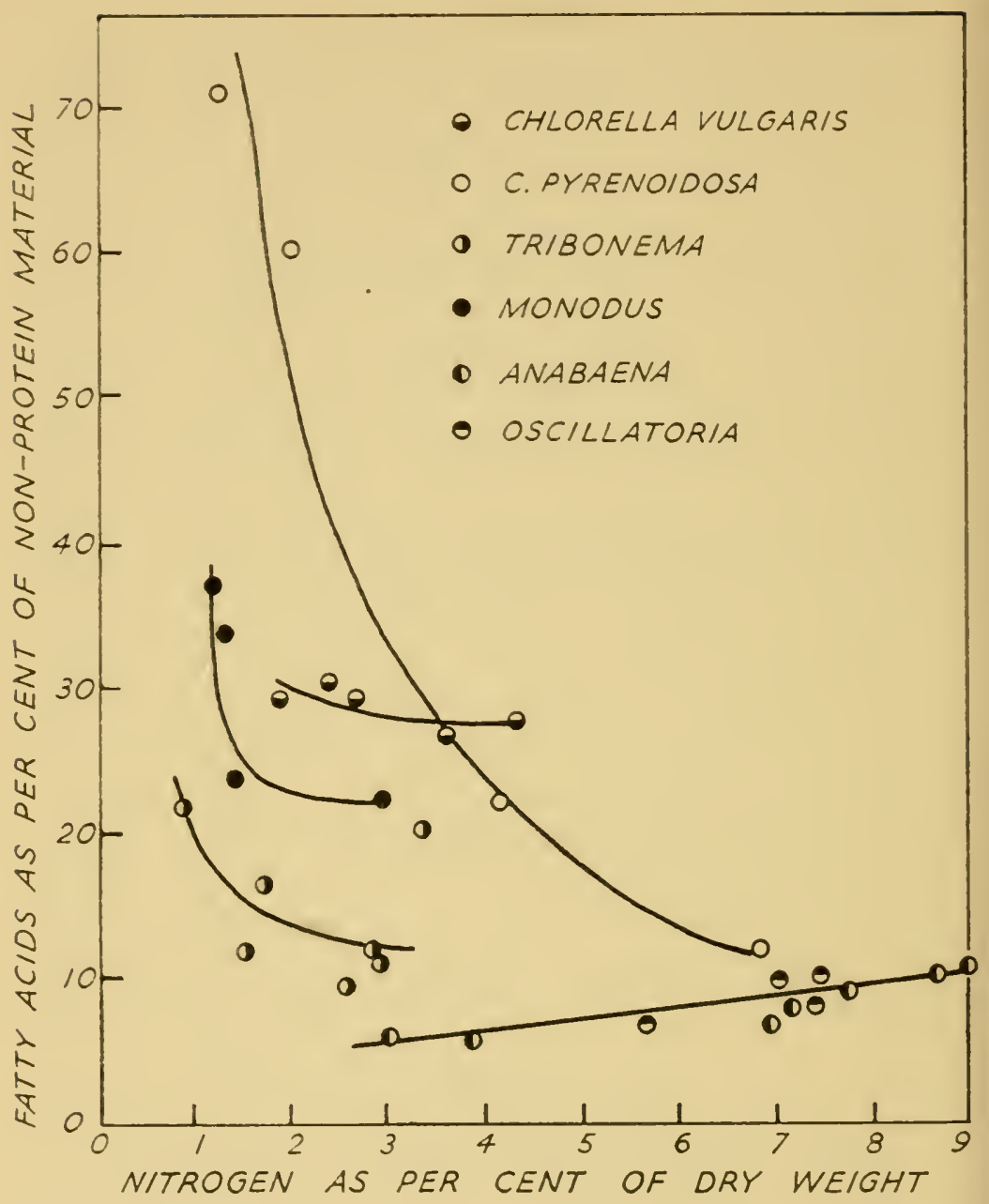

FIG. 18 . Production of fatty acids by various algae as a function of their nitrogen contents (after ref. 94).

will be seen that not only is the fatty acid production of the various species different when compared at corresponding nitrogen contents but that the capacity of a species to synthesize fat is not the same at all levels of cell nitrogen. The manner in which the capacity for fat synthesis varies in relation to nitrogen content is different in different species. 
In Chlorella vulgaris, at least within certain limits and under the particular experimental conditions used, the proportion which fatty acids form of the total reserve material changes little as the nitrogen content of the cell varies. In Monodus, Tribonema and C. pyrenoidosa, however, a decrease in nitrogen content produces a considerable alteration in favour of lipide synthesis, whereas in Anabaena cylindrica and Oscillatoria sp. there is a less marked trend in the opposite direction. From this it appears that algae which characteristically store lipide are able to develop the mechanism for converting the primary products of photosynthesis into lipide on nitrogen starvation whereas in other algae the balance of the lipide and carbohydrate synthesizing systems is not altered to any great extent by nitrogen deficiency.

\section{GROWTH AND METABOLISM IN THE HIGHER ALGAE}

The changes in metabolism which occur during the growth of a structurally complex plant are in a general way similar to those which have just been described as occurring in cultures of simple algae. ${ }^{225}$ However, in most multicellular organisms the situation is complicated by the specialization of tissues for particular functions. Thus, while a growing point of one of the higher algae may show the same type of metabolism as a unicellular alga in the exponential phase of growth, the metabolism of other tissues will be more equivalent to that of a population of single cells in the stationary phase. The activities of the two types of tissue cannot be considered entirely separately since in the intact plant the one will be interrelated with the other.

Studies of the growth and metabolism of the larger algae, most of which are seaweeds belonging to the classes Chlorophyceae, Phaeophyceae or Rhodophyceae, have been restricted because of the difficulty of growing these plants under controlled conditions. Detailed accounts of growth appear to exist only for certain Laminariaceae and Fucaceae. (e.g. 162,220 ). Since a fair amount of information on both growth and chemical constitution is available for 
Laminaria saccharina, this alga has been selected for detailed consideration here.

Laminaria saccharina, which grows at and just below low tide level, consists of a broad ribbon-like frond arising from a stipe terminating in the holdfast by means of which it is attached to the substratum. This plant is the sporophyte; the microscopic gametophyte generation with which it alternates need not concern us here. Sporophytes are produced at all times of the year but generally it is only spring sporophytes which persist until maturity. On the British coast their life span does not exceed three years. Growth of the plant is continuous throughout life but shows seasonal variation, being most rapid from January to June. Growth also changes with the age of the sporophyte, the maximum both in rate and total amount being reached during the second period of rapid growth. Tissue is worn away continuously from the distal end of the frond so that normally the age of the oldest frond tissue is not more than 5 to 7 months. Reproductive tissue develops when the plants are from $S$ to 12 months old. 220

Analyses of $L$. saccharina have been made using samples taken from naturally occurring populations and including plants of all ages. The changes which can be followed are thus seasonal ones in average chemical composition rather than those which occur in the life cycle of the individual plant. During the period of rapid growth both the mean fresh weights and mean total protein content of the plants increase in spite of the continuous wearing away of the fronds. Protein content expressed as a percentage of dry weight is highest at the beginning of this phase (Fig. 19) but falls progressively as the nitrate in the seawater becomes exhausted. The contents of mannitol and laminarin show reciprocal changes to those of protein and, in general, laminarin is almost completely absent when growth is most rapid. There is a decrease in growth rate in June to July, coinciding with the minimum of phosphate and nitrate concentrations in the seawater, and loss of material from the fronds then equals or exceeds the gains. Photosynthesis continues at a high rate for about two months after this 


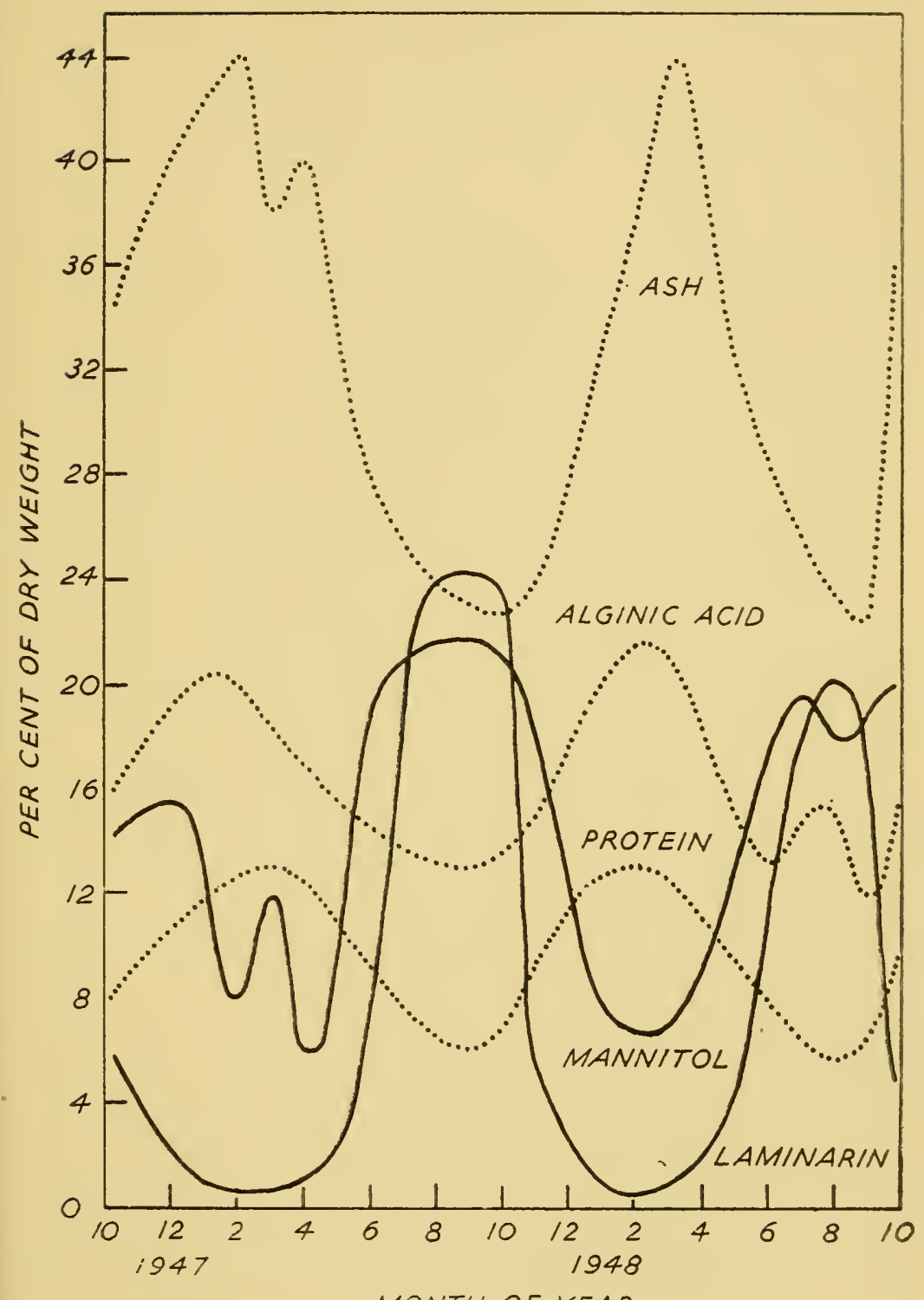

MONTH OF YEAR

FIG. 19. Seasonal variation in the amounts of various chemical constituents in whole plants of Laminaria saccharina from a Scottish loch (after ref. 37). 
point, as is shown by the continued increase in mannitol and laminarin contents. A temporary fall in mannitol content which is sometimes observed in August may be due to the effect of high temperatures in increasing the rate of respiration relative to that of photosynthesis. In the autumn, decreasing light intensity brings about a reduction in the rate of photosynthesis but the concentration of nitrate available is then rising so that the mannitol and laminarin contents fall whereas that of protein increases. ${ }^{33}, 39,37$.

The extent of the variations in the chemical composition of $L$. saccharina depends on environmental conditions, being least in the open sea and greatest in lochs and other situations where temperature and the composition of the seawater are less constant. ${ }^{37}$ In general the mannitol content increases with depth of immersion of the weed down to 6 to 10 metres and decreases below this. The maximum in mannitol content appears to correspond with a maximum in intensity of photosynthesis. Laminarin content tends to decrease progressively with depth but other constituents, such as alginic acid, protein and ash, remain at a level which is more or less independent of depth of immersion. ${ }^{36}$

These variations in chemical composition shown by $L$. saccharina are less extreme than those shown by unicellular algae. For example, the extreme recorded limits of variation of the protein content of $L$. saccharina and other brown seaweeds are 3 and 15 per cent of the dry weight ${ }^{33}, 35,37$ which is a much narrower range than that shown by Chlorella pyrenoidosa (Table II). However, the variations just described for L. saccharina are those taking place in whole plants. If blades and stipes are analysed separately it is found that the variations occurring in the blades cover a wider range than those of the plant as a whole. Fluctuations in the chemical composition of the stipes follow those in the blades but their range is smaller. Laminarin is absent from the stipes throughout the year. ${ }^{33,}{ }^{37}$ This state of affairs is to be expected since growth and photosynthesis are more intense in the blade. Appreciable translocation of material can evidently occur in species of Laminariales and in the largest, e.g. Macrocystis spp., the holdfast and 
lower part of the stipe are entirely dependent on products of photosynthesis translocated from above. ${ }^{257}$

Both seasonal and diurnal fluctuations of the mannitol content of Phaeophyceae are less extreme than those in laminarin content. ${ }^{210}, 33,37,39$ The enzymic interconversion of mannitol and laminarin does not appear to have been demonstrated, but it seems from this behaviour that they constitute a reserve substance system in which their rôles are analogous to those of sugar and starch respectively in higher plants. Fluctuations in the amount of another carbohydrate, alginic acid, however, parallel those in protein content rather than those in mannitol and laminarin, apart from a tendency to a second maximum in autumn (Fig. I9). Two maxima in the amounts of cellulose expressed upon a dry weight basis occur during the year. The cellulose content of L. saccharina is at a maximum in spring, falling to a minimum during the period of rapid growth, reaching a second maximum in autumn and falling again in the winter. ${ }^{38}$ These fluctuations in cellulose and alginic acid are evidently due to the rate of deposition of these cell wall constituents being considerably slower than that of formation of protoplasmic material during the period of rapid growth. The ash constituents of $L$. saccharina are present in the living plant as salts accumulated by the protoplasts and bases associated with the intercellular sulphuric acid esters. It is to be expected therefore that the seasonal variation in their amount should follow those of protein and alginic acid (Fig. I9). The substances that have so far been mentioned in this account of variations in chemical composition of $L$. saccharina together make up over 90 per cent of its dry weight. Fluctuations in minor constituents such as lipides do not appear to have been studied.

The pattern of metabolism in other Phaeophyceae appears to be substantially the same as that which has been described for $L$. saccharina, both in sub-littoral, e.g. $L$. digitata, L. cloustoni and Saccorhiza bulbosa, ${ }^{33},{ }^{37}$ and littoral species, e.g. Ascophyllum nodosum and Fucus spp. ${ }^{34,} 35,188$ In the littoral species the tendency seen in the algae of the sub-littoral zone towards more than one maximum in 
mannitol and laminarin contents during the year is more pronounced (Fig. 20). These fluctuations are due to the interactions of a number of factors; degree of exposure, temper-

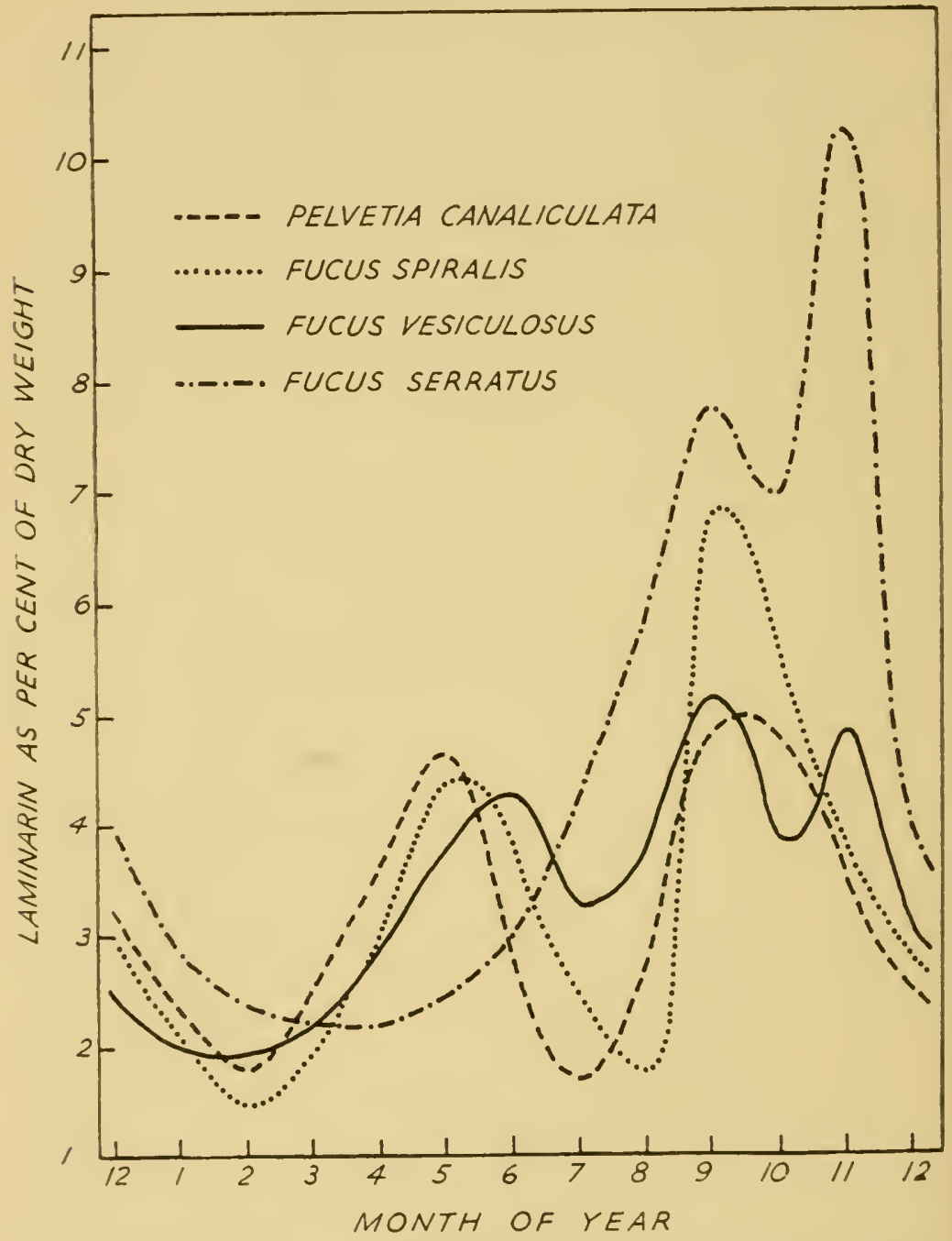

FIG. 20 Seasonal variation in the amounts of laminarin in various littoral algae. The algae occur in the following order upwards from low tide level: Fucus serratus, $F$. vesiculosus, $F$. spiralis and Pelvetia canaliculata (data from ref. 35 ). 
ature and formation of fructifications being perhaps of most importance. The minimum in laminarin content occurring in July and August is almost certainly the result of the reduction in photosynthetic activity which is known to be brought about by increased desiccation. ${ }^{269}$ The increase in this effect with degree of exposure is shown in Fig. 20, from which it will be seen that the early summer maximum occurs sooner and the summer minimum is more pronounced the higher the position which the species occupies on the shore. Judging by the behaviour of simple algae as described earlier in this chapter, it seems unlikely that exhaustion of nutrients such as nitrate and phosphate from the seawater would affect photosynthesis directly and lead to the summer minimum in laminarin and mannitol, as has been suggested. ${ }^{39}$ Differences in lipide metabolism of various Phaeophyceae are also correlated with depth of immersion, e.g. Pelvetia canaliculata, which grows at highwater mark, has been found to contain 6.2 per cent of fat, whereas Laminaria digitata, which grows below low water mark, has been found to contain only 0.16 per cent. ${ }^{255}$ These differences may depend on the decreasing amounts of nitrogen available to plants growing higher up the shore but other factors besides this are almost certainly involved.

Few studies of seasonal variation in chemical constitution have been made with representatives of the Rhodophyceae. In conformity with the results obtained with Phaeophyceae the carbohydrate content of Chondrus crispus has been found to be lowest in early spring and highest from June to September. ${ }^{51}$ The agar extracted from Gigartina in autumn gives a gel of greater strength than that extracted in spring, ${ }^{189}$ a variation that is perhaps related to seasonal changes in the type of sulphuric esters 'present, such as have been observed in Chondrus. ${ }^{51}$ 


\section{SUMMARY AND CONCLUSIONS}

Of the great variety of organisms classified together as algae only a few species have been examined from the physiological and biochemical points of view. Thus the account of the mechanisms of carbon and nitrogen assimilation in algae given in this book is largely based on the results of studies with unicellular green algae, whereas for the consideration of the chemistry of the final products of metabolism most information is available for the brown and red seaweeds. In spite of this incompleteness in our knowledge it seems possible to draw certain general conclusions regarding algal metabolism.

There is no reason to suppose that the patterns of such major metabolic processes in these organisms as photosynthesis, respiration and nitrogen assimilation, differ in any fundamental way from those occurring in other forms of life. The algae do, however, show a considerable amount of variety in metabolism of a kind which is also found among the bacteria and which appears to be one characteristic of the most primitive organisms. This is best exemplified in photosynthesis, the characteristic method of carbon assimilation in algae. In higher plants this process is stereotyped in that the photosynthetic pigments are always of the same kind and that the hydrogen needed for the reduction of the carbon dioxide is always derived from water. In algae the principal photosynthetic pigment appears to be the same, i.e. chlorophyll $a$, as it is in higher plants. This, together with other evidence, indicates that the fundamental reaction of photosynthesis, in which light energy is transformed into chemical energy available for the reduction of carbon dioxide, is the same in all algae and in higher plants. However, the accessory pigments associated with chlorophyll $a$ differ both in kind and proportions in the various 
algal classes. Light absorbed by certain of these pigments can be transferred to chlorophyll $a$ and used in photosynthesis so that the efficiency and manner of utilization of light of different wavelengths varies considerably from class to class. Similarly, while it appears that the primary photochemical reaction in photosynthesis always results in the splitting of water, the ultimate hydrogen donor, although usually water as in higher plants, may, in many algae under certain conditions, be elementary hydrogen or hydrogen sulphide. There is also a related tendency among algae to utilize reduced inorganic substrates such as these as a source of energy for growth, a tendency which is shown by no higher green plants.

Another characteristic of the metabolism of algae is its flexibility, which is apparent both in the variety of substrates which can be assimilated and the considerable variation which can occur in the proportions of the various products of metabolism accumulating within the organism. Many algae, although capable of photosynthesis, can also grow in the dark if provided with a suitable substrate and for many algae these substrates may be of very varied chemical nature. A similar flexibility is evident in the assimilation of nitrogen. Among the final products of metabolism the proportions of such materials as fats, carbohydrates and proteins, which accumulate within the cells, may vary within wide limits according to the stage of growth attained and the conditions under which it has taken place. During growth the products of photosynthesis or of the assimilation of organic substances are used for the synthesis of protoplasm but on cessation of growth the continuation of assimilation results in the accumulation of storage products the nature of which varies according to the species concerned and to other circumstances. The limits within which the chemical composition of an alga may vary as a result of this are particularly wide in the simpler forms; as a general rule structurally more complex algae are more exacting, both in their internal and external environmental requirements, and this limits the amount of variation which can occur. 
This flexibility is understandable when it is considered that the reactions in which the intermediates of metabolism are involved are mostly reversible and that the major metabolic processes share common intermediates. That this is true for carbohydrate, acid and nitrogen metabolism, has become apparent from studies of other organisms, but the idea that photosynthesis is not apart from the rest of metabolism but intermeshes with other processes at an early stage has arisen as the result of studies with algae. Material may be introduced into the metabolic system at many points and does not follow any unique pathway, but appears as ultimate products the nature of which varies according to the conditions to which the system has been exposed in the past as well as to those to which it is exposed at the moment. The variation in chemical composition of the cell material which results is perhaps more marked in algae than in comparable bacteria or fungi because algae have a marked tendency towards conservation of material within their cells rather than of excretion of surplus substances into the surrounding medium.

While many algae are thus able to utilize a wide range of substrates and are capable of synthesizing for themselves all the metabolites which they need, others have more limited metabolic capacities and are dependent upon the presence of particular substances in their environment either as energy sources or as growth factors. An inability to utilize a given substrate as energy source may be due to impermeability of the plasma membrane towards the substance, to the absence of the specific enzyme necessary for its entry into metabolism, or to less well-defined causes. Obligate phototrophy, an inability to maintain growth except when carrying out photosynthesis which is perhaps common among algae, is possibly due to the absence of a mechanism for the synthesis of a specific substance but has not yet been satisfactorily explained. In the other direction, the capacity for photosynthesis may be lost and many colourless organisms absolutely dependent on organic substances as energy sources have clearly been derived from photosynthetic algae by loss of chromatophores. Loss of 
enzymes responsible for the synthesis of specific metabolites leads to the appearance of nutritionally exacting forms similar to those well known among bacteria, fungi and other organisms. A few algae, both naturally occurring strains and artificially induced mutants, have been shown to have a requirement for thiamine and it seems likely that when a more thorough investigation is made, the growth of many algae will be found to be dependent on the exogenous supply of specific organic factors. Such growth factor requirements occur quite independently of the presence or absence of a capacity for photosynthesis.

Many of the algal classes are characterized by the general occurrence in their members of particular metabolic products. This is especially evident with the photosynthetic pigments, each class having its distinctive accessory pigments. Peculiarities in carbohydrate metabolism occur in several classes. The Phaeophyceae and Rhodophyceae, for example, tend to produce carbohydrates containing $1: 3$ linkages, rather than $\mathrm{I}: 4$ linkages such as are formed by other algae and higher plants, and polysaccharide sulphate esters. Those algae grouped together in the Chrysophyta seem unable to synthesize starch and generally accumulate fat rather than carbohydrate reserves. The occurrence of these and other biochemical characteristics confirms to a remarkable degree the classification of algae derived on morphological grounds.

Its possession of such features justifies the consideration of the algal type of metabolism as a distinct field of study which has much to contribute to comparative biochemistry and our understanding of the economy of nature. 


\section{REFERENCES}

After each entry is given the page (or pages) of the text on which the publication is cited.

${ }^{1 a}$ AACH, H. G. (1 952). Arch. Mikrobiol., I7, 2 I 3-46 (I09, I I I, I I6)

1 ALBAUM, H. G., SCHATZ, A., HUTNER, S. H., and HIRSHFELD, A.

(1950). Arch. Biochem., 29, $210-18$ ( I 1, 56)

${ }^{2}$ ALGÉUS, S. (1 946). Bot. Notiser, 1946, 1 29-278 (85)

3 - (1948). Physiol. Plant., I, 65-84 (81, 82)

4- (1948). Physiol. Plant, I, 236-44 (81, 82)

5 ___ (1949). Physiol. Plant., 2, 266-71 (81, 82)

6 _- (1950). Physiol. Plant., 3, 225-35 (79, 81, 82)

7 - (1950). Physiol. Plant., 3, 370-5 (79, 81, 82, 83)

8 - (195I). Physiol. Plant., 4, 449-58 (78, 83)

9 - (195I). Physiol. Plant., 4, 459-60 (81, 82)

10 - (I95I). Physiol. Plant., 4, 495-7 (79, 8I)

${ }^{11}$ ALLISON, F. E., HOOVER, S. R., and MORRIS, H. J. (1937). Bot. Gaz., $98,433-63(70,120)$

12 allison, F. E., and MORris, H. J. (1932). Proc. 2nd Int. Congr. Soil Sci., 3, 24-8 (9o)

13 ANDERSON, E. H. (I 945). F. gen. Physiol., 28, 287-96 (86)

14 - (1945). F. gen. Phy'siol., 28, 297-327 (6, 9, 55, 64, 65)

15 ARNoN, D. I. (I95I). Nature, Lond., I67, I008-10 (40)

16 ASTBURY, w. T. (1 945). Nature, Lond., 155, 667-8 (95)

17 Augier, J. (1947). C.R. Acad. Sci., Paris, 224, 1654-6 (93)

18 BÄCHLI, P., and PERCIVAl, E. G. V. (1952). F. chem. Soc., I952, 1 243-6 (94)

19 BALDWIN, E. (1952). Dynamic aspects of biochemistry, 2nd edition, Cambridge University Press (6-I I, 65, 66, 79, 8I)

20 BARkER, H. A. (1 935). Arch. Mikrobiol., 6, I 41-56 (92, I I 2, I 2 I)

21 _.(1935). Arch. Mikrobiol., 6, 157-81 (59, 75, I I 2, 120)

22 _ـ (1935). F. cell. comp. Physiol., 7, 73-93 (4, 6, 5 1, 54, 55, 63, 67)

23 (1 936). F. cell. comp. Physiol., 8, 23 I-50 $(4,63,64)$

24 BARRY, V. C., HALSALL, T. G., HIRST, E. L., and JONES, J. K. N. (1949). F. chem. Soc., I949, I 468-70 (93)

25 BEBBINGTON, A., BOURNE, E. J., STACEY, M., and WILKINSON, I. A.

(1952). F. chem. Soc., 1952, 240-5 (1 2, 56)

${ }^{26}$ BeIJerinCK, N. W. (i 890). Bot. Ztg., 48, 725-39, 741-54, 757-68, $78 \mathrm{I}-5(3)$

27 - (1904). Rec. Trav. bot. néerl., I, 14-27 (61, 62)

28 - (1904). Rec. Trav. bot. néerl., r, 28-32 (I I6, I I9)

${ }^{29}$ BENison, A. A., and CAlvin, M. (I950). F. exp. Bot., r, 63-70 (I I, I $8,42,46)$ 
30 Benson, A. A., and Calvin, M. (1950). Annu. Rev. Pl. Physiol., I, 25-42 (I $9,39,40,47)$

31 BENSON, A. A., CALVIN, M., HAAS, V. A., ARONOFF, S., HALL, A. G., BASSham, J. A., and WeIgl, J. W. (I949). Photosynthesis in plants, 38I-40I, Iowa State College Press (40)

32 BERGMANN, W., and FEENEY, R. J. (1950). F. org. Chem., I5, 8 I2-I4 (100)

33 BLACK, W. A. P. (1 948). F. Soc. chem. Ind., Lond., 67, 165-76 (92, $94,95,126,127)$

${ }^{34}$ __ (1948). Ұ. Soc. chem. Ind., Lond., 67, 355-7, (1 27)

35 - (1949). Ұ. Soc. chem. Ind., Lond., 68, $183^{-9}(94,126-8)$

36 _- (1950). F. Soc. chem. Ind., Lond., 69, 16 1-5 (126, 127)

37 - (1950). F. Mar. biol. Ass. U.K., 29, 45-72 (125-7)

38 - (1950). F. Mar. biol. Ass. U.K., 29, 379-87 (1 27)

${ }^{39}$ BLACK, W. A. P., and DEWAR, E. T. (I949). F. Mar. biol. Ass. U.K., 28, 673-99 (126, 127, 129)

40 BLINks, L. R. (195I). Mamual of phycology, 263-9r, Chronica Botanica Co., Waltham, Mass. (4, 6, I0, I I, 35)

41 Bonner, J. (1950). Plant biochemistry, Academic Press Inc., New York (6, I I, 65, 78, 79, 8I)

42 Bortels, H. (1 940). Arch. Mikrobiol., I I, 1 55-86 (70)

43 BOURNE, E. J., STACEY, M., and WILKINSON, I. A. (I950). F. chem.

Soc., I950, 2694-8 (93)

44 BRistol, B. M., and PAGE, H. J. (1923). Ann. appl. Biol., ro, $378-408(69)$

45 BROWN, A. H. (1948). Plant Physiol., 23, 331-7 (32)

46 BUChanan, J., PERcival, E. E., and Percival, E. G. V. (I943). F. chem. Soc., I943, 5 I-4 (97)

47 BURK, D., HENDRICKS, S., KORZENOVSKY, M., SCHOCKEN, V., and WARBURG, O. (1949). Science, II0, 225-9 (46)

48 BURLEW, J. S., editor (1953). Algal culture: From laboratory to pilot plant, Carnegie Institution of Washington, Publication no. $600(5)$

49 BURRIS, R. H., EPPLING, F. J., WAHLIN, H. B., and WILSON, P. W. (1943). F. biol. Chem., 148, 349-57 (69)

50 BURRIS, R. H., and wilson, P. W. (I946). Bot. Gaz., I08, 254-62 (70)

51 BUTLER, M. R. (1936). Biochem. F., 30, 1338-44 (129)

52 CALVIN, M., BASSHAM, J. A., BENSON, A. A., LYNCH, V. H., OUELLET, C., SCHOU, L., STEPKA, w., and TOLBERT, N. E. (r95I). Symp. Soc. exp. Biol., 5, 284-305 (6, 7, I I, 34, 37-40, 42-4, 46, 65,93, I I 9)

${ }^{5}$ CARTER, P. W., heilbron, I. M., and Lythgoe, B. (I939). Proc. roy. Soc., $B, \mathbf{1 2 8}, 82-109$ (100, 101, 103)

54 CHICK, H. (I903). Proc. roy. Soc., 71, 458-76 (74)

55 Clarke, H. T., and MazUr, A. (I 94I). F. biol. Chem., I4I, 283-9 $(98,100)$

${ }^{56}$ Clendenning, K. A. (I950). Arch. Biochem., 27, 75-88 (44)

57 Cold Spr. Harb. Symp. quant. Biol. (1946). II, 302-3 (1 5) 
58 colin, H., and Augier, J. (1933). C.R. Acad. Sci., Paris, 197, 423-5 (93)

59 colin, h., and guḱguen, E. (1933). C.R. Acad. Sci., Paris, 197, I 688-90 (92)

${ }^{60}$ Conchie, J., and Percival, E. G. v. (1950). F. chem. Soc., 1950, $827-32(98)$

${ }^{61}$ Connell, J. J., HiRst, E. L., and Percival, E. G. V. (I950). $\mathcal{F}$. chem. Soc., 1950, 3494-500 (94)

${ }^{6} \mathrm{coOK}$, A. H. (1945). Biol. Rev., 20, I I 5-32 (20)

${ }^{63}$ CRAmer, M., and myers, J. (1948). F. gen. Physiol., 32, 93-102 $(72-4)$

$64+$ (1949). Plant Physiol., 24, 255-64 (64, I I I)

65 (1 950). Amer. F. Bot., 37, 677 (61, 86, I I 2 )

${ }^{66}$ DE, P. K. (1939). Proc. roy. Soc., B, 127, I 2 I-39 (69-71, 90)

67 DEKKER, C. A., STONE, D., and FRUTON, J. S. (r949). F. biol. Chem., I81, 719-29 (102, 103)

${ }^{68}$ DENFFER, D. voN (1 948). Biol. Zbl., 67, 7-13 (I 1 4, 1 20)

69 DEWAR, E. T., and PERCIVAl, E. G. V. (1947). F. chem. Soc., 1947, I 622-6 (97)

70 DREWES, K. (1928). Zbl. Bakt., II, 76, 88-iо (69)

${ }^{71}$ Dusi, H. (1939). C.R. Soc. Biol., Paris, 130, 419-22 (15)

72 Dutton, h. J., and manning, w. M. (r94r). Amer. F. Bot., 28, 5 I 6-26 (24)

73 DUtToN, H. J., MANNING, W. M., and DUGGaR, B. M. (I943). F. phys. Chemt., 47, 308-1 3 (28)

74 DUYSENS, L. N. M. (195I). Nature, Lond., I68, 548-50 (28)

${ }^{75}$ EMERSON, R. (1927). Ұ. gen. Physiol., 10, 469-77 (10)

76 EMERSON, R., and GREEN, L. (1938). Plant Physiol., 13, 157-68 (34, II9)

7 EMERSON, R., and Lewis, c. M. (1942). F. gen. Physiol., 25, $579-95(26,27)$

${ }^{78}$ (1943). Amer. F. Bot., 30, 165-78 (26, 28)

79 EMERSON, R. L., STAUFFER, J. F., and UMBREIT, W. W. (I944). Amer. F. Bot., 31, 107-20 (I I)

80 engelmann, T. W. (I883). Bot. Ztg., 41, I-13, I 7-29 (4, 29)

81 - (1884). Bot. Ztg., 42, 81-93, 97-105 (29)

82 ENY, D. M. (I 950). Plant Physiol., 25, 478-95 (54)

83 _ ( I95 I). Plant Physiol., 26, 268-89 (6, 7, 54)

84 - (1952). Biochem. F., 50, 559-64 (9, I I)

85 EULER, H. VON, and ADLER, E. (I 934). Hoppe-Seyl. Z., 228, I-I 2 (I I)

${ }^{86}$ FINKLE, B. J., APPLEMAN, D., and Fleischer, F. K. (I950). Science, III, 309 (59)

87 FOGG, G. E. (1942). F. exp. Biol., 19, 78-87 (70, 90)

88 - (1944). New Phytol., 43, I64-75 (107, 109, I 10)

89 - (1947). Endeavour, 6, I 72-5 (69, 71)

${ }_{90}$ _- (1949). Ann. Bot., Lond., N.S. 13, 241-59 (70, 75, 109)

21 (195I). F. exp. Bot., 2, i I 7-20 $(69,90)$

92 (1952). Proc. roy. Soc., B, 139, 372-97 (90, 91) 
${ }^{83}$ FOGG, G. E., unpublished results $(59,70,88)$

${ }^{94}$ FOGG, G. E., and COLLYER, D. M. (I953). In Algal culture: From

laboratory to pilot plant, Carnegie Institution of Washington,

Publication no. 600 ( I I 9, I 21, I 22)

95 FOWDEN, L. (195I). Nature, Lond., I67, I030 (7 I, I01, 102)

96 _ (I95 I). Biochem. F., 50, 355-8 (IOI)

97 - (1952). Biochem. F., 52, 3 10-14 (1 I6)

98 __ unpublished results (7I, IOI)

${ }^{99}$ Franck, J. (195I). Annu. Rev. Pl. Physiol., 2, 53-86 (r9)

100 Franck, J., and LOOMIS, W. E., editors (I949) Photosynthesis in plants, Iowa State College Press (19)

101 FRANK, B. (I 889). Ber. dtsch. bot. Ges., 7, 34-42 (68)

102 FRederick, J. F. (I 95 I). Physiol. Plant., 4, 62 I-6 (I 2, 94)

103 FRENCH, C. S., and YOUng, v. K. (1952). F. gen. Physiol., 35, $873-90(28)$

104 Frenkel, A., Gaffron, H., and Battley, E. H. (I949). Biol. Bull., Wood's Hole, 97, 269 (33)

$104 a-1$ (1950). Biol. Bull., Wood's Hole, 99, I5762 ( I I 2)

105 FRENKEL, A. W., and RIEGER, C. (I95 I). Nature, Lond., 167, I030 $(31,32)$

106 FRITSCH, F. E. (1935). The structure and reproduction of the algae, vol. I, Cambridge University Press (I, I3, 35, 50, 62, $93,95,98$, 103, 104)

$107+$ (1945). The structure and reproduction of the algae, vol. 2, Cambridge University Press (1 $3,23,29,35,63,93-5,97$, $98,103,104)$

108 GAFFrON, H. (I 939). Biol. Zbl., 59, 288-302 (I I 2)

109 - (1939). Biol. Zbl., 59, 302-13 (10, 12)

110 - (1940). Amer. F. Bot., 27, 273-83 (30)

111 (1945). F. gen. Physiol., 28, 259-68 (31)

112 (1945). F. gen. Physiol., 28, 269-85 (3I)

113 gaffron, H., and fager, E. W. (I95i). Annu. Rev. Pl. Physiol., 2, 87-II4 (19,32, 39, 40,46)

114 GAFFron, H., FAGER, E. W., and ROSENBERG, J. L. (I95I). Symp. Soc. exp. Biol., 5, 262-83 (37-4I)

115 GENEVOIS, L. (1928-9). Rev. gén. Bot., 40, 654-74, 735-46; 4I, $49-63$, I I 9-28, I 54-84, 252-7 I $(6$, 10)

116 GERDES, G. (I95I). Arch. Mikrobiol., I6, 53-77 (9)

117 goryunova, s. v. (1950). Izvest. Akad. Nauk. S.S.S.R. Ser. Biol., I950, 29-42; seen in abstract only (98)

118 GRANICK, s. (I948). F. biol. Chem., r72, 717-27 (62)

119 HAAS, P. (I921). Biochem. F., I5, 469-76 (97)

120 - (I950). Biochem. F., 46, 503-5 (102)

121 HAAS, P., and HILL, T. G. (1 929). Biochem. F., 23, I000-4 (92)

122 - (1929). Biochem. F., 23, 1005-9 (92)

123 - (193 I). Biochem. F., 25, 1470-I (92)

124 - (1931). Biochem. F., 25, 1472-5 (102)

125 (1932). Biochem. F., 26, 987-90 (92) 
126 HAAS, P., and HILL, T. G. (1933). Biochem. F., 27, I 801-4 (102) 127 (1 933). Ann. Bot., Lond., 47, 55-67 (92, 98)

128 haAs, P., hill, T. G., and karstens, w. K. H. (1935). Ann. Bot., Lond., 49, 609-I 9 (IO2)

129 HAAS, P., HILL, T. G., and RUSSELl-WELls, B. (1938). Biochem. F., 32, 2 I 29-33 (IO2)

130 HAAS, P., and RUSSELl-wells, B. (1 923). Biochem. F., 17, 696-706 (96)

131 HALL, R. P. (1939). Quart. Rev. Biol., I4, I-I2 (84, 85)

132 HARDER, R. (I9I7). Z. Bot., 9, I $45^{-242}$ (3, 5 I, I I 4 )

133 HARDER, R., and WITSCH, H. vON (I 942). Forschungsdienst, I6, $270-5(5)$

134 (1 942). Ber. dtsch. bot. Ges., 60, I46-52 (I I9)

135 Harvey, H. W. (1 939). F. Mar. biol. Ass. U.K., 23, 499-520 (87)

136 - (1945). Recent advances in the chemistry and physics of sea water, Cambridge University Press $(33,36,87)$

137 Hassid, w. Z. (1933). F. Amer. chem. Soc., 55, 4163-7 (97)

138 - (1 936). Plant Physiol, Ir, 46r-3 (92)

139 HAXO, F. T., and Blinks, L. R. (1950). F. gen. Physiol., 33, $389-422(25-7)$

140 HEILBRON, I. M., PARRY, E. G., and PHIPERS, R. F. (I935). Biochem. F., 29, 1376-81 (100)

$141 \ldots-$ (I935). Biochem. F., 29, I382-3 (I I)

142 HeNRiksson, E. (I 95 I). Physiol. Plant., 4, 542-5 (7I, 90)

143 HILl, R. (I95I). Symp. Soc. exp. Biol., 5, 222-3 I (10, 39)

${ }^{144}$ Hille, J. C. VAN (1 938). Rec. Trav. bot. néerl., 35, 680-757 (6r, I I I, I I 9, I 20)

145 HINSHELWOOD, C. N. (1946). The chemical kinetics of the bacterial cell, Clarendon Press, Oxford (56, 109, г 10)

146 HÖFleR, K. (1943). Protoplasma, 38, 7 I-104 (I I 2)

147 Hutchens, J. O. (1948). F. cell. comp. Physiol., 32, 105-16 (I I 4)

148 HUTChens, J. O., POdolsky, B., and MoRales, M. F. (I948). $\mathcal{~}$. cell. comp. Physiol., 32, i i 7-4 I (94, ro7)

149 Hutchinson, G. E. (1 943). Arch. Biochem., 2, 143-50 (85)

150 HUTNER, S. H., and PROVASOLI, L. (I95I). Physiology and biochemistry of protozoa, 27-128, Academic Press, Inc., New York $(33,51,55,56,60,62,7$ I $, 78,84-6,88,93)$

151 IGGENA, M. L. (1938). Arch. Mikrobiol., 9, 1 29-66 (58)

152 INGENHOUSz, J. (I 779). Experiments upon vegetables, discovering their great power of purifying the common air in the sunshine, and of injuring it in the shade and at night, Elmsly and Payne, London $(\mathrm{x}, 2)$

153 JeENer, R. ( 1952), Biochim. biophys. Acta, 8, r25-33 (10, ro3, I I0, I I 6)

154 (1952). Biochim. biophy's. Acta, 8, 270-82 (I I 3)

155 johnston, R., and Percival, E. G. V. (1950). F. chem. Soc., r950, I 994-8 (97) 
156 JONES, W. G. M., and PEAT, S. (1942). F. chem. Soc., 1942, 225-3 I $(96,97)$

157 KATHEN, H. (1 949). Arch. Mikrobiol., r4, 602-34 (98)

158 KESSLER, E. (1952). Z. Naturf., 76, 280-4 (74)

159 ketchum, B. M. (1939). F. cell. comp. Physiol., I3, 373-8 I (I I2, I I3, I I9)

160 kETCHUM, B. H., and REDField, A. C. (1949). F. cell. comp. Physiol., 33, 281-99 (I 19)

161 klosty, M., and Bergmann, w. (1952). F. Amer. chem. Soc., 74, 1601 ( 100$)$

162 KNIGHT, M., and PARke, M. (I95I). F. Mar. biol. Ass. U.K., 29, 439-5 I4 (123)

$163 \mathrm{Kok}$, B. (1938). Enzymologia, 13, I-56 (1 12, 1 20)

164 - (195I). Symp. Soc. exp. Biol., 5, 2 I I-2 I (73)

165 KROGH, A. (I93I). Biol. Rev., 6, 412-42 (90, 9I)

166 KROGH, A., LANGE, E., and SMITH, w. (1930). Biochem. F., 24, I 666-7I (89)

167 KYlin, A. (1945). K. fysiogr. Sällsk. Lund Förh., I5 (4), I-9 (74, $8 \mathrm{r})$

168 KyliN, H. (r94I). K. fysiogr. Sällsk. Lund Förh., II (21), I-16 (87)

169 (1943). K. fysiogr. Sällsk. Lund Förh., 13 (6), 1-13 (92, 98)

170 - (1 943). K. fysiogr. Sällsk. Lund Förh., I3 (7), I-1 4 (92-4, 98)

171 - (1943). K. fysiogr. Sällsk. Lund Förh., I3 (21), I-13 (50)

172 - (1944). K. fysiogr. Sällsk. Lund Förh., I4 (17), I-5 (92)

173 _- (1944). K. fysiogr. Sällsk. Lund Förh., I4 (I8), I-I3 $(92,94,97)$

174 LEWIN, J. C. (I950). Science, II2, 652-3 (49, 59, 60)

175 _ (in the press) F. gen. Microbiol., (51, 59)

${ }^{176}$ LEWIN, R. A. (1950). Nature, Lond., I66, I96 (84, 87)

177 - (1952). F. gen. Microbiol., 6, 233-48 (60, 85-7)

178 LINDSTROM, E. S., BURRIS, R. H., and WILSON, P. W. (I949). F. Bact., 58, 31 $3-16$ (70)

1 ;9 LOVERN, J. A. (1936). Biochem. F., 30, 387-90 (99)

180 Ludwig, C. A. (1938). Amer. F. Bot., 25, 448-58 (74, 8I )

181 LUND, J. W. G. (1 949). F. Ecol., 37, 389-419 (108)

182 - (1950). F. Ecol., 38, $15-35$ ( 1 I 4 )

183 Lwoff, A. (1947). Annu. Rev. Microbiol., I, Io I-14 (84-6)

184 (1951). Biochemistry and physiology of protozoa, I-26, Academic Press, Inc., New York ( $15,5 \mathrm{I}$ )

185 Lwoff, A., and Dusi, H. (I931). C.R. Soc. Biol., Paris, ro7, I $068-9(5 \mathrm{I}, 54)$

186 LWOFF, A., IONESCO, H., and GUTMANN, A. (1950). Biochem. biophys. Acta, 4, 270-7 (1 2, 56)

187 macpherson, M. G., and young, E. G. (I949). Canad. F. Res., 27, $C, 73-7$ (II9)

188 (1952). Canad. F. Bot., 30, 67-77 (127)

189 Marshall, S. M., NEWTON, L., and ORR, A. P. (1949). A study of 
certain British seaweeds and their utilization in the preparation of agar, H.M. Stationery Office, London ( 96,129$)$

180 mazUr, A., and Clarke, H. T. (1938). F. biol. Chem., r23, 729-40 (IOI)

$191+$ (1942). F. biol. Chem., r43, 39-42 (го 1)

192 MEIER, R. L. (I 949). Chem. Engng. Nezus, 27, 3 I I 2-I6 (5)

193 MILLBANK, J. W., unpublished results (9)

193a _- (1953). Nature, Lond., r7x, 476-7 (79)

194 Milner, H. W. ( I 948). F. biol. Chem., r76, 8 I 3-I 7 (99, I I 8)

195 Molisch, H. (г 896). S.B. Akad. Wiss. Wien (Abt. I), ro5, $633-48(3)$

196 Myers, J. (1 940). Plant. Physiol., I5, 575-88 (6r)

197 - (1946). F. gen. Physiol., 29, 4 I 9-27 (I I I)

198 (1947). F. gen. Physiol., 3-, $217-27(63,64)$

199 - (1949). Photosynthesis in plants, 349-64, Iowa State College Press (4I, 73, I I I, I I 2)

200 - (195I). Annu. Rev. Microbiol., 5, I 57-80 (4, 57, 58, 61 , 697 I, 89, 90, 108, I I I, I I 9)

201 Myers, J., and Clark, L. B. (1944). F. gen. Physiol., 28, 103-12 (I IO)

202 myers, J., and Cramer, M. (1948). F. gen. Physiol., 32, ro3-ro ( $110-12$ )

203 Myers, J., and johnston, J. A. (I 949). Plant Physiol., 24, I I I-I 9 (89)

204 MYERS, J., PHILliPS, J. N., and GRAHAN, J.-R. (I95I). Plant Physiol., 26, 539-48 (5, II 4)

205 nakamura, H. (1 938). Acta Phytochim., Tokyo, 10, 27 I-8r; seen in abstract only (32)

206 NAylor, G. L., and russell-wells, B. (1934). Ann. Bot., Lond., $48,635^{-4 I}(95)$

207 NeISH, A. C. (195I). Canad. F. Bot., 29, 68-78 $(56,57)$

208 NEWTON, L. (I 95I). Seaweed utilization, Sampson Low, London $(4,96,97)$

208a NiCOLAi, E. and PREston, R. D. (i 952), Proc. roy Soc., B, 140, $244-74(95,98)$

209 NIELSEN, E. S. (1952). Nature, Lond., r69, 956-7 (I)

210 Nisizawa, K. (1 940). Sci. Rep. Tokyo Bunrika Daig., B, 5, 9-1 4 ( 127 )

211 NORMAN, R. W. VAN, FRENCH, C. S., and MACDOWALL, F. D. H. (1948), Plant Physiol., 23, 455-66 (28)

212 osterhout, w. J. v., and dorcas, M. J. (1925). F. gen. Physiol. 9, 255-67 (34)

213 ÖSTERLIND, s. (1949). Symb. bot. upsaliens., to (3), I-I4I (34, 35, I I 9)

$214-$ (1950). Physiol. Plant., 3, 353-60 (35)
$215-$ (1950). Physiol. Plant., 3, 430-4 (35)
$216-$ (195 ). Physiol. Plant., 4, 242-54 (35)
$217-$ (1951). Physiol. Plant., 4, 514-27 (35)
$218-$ (1952). Physiol. Plant., 5, 292-7 (10, 74) 
219 PAAUw, F. VAN DER (1932). Rec. Trav. bot. néerl., 29, 497-620 (I I 2)

220 PARKE, M. (1 948). F. Mar. biol. Ass. U.K., 27, 65 I-709 (г 23, г 24) 221 PAYEN, J. (I 938). Rev. algol., II, I-99 (92-4, 98)

222 pearsall, w. H., and BeNGry, R. P. (I940). Ann. Bot., Lond., N.S. 4, 486-94 (58)

223 PeArSall, W. H., and fOgG, G. E. (I95I). Food Sci. Abstr., 23, $\mathrm{I}-\mathrm{I} I(5)$

224 PEARSALL, W. H., GARDINER, A. C., and GREENSHIELDS, F. (I946) Freshwater Biological Association, Publication no. I I (I08) 225 Pearsall, w. H., and loose, L. (1937). Proc. roy. Soc., B, I2I, 45I-50I (3, 92, I07, I08, I I0, I I 5, I 20, I 23)

226 PERCIVAL, E. G. V. (I950). Structural carbohydrate chemistry, Frederick Muller Ltd., London (92)

227 PERCIVAL, E. G. V., and CHANDA, S. K. (I950). Nature, Lond., I66, $787-8(96)$

228 PERCIVAL, E. G. V., and Ross, A. G. (1948). Nature, Lond., I62, $895^{-6}(95)$

$229-$ (1950). F. chem. Soc., 1950, 717-20 (98)

230

231 PERCival, E. G. v., and ThOMSON, T. G. H. (I 942). F. chem. Soc., I942, 750-5 (97)

232 PIRSON, A., and Wilhelmi, G. (I 950). Z. Naturf., 5 b, 21 I-I8 (I 12, I I3, I I9)

233 pratt, R. (I 943). Amer. F. Bot., 30, 32-3 (1 20)

234 PRATT, R., and FONG, J. (I 940). Amer. F. Bot., 27, 43 I-6 (I I4) 235 ( 1 940). Amer. F. Bot., 27, 735-43 (74, 75)

${ }^{236}$ PRESTON, R. D., and KUYPER, B. (I95I). F. exp. Bot., 2, 247-55 (95)

237 PRIESTLEY, J. (I779, I 781). Experiments and observations relating to various branches of natural philosophy; with a continuation of the observations on air, vols. $\mathrm{I}$ and $\mathbf{2}$, J. Johnson, London (2)

238 PRINGSHEIM, E. G. (1914). Beitr. Biol. Pfl., 12, 49-108 (74)

239 - (1937). Nature, Lond., 139, I96 (5 I)

240 - (194I). Biol. Rev., I6, I9 I-204 (62, 63)

241 (1946). Pure cultures of algae, Cambridge University Press $(3,84,87)$

242 - (1948). New Phytol., 47, 52-87 (6I-3)

243 - (1949). Bact. Rev., 13, 47-98 (49, 62)

244 - (195 I). Arch. Mikrobiol., 16, 18-27 (55, 59, 62)

244a _- (1952). Quart. F. micr. Sci., 93, 7 I-96 (50, 95)

245 PRingSheIM, E. G., and PRINGSHEIM, O. (1952). New Phytol., 5I, 65-76 (62)

246 Provasoli, L., hutNer, S. H., and schatz, A. (1948). Proc. Soc. exp. Biol., N.Y., 69, 279-82 (62)

247 RABINOWITCH, E. I. (I945). Photosynthesis and related processes, vol. I, Interscience Publishers, Inc., New York (I, I 5, I6, I $9,20,29-33,39,44,48-50,73$ ) 
248 RABINowitCH, E. I. (I95I). Photosynthesis and related processes, vol. 2, part I, Interscience Publishers, Inc., New York (19, $20,22,23,29)$

249 RIEKE, F. F. (1949). Photosynthesis in plants, $25 \mathrm{I}-72$, Iowa State College Press (3I)

250 ROACH, B. M. BRISTOL (1926). Ann. Bot., Lond., 40, r 49-20I (3, $5 \mathrm{I}-3,55,56, \mathrm{I} 07)$

251 ___ ( 92.7). Ann. Bot., Lond., 4I, 509-I 7 (5I)

252 - (1928). Ann. Bot., Lond., 42, 31 7-45 (52, 57)

253 ROBERG, M. (1 930). $\mathcal{F} b$. wiss. Bot., 72, 369-84 (89)

$253 a$ Roche, J., and LAFON, M. (1949). C.R. Acad. Sci., Paris, 229, 48 I-2 (IO2)

${ }^{254}$ RODHE, w. (1948). Symb. bot. upsaliens., ro (I), I-I $49(87,88$, 107)

${ }^{255}$ RUSSEll-Wells, B. (1932). Nature, Lond., 129, 654-5 (i 19, 129)

256 SACHS, J. VON (I 887). Lectures on the physiology of plants, translated by $H$. Marshall Ward from the 1882 German edition, Clarendon Press, Oxford (2)

257 Sargent, M. C., and Lantrip, L. w. (1952). Amer. F. Bot., 39, 99-107 (127)

258 SKINNER, C. E., and GARDNER, c. G. (I930). F. Bact., I9, I6I-78 $(50,55)$

259 sмith, G. M. (I95I). Manual of phycology, I3-I9, Chronica Botanica Co., Waltham, Mass. (I, I 3, 103, 105)

260 SMITH, J. H. C. (1949). Photosynthesis in plants, 53-94, Iowa State College Press $(92,95)$

261 Society for Experimental Biology (195I). Carbon dioxide fixation and photosynthesis, symposium no. 5, Cambridge University Press (I9)

262 SPOeHr, H. A. (195I). Proc. Amer. phil. Soc., 95, 62-7 (5)

263 SPOEHR, H. A., and MILNER, H. W. (I947). Carnegie Institution of Washington, Year Book no. 47, 100-3 (5)

264 - (1949). Plant Physiol., 24, I 20-49 (69, 89, I I6-18, 120)

265 SPOEHR, H. A., SMITH, J. H. C., STRAIN, H. H., MILNER, H. W., and HARDIN, G. J. (I 949). Fatty acid antibacterials from plants, Carnegie Institution of Washington, Publication no. 586 (I I 4)

266 STANFORD, E. C. C. (1883). Chem. News, 47, 254-7, 267-9 (2)

267 STEPHENSON, M. (I949). Bacterial metabolism, and edition, Longmans, Green \& Co., London (6, I 6, 30, 48, 49, 59, 66, 86,87 )

268 STEWARD, F. C., and thompson, J. F. (I950). Nature, Lond., I66, 593-6 (47)

269 STOCKER, O., and HoldHeide, w. (1938). Z. Bot., 32, I-59 (129)

270 STOSCH, H. A. voN (I95 I). Naturwissenschaften, 38, 192-3 (95)

271 Strain, H. H. (1949). Photosynthesis in plants, I33-78, Iowa State College Press (20) 
272 STRAin, H. H. (I95I). Manual of phycology, 243-62, Chronica Botanica Co., Waltham, Mass. (18, 20, 21, 103)

273 sweEny, B. M. (I95I). Amer. F. Bot., 38, 669-77 (87)

${ }^{274}$ Syrett, P. J. (1951). Ann. Bot., Lond., N.S. 15, 473-92 (10, 63, $66,67)$

275 - (1953). Ann. Bot., Lond., N.S. I7, I-19 (75, 76, I I 2)

276 _- (1953). Ann. Bot., Lond., N.S. 17, 2 I-36 (77-80)

277 _ unpublished material $(80,8 \mathrm{I})$

278 SYrett, P. J., and Fowden, L. (1952). Physiol. Plant., 5, 558-66 $(78,79)$

279 takahasi, E., SiRAhama, K., and togasawa, N. (I939). F. chem.

Soc., Japan, 60, 56-60 (98, 99, I I 9)

280 TANADA, T. (I95 I). Amer. F. Bot., 38, 276-83 (1 9, 24, 25, 28)

281 TAYLOR, F. J. (1950). F. exp. Bot., I, 30I-2I $(63,64,67)$

282 THURGUR, H. M., unpublished results (9)

283 tolmach, L. J. (195 I). Arch. Biochem. Biophys., 33, 120-42 (40)

284 TSENG, C. K., and sweeny, B. M. (i 946). Amer. F. Bot., 33, $706-15(36$, I 1 2$)$

285 virtanen, A. I. (1948). Anmu. Rev. Microbiol., 2, 485-506 (68, $70,74)$

286 (1950). Acta agric. Scand., I, I-19 (74)

287 virtanen, A. I., and Miettinen, J. K. (I949). Acta chem. scand., 3, I 437-9 (I2I)

288 vishNiAC, w., and ochoA, s. (I95I). Nature, Lond., r67, 768-9 (40)

289 Wann, f. B. (I 92 I). Amer. F. Bot., 8, I-29 (69)

290 WARBURG, O. (1919). Biochem. $Z$., I00, 230-70 (4, 34)

291 (1949). Heavy metal prosthetic groups and enzyme action, translated by A. Lawson, Clarendon Press, Oxford (39)

292 WARBURg, O., and NEGELEIN, E. (1920). Biochem. $Z$., I Io, 66-I I 5 $(7 \mathrm{I}, 73,74)$

293 WASSINK, E. C., and KERSTEN, J. A. H. (1946). Enzymologia, 12, $3-32(23,24)$

294 watanabe, A. (1932). 'Acta Phytochim., Tokyo, 6, 315-35 (6, I0)

295 _ (1937). Acta Phytochim., Tokyo, 9, 235-54 (6, 7, 9, 50)

296 _ ( I 937). Acta Phytochim., Tokyo, 9, 255-64 (6, I I)

297 - (195I). Arch. Biochem. Biophys., 34, 50-5 (69, 7I)

298 webster, G. C. (1950). Amer. F. Bot., 37, 682 (9)

299 WIElding, S. (I94I). Bot. Notiser, I94I, 375-92 (86)

300 williams, A. E., and BURris, R. H. (1952). Amer. F. Bot., 39, $340-2(69,71,101)$

301 WILLSTÄTTER, R., and STOLL, A. (1913). Untersuchungen ïber das Chlorophyll, Springer, Berlin (2)

301a Wilson, P. W. (I952). Advances in Enzymol., 13, 345-75 (68, $70,78)$

302 winokur, M. (1 948). Amer. F. Bot., 35, I I8-29 (107)

303 ㄴ. (I 949). Amer. F. Bot., 36, 287-91 (120) 
304 wintermans, J. F. G. M., and tjia, J. E. (1952). Proc. Kon. Ned. Akad. Wetensch. Amsterdam, C, 55, 34-9 (I I)

305 wiTsCH, H. VON (I 946). Naturwissenschaften, 33, 22 I-2 (9)

306 - (1948). Biol. Zbl., 67, 95-100 (1 16)

307 - (1948). Arch. Mikrobiol., 14, 128-4I ( I 17)

308 WOLFE, M., unpublished results (70, 74)

309 WORK, E., unpublished results (IO2) 


\section{INDEX}

absorption spectra, 19, 20, 22-7

acetate, $8,9,43,44,5 \mathrm{I}, 54,55,58$, $60,63-6$

- organisms, $5^{\mathrm{I}}, 55$

acetylcoenzyme A, 65

adaptation, 29-30, 56, 57, 109, 121 adenosine diphosphate, 7, I I , 80, 8 I - triphosphate, 7, I I, 79-8I

adenylic acid, 8I

agar, 96, 97, 105

alanine, $36,37,43,79,82$, I01, I02 Alaria, 14, 98, 99

algin, 95, 104

alginic acid, 2, 95, 96, I 25, 127

amide, $76,77,79-83,90$, Ior

amino-acids, $43,44,50,70,71,77^{-}$ $82,84,85$, IOI, IO2

p-amino-benzoic acid, 86,87

ammonia, $16,43,47,68,70-83,85$, 90 , I I I, I I 4, I I6, I I 7

amylase, 93

amylopectin, 93, 94

amylose, 93, 94

Anabaena, 15, 46, 59, 69, 70, 74, 75, 90, 101, 102, 107, 109, I 10, 122,123

Anabaeniopsis, 15, 69

anaerobic conditions, $6,30-2,36$, 63,76

Ankistrodesmus, 13, 32, 74, 82

Aphanizomenon, 15, 69

apochlorosis, 61, 62, 132

arginine, 78, 79, Iо1, 102

Ascophyllum, 14, 32, 94, 127

ash constituents, 96, 125, 127

asparagine, 43,82

aspartic acid, $36,37,43,70,79,82$, 84,85 , IOI, 102

Astasia, 14, 62, 86

Asterionella, I3, II 4

Athiorhodaceae, 15

Aulosira, 15, 69

autotrophy, I 2, I6, 68-83, 84

Azotobacter, 68, 70

Bacillariophyceae, 5, 9, 13, 20-4, $32,59,92,95,99,102,104$, I05, I I 2, I I6, I I9, I 2 I
Bacillus, 48

bacteria, compared with algae, 1 , I8, 30-2, 48, 49, 55, 59, 68, $70,79,82,86,90,96,102$, 106, 1 08, 109, 1 30, 132, 133

Beggiatoa, 15, 49

bicarbonate, 33-5

Bostrychia, 15, 92

butyric acid, 5 I

calcareous algae, 35

Calothrix, 15, 69

carbohydrate deficient cells, 67 , $72,73,82$, I I I

- synthesis, $36,42,43,63-7$

carbohydrates, 9I-8, I06, I I 2, II 5 , I 8, I 20, I21, I 3 I, I 33

carbon dioxide and photosynthesis, I 7, I 8, 30, 33-4I, 58, 60, I I 7 - -, 'extra', 71, 72

carbon monoxide, inhibition by, 10, 70

carbonate, 33,35

carbonic anhydrase, 35,60

carboxylation, see decarboxylation

carotene, 20, 21

carotenoids, 19, 20, 24-6, 28 .

carragheenin, 97,105

cell walls, 95-8, I 04, I 10, I I6, I 27

cellobiose, 56,57

cellulose, 95, 104, 127

Ceramiales, 15,93

chemical composition of algae, $9 I-$ I03, I06, I09-29, I 3 I, I 32

chemolithotrophy, $16,48-50,60$

chemo-organotrophy, $16,50-67$

chemosynthesis, 16,48

chemotrophy, 15, 48-67, 71, 74, I I $9,120,131,132$

Chilomonas, 14, 86, 94, I14

chitin, 98, 104

Chlamydomonas, $13,31,32,49,58-$ $60,62,85-7$

Chlorella 3-7, 9-II, I3, I6, I8, $26,28,3 \mathrm{I}-6,39,40,42,46$, $54,56-64,66,67,69,71-7$, $79-82,89,93,98-102,106-20$, I22, 123,126 
Chlorococcales, I2, 13

Chlorogonium, 13, 51

Chlorophyceae, $6,9-13,20-2,32$, $50,51,69,79,83,89-93,95$, 99, 100, I02-4, I07, I I2, II3, I I 9, I 23,130

chlorophyll, I 7-2 I, 23-9, 32, 44, 61 , i 8,130

Chlorophyta, I 3 chondrillasterol, I00, 104

Chondrus, I 5, 97, 101, 129

Chorda, 14,94

chromatic adaptation, 29

chromatophore, 22, 23, 26, 61, 109, I IO, I I 6,132

Chroococcales, I 5,69

Chroococcus, 15, 26, 27

Chrysophyceae, 14, 21, 95, 104, I05

Chrysophyta, 13, 105, 133

citrate, $8,9,36,42,43,54,60,65$ Cladophora, 1 3, 99, 100

classification, 12-16, 103-5, I 33

Clostridium, 68

co-carboxylase, 9

Coccomyxa, I3, 89

coenzyme II, see triphosphopyridinenucleotide

Coilodesme, 14, 25, 26

colourless algae, I $3,6 \mathrm{I}-3$

Corallina, I 4, 35, 102

Cryptomonas, I 4,87

Cryptonemiales, 14, 93

Cryptophyceae, I $4,20,5$ I, 94, 104,105

culture of algae, $3,5,50,68,75$, $84,87-90,107,108,110-18$, I 20, 121

cyanide, inhibition by, 10, 66, 74, 76

cyanophycin, 103,104

Cyanophyta, 15

Cylindrospermum, 6, 9, I 5, 32, 69

cystine, IOI, 102

Cystococcus, see Trebouxia

cytochrome, 10, 66

- oxidase, 10

deamidation, 83

deamination, $47,82,83$

decarboxylation, $9,36,38-40,44$, $47,64,65,86$

dehydrogenases, $7,9,10,78$

diaminopimelic acid, 102

diatoms, see Bacillariophyceae diiodotyrosine, 102

dinitrophenol, $8 \mathrm{I}$

Dinophyceae, 14, 21, 95, 104, 105, I 12

disaccharides, $52,77,93,94,115$, I 6

Ditylium, I3, 87

dulcitol, 92

Ectocarpus, I4, 94

energy sources, I $5,17,48,49,59$, $60,131,132$

Enteromorpha, I3, 87

enzymes, 5, 52, 55, 56, 85, I09, I I0, I 2 I, I 32, I 33

ergosterol, $100, \mathrm{IO}_{4}$

ethyl alcohol, 63

Euglena, 10, I1, 14, 15, 51, 56, 61, $62,71,78,84-6$, I I 2

Euglenineae, 11, 14, 20, 21, 33, 51, $86,93,102,104$, I I 2

Euglenophyta, I 4

excretion, 54, 89-91, 102, 106, I I0, 132

exponential growth, $52,53,56,58$, $107-16,120,123$

fat synthesis, $36,43,44,65,67$, I 6 6-23

fats, see lipides

fatty acids, I 5, 43-5, 50, $5 \mathrm{I}, 55$, $98,99,118,121-3$

fermentation, $6,63,76$

flavoproteins, Io

floridean starch, 93, 104, 105

floridoside, $92,104,105$

fluorescence, 19, 20, 28, 29

freshwater algae, $36,71,87,90$, $93,99,107,114$

fructose, 51, 52, 56, 92

Fucaceae, 123

fucoidin, 97, 104, 105

fucose, 98

fucosterol, 100, 104

fucoxanthin, 19, 21, 24, 25

Fucus, 10, 14, 94, 98, 99, 127, 128

fumarate, $8,36,42,60$

fungi, compared with algae, I, 16, $90,98,100,106,132,133$

galactose, $52,53,92,96,97$

Gelidium, 6, 7, 9, 14, 36, 96, I I 2

Gigartina, 15, 28, 97, 129

Gigartinales, 15, 93

Gloeocapsa, 15, 69 
Gloeotrichia, $\mathbf{1 5}_{5}, 88$

glucose, I I, $30,33,5 \mathrm{I}-8,60,63-6$, $70,76-8,80,82,9$ I -5 , I I 2 glucose-I-phosphate, I I, 56, 94 glutamate, $36,43,44,46,47,70$, $78-80,82,86$, IOI

glutamic dehydrogenase, 78

glutamine, $43,47,79,80,82$, I02, I 03

glycerol, $43,52,53,60,63,65,92$, 98 , I 13

glycine, $38,43,44,82,85$, IO I

glycogen, I I , 54, 94

glycollate, $38,43,65$

glycolysis, 6, I I , 4I, 42, 47, 64, 79 growth, 3, 52, 90, I06-29, I3 I

- factors, I5, I6, 48, 59, 84-8, I I 4 , I 32, I 33

- inhibitors, 86, I I 4, I 20

Gymnodinium, I 4, 87

Haematococcus, I3, 82

Harveyella, I4, 63

hentriacontane, 100

heterotrophy, I $2,16,82,84-8$

hexokinase, 55

hexose, $6,40,42,51,52,92$, I I 6

- phosphates, 6,7 , I I, 37, 42, 43, 56,64

higher plants, compared with algae, I, 2, 1 8, 20, 22, 30, 70, 78, 79, $93,99, \mathrm{IOI}, \mathrm{I02}, \mathrm{I0} 4, \mathrm{I0}, \mathrm{I} 30$, I 3 I, I 33

Hill reaction, 39, 4I, 60, 73

histidine, 85 , IOI, I I 6

holozoic nutrition, 50

Hormidium, I3, 58, 82, I I 2

hydrocarbons, 99 , 100

hydrogen ion concentration, effects on metabolism, $33,34,55$, $64,70-2,74,75,82$, I I 4, I I 9 , 120

-, molecular, 30, 33, 70, I3 I

- sulphide, $32,33,49$, I 3 I

hydrogenase, $3 \mathrm{I}, 70$

hydroxylamine, $31,70,74$

immersion, effect on composition of seaweeds, 126,128

inulin, $5 \mathrm{I}$

Iridaea, I 5, 28, 92, 97

iron, I I 4

iso-citrate, 8,46

isoleucine, IOI

isotopic tracers, $36-47,65,69,78$ ketoglutarate, $8,43,47,78,79$

Krebs cycle, see tricarboxylic acid cycle

lactate, $6,5 x, 54,63$

lactose, 57

lag phase, 56, 57, 107, 109

Laminaria, I 4, 94, 98, 99, IO I, I 02, 124-7

Laminariaceae, I 23

Laminariales, I 4, I 26

laminaribiose, 94

laminarin, 94, 104, 105, 124-9

leucine, 79, I 01

leucosin, 95, 104

light, effects on metabolism, 35 , $46,57-6 \mathrm{I}$, I09, I I I, I I 7

lipides, 98-101, I04-6, I II-I3, I I 6-23, I 27, I 29, I 3 I, I 33

lipoids, 99-I0 I, 109, I 8

lysine, 78,79, IOI, I02

Macrocystis, I4, I 26

malate, $8,36-40,42,43,60$

'malic' enzyme, 40

malonate, inhibition by, 9,40

maltase, 56

maltose, 52,56

manganese, 74

mannitan, 92

mannitol, 52, 92, 104, 1 24-9

mannoglycerate, 93

mannose, 92

mannuronic acid, 95

marine algae, I, 2, 4, I4, 29, 3 I, 35, $50,87,90,92-103,123-9$

Mastigocladus, 15, 69, 102

mesotrophy, I6, 75

metabolic pool, 4I, 43, 64, 8I, I20, I 32

methionine, I0r, 102

methyl- $\beta$-D-glucoside, 57

Microcystis, I5, 69, I0I

molybdenum, 70,74

Monodus, 13, 122, 123

Monostroma, 13, 26

mutants, 60-2, 86, 87, I33

Myelophycus, 6, 7, 9, 14

Myxophyceae, 9, 15, 21, 22, 32, $35,49,68,69-71,90,92-5$, I I -4 , I I 2 , I I 9

Navicula, 13, 19, 24, 25, 28, 5 1, 54, ror

Nitella, I3, 99, 100 
nitrate, I6, 68, 70-4, 90, I I I , II 7 , $124,126,129$

nitrite, 74

nitrogen assimilation, $68-85$, I 12 , I 30 , I 31

- fixation, 68-71, 90

nitrogen-deficient cells, $71,75-8$, $8 \mathrm{I}, \mathrm{III-13}$, I I6, I I 7, I I $9-23$

Nitrosomonas, I 6

Nitzschia, I $3,28,32,36,55,86,98$, 99, I I $2-14,120$

Nostoc, 1 5, 32, 51, 69, 70, 78, I 14 nucleic acid, 86, I03, I I0, I I 3, I 16

Ochromonas, I4, 50

Oedogonium, I3, 99, 100

organic substances, assimilation by algae, $50-67,81-8$, I $_{3}$ I

ornithine, 78,79

Oscillatoria, 12, 1 5, 28, 32, 49, 94, $102,122,123$

Oscillatoriaceae, I 5, 69

oxaloacetate, $8,9,39,43,47,65$, 66,79

oxidative assimilation, $4,63-7$, I I I oxyhydrogen reaction, $30,48,49$

palmitic acid, 98, I I 3

paramylum, 93, 104

pectin, 98, 104

Pelvetia, 14, 92, 94, 102, 128, I 29

pentose, 52, 64, 90, 92, 98

peptides, I02, 103

Peridinium, $14,59,75$, I 12

permeability, $33,34,54,55,71-3$, 89,132

peroxidase, II

Phaeophyceae, 9, II, 21, 23, 25, $32,50,92,94-6,98-100,102$,

I04, I O5, I I 9, I 23-9, I 30, I 33

Phaeophyta, 14

$o$-phenanthroline, 3 I

phenylalanine, 44,85 , I O I

Phormidium, 15, 69, 101, 102

phosphate deficient cells, II 3

phosphoglyceraldehyde, 7 , I I

phosphoglyceric acid, 6, 7, 11 , 37$43,51,59,64$

phosphorylation, $6,11,44,56,64$, $66,79,96$

photolithotrophy, I 5, 33

photo-organotrophy, i5, 33

photoreduction, $30,32,49$

photosynthesis, 1, 2, 4, 5, 10, 12,

$17-47,57-61,71,73,108$,

I I $9-2$ I, I 30,132, I 33 photosynthesis, acceptor in carbon dioxide fixation, $38-40,43,44$ action spectra, 22, 23, 25-7

dark reactions, $18,36-4$ I

hydrogen donors, $15,17,18,30-$

3,130, I 3 I

inhibitors, 32, 4I, 120

light absorption, $17,22-30, x_{3} 1$

oxygen evolution, $17,22,31,32$, $39,58,72,73$

photochemical reaction, 15,18 , $28,31,39-41,44,60,61,73$, 74, I 31

products, $17, x 8,36-47,73,79$,

I 13, I $19-23,127,132$

quantum efficiency, $17,22,24$, $25,27,31,120$

rate, 35, I O8, I I I, I I 4, I I 9, I 20, 1 24, 1 26, 129

photosynthetic bacteria, I5, I 8 , 30,68

- pigments, 2, го, 17-30, 48, 50, $61-3,99,103,105,109,130$, 133

- quotient, $17,72,73$, I II-1 3 , I 20, I 2 I

phototrophy, I 5, 17-47, 57-61, $70,71,74,86$

-, obligate, $54,59-6$ I, 85,132

phycobilins, 19, 20, 22, 26-9

phycocyanin, 20-2, 27

phycoerythrin, 20-2, 27

Pinnularia, 13, 32, I1 2

polypeptides, 90,102

polyphenol oxidase, I I

polysaccharides, $67,77,78,80$, $93-8,104,133$

Polytoma, 1 $3,62,85$

Polytomella, 10, 12, 13, 56, 62, 85, 93,103, I $10,113,116$

Porphyra, 10, 14, 27, 28, 32

Porphyridium, I 4, 28, 32

proline, IOI

propionic acid, 63

Prorocentrum, 14, 59, 75

protein, IOI-3, 106, 109-II, I13,

I 5 , I I 6, I I $8,120,12$ I, $124^{-}$ 7,131

- synthesis, 36, 43, 44, 47,67, 73,8 I, I I O, II 3, I I 5,120

proteinase, 55

Prototheca, 4, 6, 9, 13, 16, 51, 54, $55,60,62,63,65,66,86$

pyranose structure, 9 I

pyrimidine, 85,86 
L-pyrrolidonoyl- $\alpha$-glutaminyl-Lglutamine, 103

Pyrrophyta, 14, 105

pyruvate, $6,37-43,47,5 \mathrm{I}, 54,55$, $60,64-6,79,86$

pyruvic dehydrogenase, 9

relative growth rate, $52,53,107-$ I I reserve products, 91-5, $103-5$, I I O I I 3, I I 9-23, I 27

respiration, 5-1 $2,36,44-7,52,54$, $58,60,63-7,71,76,79-81$, I I I, I 26,130

respiratory quotient, I I I, I I 2, I 2 I Rhisobium, 68, 70

Rhodophyceae, 9, I I, I4, 21, 22, $27,32,35,50,92,93,95,96$, 99, 100, 102, 104, 105, I I 2, I $19,123,129,130,133$

Rhodophyta, I 4

Rhodymenia, 1 5, 96, 99

riboflavin, Io

Saccorhiza, 14, 127

Scenedesmus, 6, 7, I I, I3, I8, 31$3,35-7,41,42,44,45,48,49$, $5 \mathrm{I}-3,55-7,63,65,67,78,82$, $89,93,98,100$, I 12

seasonal variations in seaweeds, 1 24-9

serine, 43 , I or

sewage organisms, 49-5 I, 82

silica, $104, I_{1} 4$

Siphonales, I $3,20,21,35$

sitosterol, 100, 104

soil algae, $3,50,62,71,87$

- extract, 87,88

sorbitol, 92

starch, I I, 51, 54, 93, 94, 96, 104, 105, I I I, II 5, I $6,127,133$

stationary phase, I07, II5, I 6 , I 20, 123

sterols, 99-IOI, 104

Stichococcus, 13, 82

streptomycin, 62

succinamide, 82

succinate, $8,9,36,42,43,5$ r, 54, 60,66

succinic dehydrogenase, 9

sucrose, $37,42,52,56,93$, I I 2 sulphanilamide, 86,87

sulphuric esters, 96-8, г 05, 127, I $29, \quad 133$

symbiotic algae, 50, $7 \mathrm{I}$

Synechococcus, 15, 32, I 12

Synechocystis, 15, 32

Synura, I 4,87

tartaric acid, 51

Tetrachloris, 13,62

thiamine, $9,65,66,85,86$, I 33

thiazole, 85,86

Thiobacillus, 59

threonine, 44, I 101

Tolypothrix, I 5, 69

transamination, $79,83,85$

translocation, 126

Trebouxia, I3, 5 I

trehalose, 93

Tribonema, 13, 95, 101, 122, 123

tricarboxylic acid cycle, 7-10, 42-4, $46,47,65,66,79,86$

triose phosphates, $6,37,42,43$

triphosphopyridine nucleotide, 39 , 40

tryptophane, 101

tyrosine, 44, IOI, ro2

Ulva, 6, 7, 9, 13, 26, 32, 50, 87, I01, 102

utilization of algae, 4, 5,.96

valine, ror

Valonia, 13, 34, 95

Vaucheria, 10, 13

vitamin $B_{1}$, see thiamine

$-\mathrm{B}_{12}, 86$

- requirements of algae, $85-8$

Volvocales, 13, 5 I

Xanthophyceae, I O, r 3, 21, 95, 98, $100,102,104,105,119$

xanthophylls, 20-2

xylose, 52,96

yeast, 5, 6, I I , I 2, 65, 87, I08, I I

zeaxanthin, 21,22

zonation of algae, 29, I 29

Zygnema, I 3,82 
Printed in Great Britain by Butler \& Tanner Ltd., Frome and London 



